\title{
A SCOPING STUDY OF SPENT FUEL CASK TRANSPORTATION ACCIDENTS
}

\section{W. R. Rhyne}

R. E. Ritzman

H. E Cothran, Jr,

J. P. Allgeier

C. J. Barton, Sr.

Science Applications, Inc.

Prepared for

U. S. Nuclear Regulatory Commission 


\section{DISCLAIMER}

This report was prepared as an account of work sponsored by an agency of the United States Government. Neither the United States Government nor any agency Thereof, nor any of their employees, makes any warranty, express or implied, or assumes any legal liability or responsibility for the accuracy, completeness, or usefulness of any information, apparatus, product, or process disclosed, or represents that its use would not infringe privately owned rights. Reference herein to any specific commercial product, process, or service by trade name, trademark, manufacturer, or otherwise does not necessarily constitute or imply its endorsement, recommendation, or favoring by the United States Government or any agency thereof. The views and opinions of authors expressed herein do not necessarily state or reflect those of the United States Government or any agency thereof. 


\section{DISCLAIMER}

Portions of this document may be illegible in electronic image products. Images are produced from the best available original document. 
NUREG/CR-0811

SAI-OR.79-140.04

RT

\title{
A SCOPING STUDY OF SPENT \\ FUEL CASK TRANSPORTATION ACCIDENTS
}

\author{
W. R. Rhyne \\ R. L. Ritzman \\ H. E. Cothran, Jr. \\ J. P. Allgeier \\ C. J. Barton, Sr. \\ Manuscript Submitted: June 1979 \\ Date Published: June 1979 \\ Science Applications, Inc. \\ Oak Ridge, TN 37830
}

\section{Prepared for}

Division of Safeguards, Fuel Cycle and Environmental Research

Office of Nuclear Regulatory Research

U. S. Nuclear Regulatory Commission

Washington, D. C. 20555

NRC FIN No. B5790 


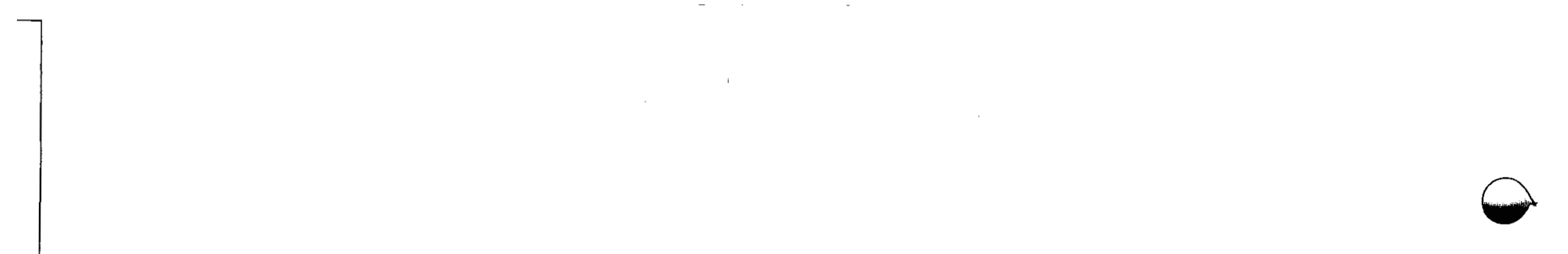

0 
A scoping study of spent fuel cask transportation accidents was performed to provide the NRC with an assessment of existing information and to recommend, on a priority basis, the additional information that should be obtained to allow specification of increasingly realistic source terms. The scope was limited to the escape of radionuclides from the cask to the environment resulting from severe accidents. The accident environment definition associated with a severe accident is the starting point and was selected not for its realism but to allow sensitivity studies on the remaining variables in the accident scenario. However, given this accident definition, the remainder of the evaluation of the accident scenarios is to be as realistic as possible. Information was found to be inadequate to make correlations between accident severity and radionuclide release. Generally, cask and fuel rod thermal-hydraulic data and analytical capability were found to be reasonably adequate; however, data and analytical capability for evaluating structural response to impact are not. Radionuclide behavior information is adequate for noble gases but generally inadequate for most volatile radionuclides and for fuel particulates. A series of gauging calculations were performed to permit prioritization of the information needs, and research recommendations were made in eight areas. 
○

○ 
A hypothetical severe spent fuel transportation accident (SFTA) is usually initiated by impact (or puncture) and fire. Subsequent evaluation of the radionuclide source terms resulting from the postulated SFTA consists of analyses of the structural response of the cask and the fuel to impact, the thermal-hydraulic response, and the dynamic behavior of radionuclides.

Little generic research is available for reference in addressing the more severe challenges to cask and fuel structural integrity, especially in the areas of response of irradiated fuel assemblies to impact and cask response to puncture threats. The emphasis of current fuel programs is on reactor conditions; SFTA's receive little consideration. Most of the research to date is directed toward compliance with the requirements of 10CFR71. Two notable exceptions are Sandia's recent full-scale cask crash program and the continuing Battelle program, which is producing some relevant irradiated Zircaloy data. Results of cask crash and drop tests with unirradiated stainless steel clad fuel are interesting, but inapplicable for irradiated Zircaloy fue1. A review of the designs of currently licensed casks revealed no unsoundness in design, but indicated no means for measuring their survivability in the more severe environments.

A loss-of-coolant situation may be induced either by the initial impact or by subsequent thermally induced effects. For fire or loss-of-coolant scenarios, either independent or superimposed, an adequate data base exists to perform-thermal-hydraulic analysis on the cask and the fuel rods at several levels of sophistication.

Existing information that could be used to characterize the dynamic behavior of radionuclides in a severe SFTA was surveyed. Emphasis was placed on methods and data which contribute to definition of release magnitudes and to specification of the chemical and physical forms of the radionuclides. Methods and data for the noble gas fission products are probably sufficient for accident analysis purposes. However, numerous gaps were noted in the information base for the other volatile fission products and in data concerning the release and characterization of fue 1 particulates. The principal 1 imitations regarding the other volatile fission products were found to be a lack of quantitative data on chemical forms and hence volatilities under various conditions. The existing information concerning possible fuel particulate releases was found to be extremely limited with respect to the amount that might escape, as well as the particle size distribution of the material within or outside the shipping cask systems.

Two accident severity classification schemes were found to be of potential use, specifically; the schemes presented in WASH-1238 and NUREG-0170. Both schemes can be displayed graphically on a plot of impact speed versus fire duration time, but the NUREG-0170 procedure for determining ordinate (speed) values and abscissa (time) values is considered the more meaningful. The classification procedure for both schemes generally results in putting high-impact (or puncture, depending on transportation mode) and 
short-duration fire events in the same category as low-impact and longduration fire events, which is not considered as meaningful for generating a correlation between accident category and cask response and subsequent radionuclide release. An alternate scheme is presented which reduces the difficulty. Numerical correlations between accident severity and radionuclide release have been based, to a large extent, on engineering judgment and are not considered appropriate as realistic correlations.

Gauging calculations were performed to estimate cask and fuel assembly failure threshholds when faced with various challenges, mainly impact environments. The calculations indicated that gross cask failure is unlikely, and that such a conclusion can be demonstrated with a feasible development program. It was also seen that the failure threshhold for fuel rods subjected to impact is probably much lower than the cask itself. A program to establish failure threshholds for fuel, to design shock absorption mechanisms based on that data, and to strengthen seal and appurtenance design might result in greatly reduced threat of exposure to the public. Other potentially fruitful areas of research included penetration mechanics and generation of high-strain-rate material properties data.

Gauging calculations were performed to develop a range of radionuclide source term estimates for several severe SFTA scenarios which would reflect the inherent uncertainties that exist in data or models concerning fuel and fission product behavior. Possible effects on public health of the variability of these source terms were examined by performing radiation dose calculations using standard environmental transport and dose evaluation models. The results were used to indicate which portions of the radiological source terms have the greater influence on estimated public health impacts. Findings showed that the potential release of respirable fuel dust in a severe SFTA has the greatest effect on radiation dose estimates, particularly with respect to the lung and bone organs. In addition, if the cesium and/or ruthenium fission products should exist as volatile species, these materials would also become significant dose contributors. The other volatile fission products (krypton, iodine, and tellurium) were found to be minor dose contributors under nearly all release variation conditions.

Based on the literature surveys and on the results of the gauging calculations, information needs in order to specify increasingly realistic source terms for a severe SFTA are ranked in a priority list. Recommendations for research are also included. 
ABSTRACT . . . . . . . . . . . . . . . . . . .

EXECUTIVE SUMMARY . . . . . . . . . . . . . . . . . . . v

LIST OF FIGURES . . . . . . . . . . . . . . . . . . . . . $x i$

LIST OF TABLES . . . . . . . . . . . . . . . . . . . . . xii

PREFACE ........................... . . xvii

1.0 INTRODUCTION . . . . . . . . . . . . . . . . . . . . . 1

2.0 STUDY SCOPE AND GAUGING CALCULATION APPROACH . . . . . . . . 2

2.1 GENERAL SCOPE OF THE PROJECT . . . . . . . . . . . . . . 2

2.2 OVERALL APPROACH FOR THE GAUGING CALCULATIONS . . . . . 2

2.3 GAUGING CALCULATION SCENARIO . . . . . . . . . . . . 3

2.3.1 Fuel . . . . . . . . . . . . . . . 3

2.3.2 Cask . . . . . . . . . . . . . . . . . . 3

2.3.3 Impact Accident Environment. . . . . . . . . 5

2.3.4 Fire Accident Environment . . . . . . . . . . . 5

REFERENCES . . . . . . . . . . . . . . . . . . . 6

3.0 SUMMARY OF FUEL MECHANICAL, STRUCTURAL, AND THERMAL DATA . . 7

3.1 MECHANICAL/STRUCTURAL PROPERTIES OF SPENT FUEL RODS

AND THEIR RESPONSE TO IMPACT . . . . . . . . . . . . . . 7

3.1.1 Introduction . . . . . . . . . . . . . . . . . . 7

3.1.2 Fuel Fracture Strength . . . . . . . . . . . . . 7

3.1.3 Zircaloy Cladding Fracture . . . . . . . . . . . 8

3.2 THERMAL/MECHANICAL PROPERTIES OF SPENT FUEL RODS

AND THEIR BEHAVIOR IN FIRE AND LOSS OF COOLANT

ENVIRONMENTS . . . . . . . . . . . . . . . . . . . . . . 10

3.2.1 Limiting Temperature and Stress for Zircaloy

Cladding Integrity . . . . . . . . . . . . 10

3.2.2 Deterministic Simulation of the Fuel Rods . . . . 11

REFERENCES . . . . . . . . . . . . . . . . . . . 12

4.0 REVIEW OF ACCIDENT SCENARIOS AND CATEGORIZATIONS . . . . . . 14

4.1 WASH-1238 . . . . . . . . . . . . . . . . . 14

4.2 BROBST . . . . . . . . . . . . . . . . . 14

4.3 YADIGAROGLU ....................... . . . . 21

4.4 ROSS . . . . . . . . . . . . . . . . . . . . . 21

4.5 WASH-1238, SUPPLEMENT II . . . . . . . . . . .... . 21

4.6 HODGE AND JARRETT . . . . . . . . . . . . . . . . . . . 23

4.7 WASH-1400 .......................... . . . . . . 23

4.8 NUREG-0170.......................... . . . . . . . . 23

4.9 HEABERLIN . . . . . . . . . . . . . . . . . . . . . . . 25

REFERENCES .......................... . . . . . 27 
TABLE. OF CONTENTS (Cont'd)

Page

5.0 CASK RESPONSE TO ACCIDENT ENVIRONMENTS . . . . . . . . . . . 29

5.1 INTRODUCTION . . . . . . . . . . . . . . . . . . . . 29

5.2. SAFETY ANALYSIS REPORTS BY LICENSE APPLICANTS . . ... . 29

5.3 NATIONAL LABORATORY TESTING AND ANALYSIS PROGRAMS . . 29

REFERENCES . . . . . . . . . . . . . . . . . . . . . 35

6.0 FISSION PRODUCT BEHAVIOR CHARACTERIZATION . . . . . . . . . 38

6.1 INTRODUCTION . . . . . . . . . . . . . . . . . . . . 38

6.2 RELEASE OF RADIONUCLIDES FROM FAILED FUEL RODS . . . . 38

6.2.1 Rapid Release Model Information Survey . . . . . 40

6.2.2 Extended Release Mode Information Survey . . . . 45

6.3 TRANSPORT AND DEPOSITION OF RADIONUCLIDES WITHIN CASKS . . . . . . . . . . . . . . . . . 49

6.3.1 Integral Experimental Tests . . . . . . . . . . 49

6.3 .2 Potential Analytical Models . . . . . . . . . 51

6.3.3 Experimental Data for Model Input . . . . . . . 51

REFERENCES ....................... 54

7.0 EVALUATION OF THE ADEQUACY OF EXISTING DATA . . . . . . . 59

7.1 ABILITY TO CORRELATE FISSION PRODUCT RELEASE

TO ACCIDENT CATEGORIZATION ............... 59

7.2 ADEQUACY OF EXISTING DATA FOR EVALUATING FUEL

RESPONSE . . . . . . . . . . . . . . . . . 63

7.3 ADEQUACY OF EXISTING DATA ON CASK RESPONSE . . . . . . . 64

7.4 ADEQUACY OF FISSION PRODUCT RELEASE AND BEHAVIOR INFORMATION ................... . . . 64

7.5 SUMMARY OF THE ADEQUACY OF EXISTING INFORMATION . . . 65 REFERENCES . . . . . . . . . . . . . . . . 72

8.0 THERMAL-HYDRAULIC GAUGING CALCULATIONS ........773

8.1 SOLUTION TECHNIQUE . . . . . . . . . . . . . . . . . . . 73

8.2 RESULTS . . . . . . . . . . . . . . . . . 74

8.3 UNCERTAINTIES AND CONCLUSIONS . . . . . . . . . . . . . 77

REFERENCES . . . . . . . . . . . . . . . . . 79

9.0 CASK AND FUEL GAUGING CALCULATIONS ........... 80

9.1 GENERAL CONSIDERATIONS . . . . . . . . . . . . . . . . 80

9.2 APPROACH .................... . . . . 80

9.2.1 Description of Reference Cask . . . . . . . . 81

9.2.2 Treatment of Fuel Assembly Response . . . . . . . 83

9.3 CASK-RELATED GAUGING CALCULATIONS . . . . . . . . . . . . 83

9.3.1 Cask Body . . . . . . . . . . . . . . . . . . . . 83

9.3.2 Puncture . . . . . . . . . . . . . 84

9.4 FUEL ASSEMBLY-RELATED GAUGING CALCULATIONS . . . . . 89 
$\underline{\text { Page }}$

9.5 CONCLUSIONS AND SUMMARY OF UNCERTAINTIES . . . . . . . 90

9.5.1 Cask Body . . . . . . . . . . . . . . . . . . 90

9.5.2 Cask Puncture . . . . . . . . . . . . . . 91

9.5.3 Fuel Response .............. . 92

REFERENCES . . . . . . . . . . . . . . . . . . . . 93

\begin{tabular}{l}
10.0 FISSION PRODUCT RELEASE, TRANSPORT AND DEPOSITION \\
GAUGING CALCULATONS... \\
\hline
\end{tabular}

10.1 INTRODUCTION . . . . . . . . . . . . . . . . . 94

10.2 ESTIMATION OF VOLATILE RELEASES . . . . . . . . . . . 94

10.2.1 Release of Volatiles from Fuel Pellets. . . . 94

10.2.2 Estimation of Releases from Casks . . . . . . 105

10.3 ESTIMATION OF PARTICULATE RELEASES . . . . . . . . . . 111

10.3.1 Fuel Dust Release from Fuel Rods . . . . . . . 111

10.3.2 Fuel Dust Release from Casks.......... 114

10.4 EXAMINATION OF PUBLIC HEALTH IMPACT OF RELEASE

VARIATIONS . . . . . . . . . . . . . . . . . . . 116

10.4.1 Dose Model for Airborne Sources . . . . . . . 116

10.4.2 Direct Radiation Dose Model: Outline

121

10.4.3 Results of Dose Calculations for Various

Cask Release Cases............. 122

10.4.4 Inspection and Anatys is of Dose Results . . . 122

REFERENCES ....................... 131

11.0 RECOMMENDATIONS FOR INFORMATION DEVELOPMENT . . . . . . . 133

11. 1 METHOD OF ESTABLISHING PRIORITIES . . . . . . . . . . 133

11.2 RECOMMENDATIONS ................. . . 134

11.2.1 Area 1 - Fuel Dust Particulate Sources . . . . 140

11.2.2 Area 2 - Volatile Fission Produce Sources . . 141

11.2.3 Area 3 - Other Radionuclide Release

Uncertainties ............... . 141

11.2.4 Area 4 - Response of Cask Body to Impact. . . 142

11.2.5 Area 5 - Appurtenances, Seals, and

Other Key Design Features. . . . . . . . . . . 142

11.2.6 Area 6 - Fuel Assembly Response to Impact . . 143

11.2.7 Area 7 - Cask Puncture . . . . . . . . . . . 143

11.2.8 Area 8 - Other Cask Structural

Response-Related Recommendations . . . . . 144 
$\ominus$

- 


\section{LIST OF FIGURES}

$\underline{\text { Page }}$

4.1 ACCIDENT SEVERITY CATEGORY CLASSIFICATION SCHEME-RAIL . . . . 24

7.1 GRAPHICAL. DISPLAY OF WASH-1238 ACCIDENT SEVERITY

CATEGORIES . . . . . . . . . . . . . . . 60

7.2 ACCIDENT SEVERITY CATEGORY CLASSIFICATION SCHEME . . . . . 62

9.1 SCHEMATIC OF REFERENCE CASK . . . . . . . . . . . . . 82

10.1 FUEL TEMPERATURES AND ROD FAILURES FOR THREE

REPRESENTATIVE RODS IN HELIUM-COOLED CASK IN SFTA

INVOLVING IMPACT AND FIRE ............... . 96

10.2 FUEL TEMPERATURES AND ROD FAILURES FOR THREE

REPRESENTATIVE RODS IN WATER-COOLED CASK IN SFTA

INVOLVING IMPACT AND FIRE . . . . . . . . . . . . 104 
○

0 


\section{LIST OF TABLES}

Page

2.1 LICENSED AND AVAILABLE SHIPPING CASKS FOR CURRENT GENERATION LWR SPENT FUEL .................. 4

4.1 SUMMARY OF ACCIDENT CLASSIFICATIONS AND SCENARIOS . . . . . 15

4.2 ACCIDENT SEVERITY CATEGORIES . . . . . . . . . . . . . . 17

4. 3 SUMMARY OF WASH-1238 POSTULATED ACCIDENTS . . . . . . . . . 18

4.4 RADIONUCLIDE INVENTORY IN FUEL ROD VOID SPACE . . . . . . . 19

4.5 PREDICTED FRACTION OF CASKS DAMAGED VS ACCIDENT SEVERITY . . 20

4.6 COMPARISON OF CESIUM RELEASE SCENARIOS . . . . . . . . . 22

4. 7 NUREG-0170 CORRELATION OF RELEASE FRACTION WITH ACCIDENT SEVERITY . . . . . . . . . . . . . . . . . . 26

5.1 SUMMARY OF CASK SAR STRUCTURAL AND THERMAL ANALYSES . . . . 30

5.2 SUMMARY OF CASK RESPONSE TESTS . . . . . . . . . . . . . 32

6. 1 FACTORS AND PHENOMENA IMPORTANT TO CHARACTERIZING FUEL ROD RELEASES . . . . . . . . . . . . . . . . . . . 39

6.2 FACTORS AND PHENOMENA IMPORTANT TO CHARACTERIZING FAILED CASK RELEASES .................. . . 50

7.1 EVALUATION OF THE ADEQUACY OF EXISTING DATA . . . . . . . . 66

8.1 THERMAL-HYDRAULIC SCOPING PARAMETERS . . . . . . . . . . 75

9.1 PUNCTURE VELOCITY FOR TARGET THICKNESS.

(8.8 1b, 2 in diameter) . . . . . . . . . . . 86

9.2 PUNCTURE VELOCITY FOR TARGET THICKNESS

(65 1b, 4 in diameter) . . . . . . . . . . . 86

9.3 PUNCTURE VELOCITY FOR PENETRATOR THICKNESS

$(68,000$ lb cask, 2.75 in shel1 thickness $)$. . . . . . . 87

9.4 VERTICAL LOAD TO FAIL, 12-IN LONG 2-IN. DIAMETER STEEL PROJECTION FOR ANGLE OF INCIDENCE . . . . . . . . . . . . . 87

9.5 ESTIMATED LOAD TO FAIL STEEL PLATE BY PLUGGING FOR VARIOUS THICKNESS AND DIAMETER VALUES $. . . \cdots . . . . . .88$ 
LIST OF TABLES (Continued)

Page

10.1 SOME REACTOR CORE AND FUEL CHARACTERISTICS AS APPLIED TO PRESENT ANALYSIS . . . . . . . . . . . . . . . . 95

10.2 LIMITING DIFFUSION PARAMETERS AND ACTIVATION ENERGIES FOR VOLATILE FISSION PRODUCTS . . . . . . . . . . . 99

10.3 RESULTS OF REGAP CALCULATIONS OF RELEASES OF VOLATILES FROM FUEL PELLETS . . . . . . . . . . . . . . . . 101

10.4 RESULTS OF FRCRL2 CALCULATIONS OF RELEASES OF VOLATILES FROM FUEL PELLETS OF THREE REPRESENTATIVE RODS DURING SFTA TEMPERATURE TRANSIENT . . . . . . . . . . . . . 102

10.5 SUMMARY OF CALCULATED TOTAL RELEASES OF VOLATILES FROM FUEL PELLETS (FRCRL2/REGAP) . . . . . . . . . . . 103

10.6 POTENTIAL VOLATILE FISSION PRODUCT CHEMICAL FORMS AND VAPOR PRESSURE DATA . . . . . . . . . . . . . . . 106

10.7 RESULTS OF GAUGING CALCULATIONS OF VOLATILE FISSION PRODUCT RELEASES FOR A SFTA INVOLVING IMPACT PLUS FIRE . . . 108

10.8 ESTIMATED VOLATILE FISSION PRODUCT RELEASES FOR THE FUEL ASSEMBLY EJECTION ACCIDENT . . . . . . . . . . . . . . 112

10.9 FUEL ROD PARTICULATE RELEASE ESTIMATES . . . . . . . . . 115

10.10 CASK PARTICULATE RELEASE ESTIMATES . . . . . . . . . . . 117

10.11 NUCLIDES OF RADIOLOGICAL SIGNIFICANCE AND THEIR CASK INVENTORIES . . . . . . . . . . . . . . . . . . . . . . 119

10.12 DOSE CONVERSION FACTORS USED WITH RSRCON . . . . . . . . . . 120

10.13 SUMMARY OF CASK RELEASE FRACTIONS DEVELOPED FOR FOUR TRANSPORTATION ACCIDENT SCENARIOS . . . . . . . . . . . . 123

10.14 INDIVIDUAL DOSES FROM HE-COOLED CASK INVOLVED IN IMPACT AND FIRE; LOWER-LIMIT AIRBORNE RELEASE ESTIMATES . . . . . . 124

10.15 INDIVIDUAL DOSES FROM HE-COOLED CASK INVOLVED IN IMPACT AND FIRE; UPPER-LIMIT AIRBORNE RELEASE ESTIMATES . . . . . . 125

10.16 INDIVIDUAL DOSES FROM HE-COOLED CASK INVOLVED IN IMPACT AND FIRE WITH EJECTION OF ONE FUEL ASSEMBLY; LOWER-LIMIT AIRBORNE RELEASE ESTIMATES . . . . . . . . . . . . . 126 
Page

10.17 INDIVIDUAL DOSES FROM HE-COOLED CASK INVOLVED IN IMPACT AND FIRE WITH EJECTION OF ONE FUEL ASSEMBLY; UPPER-LIMIT AIRBORNE RELEASE ESTIMATES . . . . . . . . . . . . 127

10.18 POPULATION DOSES FROM HE-COOLED CASK INVOLVED IN IMPACT AND FIRE (FOUR SFTAS) . . . . . . . . . . . . 128

11.1 EVALUATION OF THE ADEQUACY OF EXISTING DATA AND PRIORITY RECOMMENDATIONS FOR INFORMATION DEVELOPMENT . . . 135 


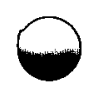

$\theta$

$[\ldots$
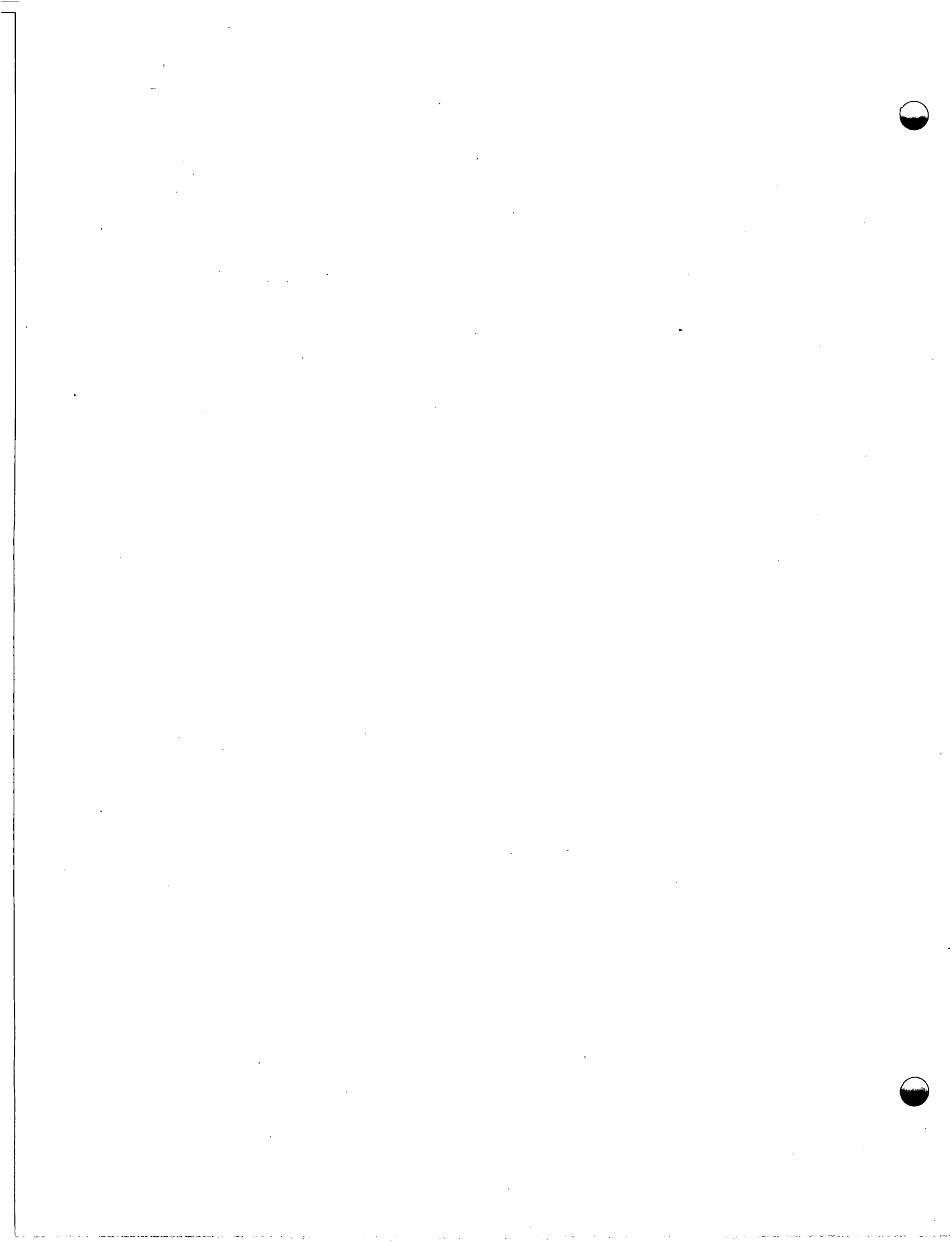
. 
The authors wish to thank Mr. D. P. Bozarth for assistance in gathering information on the licensed spent fuel casks and Mr. R. A. Hedrick for performing the thermal-hydraulic gauging calculations. The assistance of Dr. Jack Goodman in evaluating aerosol transport questions and in performing direct radiation dose calculations is also acknowledged. 


\subsection{INTRODUCTION}

A scoping study was performed to provide the NRC with (1) an assessment of the status of existing information for specifying realistic radiological source terms for severe spent fuel cask transportation accidents; (2) an evaluation of the literature in order to determine if radionuclide releases can be correlated with severe accident environments; and (3) to recommend, on a priority basis, additional information that should be obtained to allow specification of increasingly realistic source terms. The work consisted of four tasks which are described below.

Task 1 consisted of a search for and a review of analytical results and experimental data pertinent to events leading to radionuclide release during severe accidents. Areas of particular interest were fuel thermal and mechanical data (Section 3.0); generic transport accident scenarios and categorizations (Section 4.0); cask response to accident environments (Section 5.0); and radionuclide behavior characterization (Section 6.0).

The literature searches were conducted by a progressive selection process. Recognized authorities were consulted and key resource documents were reviewed for major pertinent information and additional references. These authoritative references were progressively reviewed for pertinent information and for additional major sources. Some computerized searches were also utilized for additional sources, but were of limited use. Using this literature search method, the most pertinent information was given the highest visibility. As the work continued into Tasks 3 and 4 , additional references were reviewed and incorporated as appropriate.

Task 2 involved evaluating the information compiled in Task 1 regarding its adequacy in the following areas: (1) defining radionuclide releases in terms of the structural response of the cask and its contents, and (2) supporting realistic source-term assessments for severe cask accidents. The evaluation is contained in Section 7.

Task 3 consisted of a set of gauging calculations which would establish the relationship between the phenomena involved in the severe accident scenario and the sensitivity of the radionuclide source term to the uncertainties involved in the evaluation of realistic accidents. Thermalhydraulic (Section 8), structural (Section 9) and radionuclide release, transport, and deposition (Section 10) gauging calculations were performed.

Task 4 involved the recommendation, on a priority basis, of the information that should be obtained to allow the specification of an increasingly realistic source term for severe spent fuel transportation accidents (Section 11). 


\subsection{STUDY SCOPE AND GAUGING CALCULATION APPROACH}

\section{1 GENERAL SCOPE OF THE PROJECT}

A primary objective of this project was to determine areas in which further research will permit increasingly realistic evaluation of more severe spent fuel transportation accidents (SFTA). The accident environment will not be considered realistic; rather, it was selected to allow sensitivity studies to be undertaken on the remaining variables. Given the definition of the accident environment, the remainder of the accident scenario is to be as realistic as possible. Research recommendations were to be ranked in order of suggested priority; therefore, the relative sensitivity of the accident source term to the uncertainties identified needed to be established to assist in the priority assignment. The authors selected accident environments which would ensure a release of radionuclides and which have no other significance.

The area of interest was considered to be the escape of radionuclides from the cask to the environs; therefore, shielding and criticality aspects were not considered in this project.

The regulations specify a series of performance tests to which spent fuel casks are subjected. One of these is a fire test of specified constant temperature, evenly enveloping the cask, and of specified duration. The authors selected a similar definition of a specific accident environment as a boundary condition for thermal-hydraulic calculations. The practicalities of testing a cask in such an environment is not in the scope of this project, nor are such difficulties as accurately measuring the fire temperature or the cask response in the project scope.

Recommendations regarding such topics as the need for demonstrating emergency response capability, investigating the need for better operational quality assurance, or the advisability of developing modal-dependent regulations were not in the scope of this project. One area of needed information, however, is a clear, written explanation of the philosophy of the performance testing licensing approach: what it means, what it does not mean, and contrasts with other approaches such as the design basis accident licensing approach.

\section{2 OVERALL APPROACH FOR THE GAUGING CALCULATIONS}

The NRC specified that this project should emphasize the more severe accident environments, including at least some accident environments which produce significant loss of cask integrity. As is discussed in Sections 4 and 7 , previous studies have been unable to link the response of the cask and its contents to the severe environment; therefore, an a priori accident environment definition may not yield the desired radionuclide release severity. To avoid this potential problem, the approach selected for this project was (1) to define the condition of the fuel and cladding resulting from the accident as the starting point for the radionuclide release and 
behavior scenario and (2) to look for the accident environment that would be required to produce the defined conditions. Both are used to determine the uncertainties that need future research as well as to develop a model for priority evaluations. The former could be called an event tree tactic and the latter a fault tree tactic, except that this terminology implies a comprehensive and exhaustive classification, and this study is concerned with fewer, but representative, situations.

Originally, several accident scenarios were postulated which ranged in severity from the onset of cask failure to an extreme event involving the ejection of an intact fuel assembly into a solid object. Generally varying such parameters as the size of the assumed failure in the cask, the fire temperature, or the fire duration, as well as consideration of an ejected fuel assembly, did not introduce new phenomena. Therefore, the gauging calculations were generally based on one scenario with a variable cask coolant, helium or water. Fuel. assembly ejection was an additional consideration in Section 10. The considerations for the selection of the major scenario parameters (definition of the severe accident environment) is described below.

\subsection{GAUGING CALCULATION SCENARIO}

The specific scenario parameters were chosen to provide a calculational vehicle which would permit research needs to be identified. The calculations performed do not produce answers but are a means to identify the range of values of interest so that the evaluation can proceed in an orderly fashion.

\subsubsection{Fuel}

Chapter 1 of Reference 1 and Appendix $G$ of Reference 2 provide a good description of the various types of LWR fuel; therefore, that information will not be repeated here. A PWR fuel assembly was chosen for the accident scenario because of its higher burnup and heat loading. A heat loading of $8.4 \mathrm{~kW} /$ assembly, based on $30 \mathrm{MW} / \mathrm{MTU}$ and $33,000 \mathrm{MWD} / \mathrm{MTU}$, and 180 days cooling was chosen to be consistent with Reférence 1 . (Reference 2 used $35 \mathrm{MW} / \mathrm{MTU}$ and 25,000 MWD/MTU:). Although current LWR spent fuel shipping casks are designed and licensed for fuel cooled as little as 120 to 180 days, in practice fuel is seldom shipped unless it has cooled for at least one year and probably several years. (The additional cooling at one and two years results in heat loadings $60 \%$ and $32 \%$ respectively of that at 180 days.) Definition of secondary fuel characteristics is stated in Table 10.1 and Table 8.1.

\subsubsection{Cask}

Table 2.1 is a listing of the current LWR spent fuel shipping casks. Of interest is the variety of sizes and cavity coolants. A large cask would have a larger potential source term, but since the project was concerned 
TABLE 2.1 LICENSED AND AVAILABLE SHIPPING CASKS FOR CURRENT GENERATION LWR SPENT FUEL

\begin{tabular}{|c|c|c|c|c|c|c|c|c|c|}
\hline \multirow{2}{*}{$\begin{array}{c}\text { Cask } \\
\text { Designation }\end{array}$} & \multicolumn{2}{|c|}{$\begin{array}{l}\text { Number of } \\
\text { Assemblies }\end{array}$} & \multirow{2}{*}{$\begin{array}{l}\text { Loaded } \\
\text { Cask } \\
\text { Weight, MT }\end{array}$} & \multirow{2}{*}{$\begin{array}{l}\text { Usual } \\
\text { Transport } \\
\text { Mode }\end{array}$} & \multicolumn{2}{|c|}{ Shielding } & \multirow{2}{*}{$\begin{array}{l}\text { Cavity } \\
\text { Coolant }\end{array}$} & \multirow{2}{*}{$\begin{array}{l}\text { Maximum } \\
\text { Heat } \\
\text { Removal, } \\
\text { kW }\end{array}$} & \multirow[b]{2}{*}{ Status } \\
\hline & PWR & BWR & & & Gamma & Neutron & & & \\
\hline $\begin{array}{l}\text { NFS }-4 \\
(N A C-1)\end{array}$ & 1 & 2 & 23 & Truck & $\begin{array}{l}\text { Lead and } \\
\text { steel }\end{array}$ & $\begin{array}{l}\text { Borated } \\
\text { water and } \\
\text { antifreeze }\end{array}$ & Water & 11.5 & Licensed \\
\hline NFS- 5 & 2 & 3 & 25 & Truck & $\begin{array}{l}\text { Uranium } \\
\text { and steel }\end{array}$ & $\begin{array}{l}\text { Borated } \\
\text { water and } \\
\text { antifreeze }\end{array}$ & Water & 24.7 & $\begin{array}{l}\text { SAR submitted } \\
\text { in U.S. }\end{array}$ \\
\hline NLI $1 / 2$ & 1 & 2 & 22 & Truck & $\begin{array}{l}\text { Lead, } \\
\text { uranium } \\
\text { and steel }\end{array}$ & $\begin{array}{l}\text { Water and } \\
\text { antifreeze }\end{array}$ & Helium & 10.6 & Licensed \\
\hline$T N-8$ & 3 & & 36 & Truck ${ }^{\mathrm{a}}$ & $\begin{array}{l}\text { Lead and } \\
\text { stee } 1\end{array}$ & $\begin{array}{l}\text { Borated } \\
\text { solid } \\
\text { resin }\end{array}$ & Air & 35.5 & Licensed \\
\hline$T N-9$ & & 7 & 36 & Truck $^{a}$ & $\begin{array}{l}\text { Lead and } \\
\text { steel }\end{array}$ & $\begin{array}{l}\text { Borated } \\
\text { solid } \\
\text { resin }\end{array}$ & Air & 24.5 & Licensed \\
\hline $\mathrm{TN}-12$ & 12 & 32 & 97 & Rail & Stee 1 & $\begin{array}{l}\text { Borated } \\
\text { solid } \\
\text { resin }\end{array}$ & Air & 135 & $\begin{array}{l}\text { Licensed in Europe } \\
\text { only, SAR submitted } \\
\text { in U.S. }\end{array}$ \\
\hline$I F-300$ & 7 & 18 & 63 & $\operatorname{Rai1}{ }^{b}$ & $\begin{array}{l}\text { Uranium } \\
\text { and steel }\end{array}$ & $\begin{array}{l}\text { Water and } \\
\text { antifreeze }\end{array}$ & $\begin{array}{l}\text { Water } \\
\text { or air }\end{array}$ & $76^{C}$ & Licensed \\
\hline NLI $10 / 24$ & 10 & 24 & 88 & Rail & $\begin{array}{l}\text { Lead, } \\
\text { uranium, } \\
\text { and steel }\end{array}$ & $\begin{array}{l}\text { Water and } \\
\text { antifreeze }\end{array}$ & Helium & $97^{d}$ & Licensed \\
\hline $\begin{array}{l}\text { a Overweight } \\
\text { b Truck ship } \\
\text { c Licensed } \\
\text { d Lnsed }\end{array}$ & $\begin{array}{l}\text { perm } \\
\text { ment } \\
\text { lecay }\end{array}$ & $\begin{array}{l}\text { requ } \\
\text { sho } \\
\text { it } 10\end{array}$ & $\begin{array}{l}\text { ed. } \\
\text { distances } \\
\text { is } 62 \mathrm{~kW} \text {. } \\
\text { is } 70 \mathrm{~kW} \text {. }\end{array}$ & th overw & permit. & & & & \\
\hline
\end{tabular}


with research needs, not absolute answers, the absolute magnitude of the source term is not a consideration. To make use of previous SAI work, a cask typical of the NLI $10 / 24$ cask was selected. Note that our use of ten fuel assemblies, each producing $8.4 \mathrm{~kW}$, exceeds the licensed, but not the design, heat loading of the NLI 10/24 cask. The fuel assemblies are assumed to be contained in an aluminum fuel basket. Thermal analyses were performed in the radial direction only, and in that direction the gamma shielding is lead and steel. A water jacket provides neutron shielding. Both a helium-cooled case and a water-cooled case were analyzed.

\subsubsection{Impact Accident Environment}

An impact (or puncture) environment which produced a leak flow path area of $20 \mathrm{~cm}^{2}$ and a flow friction loss factor of 4 was picked. This area could result from a number of cask failures including the shearing of a line one inch in radius or a circumferential, thru-wall crack of 0.02 inch width. The friction loss factor could also be obtained from a variety of leak flow paths, including a one-inch radius line with several bends followed by expansion and contraction and another $20 \mathrm{~cm}^{2}$ opening to the outside atmosphere. Variations in these parameters had been planned originally, but it was found that additional parameter studies were unnecessary.

The impact was assumed to cause $10 \%$ of the cladding to rupture at the start of the accident. Initial ruptures were considered an essential part of the scenario because of the possibility for pre-accident failures, the potential for initial release to the atmosphere, and to investigate the in-cask behavior of radionuclides during blowdown and heatup. As stated earlier, this project was concerned with the identification of phenomena, not the absolute magnitude of the source term; therefore, the choice of $10 \%$ initial failures, vs $20 \%$ or $1 \%$, was not an important consideration.

\subsubsection{Fire Accident Environment}

The NRC regulations specify the consideration of a fire of $1475^{\circ} \mathrm{F}$ with a duration of one-half hour. Examination of cask Safety Analysis Reports shows that this fire produces neither cask failures or fuel failures. A $1475^{\circ} \mathrm{F}$ fire of two hours' duration, was arbitrarily chosen. In the heliumcooled case, an additional $40 \%$ of the rods experienced thermal-induced failures, but in the water-cooled case no additional failures occurred. Hotter and longer fires were planned originally, but did not appear necessary. Additional discussion of the results is provided in Sections 8 and 10.

The fire and impact accident environments were combined since, as discussed in Section 2.3.3, the initial failures seemed important and since the subsequent fire-induced heatup is the upper bound for heatup calculations. 


\section{REFERENCES}

1. U.S. Department of Energy, "Analytical Methodology and Facility Description--Spent Fuel Policy", DOE-ET-0054 (August 1978).

2. U.S. Nuclear Regulatory Commission, "Draft Generic Environmental Impact Statement on Handling and Storage of Spent Light Water Power Reactor Fue1", NUREG-0404 (March 1978). 


\section{0 SUMMARY OF FUEL MECHANICAL, STRUCTURAL,}

AND THERMAL DATA

This section presents a summary of irradiated LWR fuel property data that would be applicable to a spent fuel transportation accident. Accident scenarios of interest in this section usually consist of two components, impact and fire. Summary information is therefore presented separately for each situation.

\subsection{MECHANICAL/STRUCTURAL PROPERTIES OF SPENT FUEL RODS AND THEIR RESPONSE TO IMPACT}

\subsubsection{Introduction}

This section considers the mechanical and structural properties of fully irradiated (33,000 MWD/MTU at $30 \mathrm{MW} / \mathrm{MTU})$ LWR fuel, as well as the possible response of such fuel to impact.

The primary source of mechanical/structural property data is the handbook of material properties ${ }^{1}$ prepared at the Idaho National Engineering Laboratory (INEL). A wide range of properties of materials is covered in this handbook, including those of the fuel material, the cladding, and the gap between the fuel and cladding. Not all of these properties are relevant to transportation accidents, and the present coverage is confined to the more important properties in this regard.

The previously mentioned continuing program at INEL for improved understanding of. LWR fuel performance under reactor accident conditions has resulted in the development of $\mathrm{MATPRO}^{1}$, a computer library of uranium dioxide and mixed uranium-plutonium dioxide, Zircaloy cladding, and gas mixture material properties. The approaches used in modelling material properties range from (1) a least square fit of available data using polynomial or other functional forms having little or no theoretical basis to (2) a semiempirical correlation employing a theory-suggested analytical expression with constants determined by comparison with data. The authors state 1 that the intent of current and future work is to take the second approach whenever possible.

\subsubsection{Fuel Fracture Strength}

The fracture strength of brittle $\mathrm{UO}_{2}$ is calculated as a function of porosity and temperature for temperatures up to $500^{\circ} \mathrm{C}$, the lowest temperature at which plasticity has been observed in pile. For temperatures above $500^{\circ} \mathrm{C}$, a constant value is used to represent the in-pile fracture strength of plastic $\mathrm{UO}_{2}$. The equation for calculating fracture strength of brittle $\mathrm{UO}_{2}$ below $500^{\circ} \mathrm{C}$ is based on out-of-pile $\mathrm{UO}_{2}$ fracture strength data while that for plastic $\mathrm{UO}_{2}$ is based on theoretical considerations and fragmentary out-of-pile data. Apparently no in-pile measurements of $\mathrm{UO}_{2}$ fracture 
strength have been made. Since it is known that fracture of $\mathrm{UO}_{2}$ pellets occurs during irradiation, calculations of $\mathrm{UO}_{2}$ fracture strength based on out-of-pile measurements with unfractured and unirradiated pellets seem to be of questionable value in assessments of possible consequences of spent fuel shipping accidents where the pellets are partially fractured before shipment. Also, it should be kept in mind that $\mathrm{UO}_{2}$ fracture is of little consequence unless the cladding is also fractured.

Knowledge of the fracture strength of highly irradiated $\mathrm{UO}_{2}$ appears to be inadequate to provide suitable input to modelling the behaviour of fuel material in a spent fuel shipping accident.

\subsubsection{Zircaloy Cladding Fracture}

\subsubsection{Material Property Models}

Seventeen material properties of LWR cladding (Zircaloy-2 or -4) were modelled for inclusion in MATPRO-version 10, but only a few of these appear to be relevant to accident conditions for fuel shipments. Although some LWR fuel with stainless steel cladding has been used and could conceivably be involved in a shipping accident, Zircaloy-clad fuel is the only fuel currently of interest in the nuclear industry.

Cladding true stress and engineering stress is calculated as a function of true strain, true strain rate, cladding temperature, maximum previous cladding temperature, cold work, and fast neutron fluence. A power law expression can also be used for true stress. All input strain or stress values are assumed by MATPRO mechanical property routines to be true strain (change in length divided by length at the instant of change integrated from the original to the final length) or true stress (force per unit cross sectional area with the area determined at the instant of measurement of the force). Output values from MATPRO generally are given both as true and as engineering values of stress or strain.

Effects of cladding temperature, in-reactor annealing, cold work, and irradiation on mechanical properties are expressed as changes in the strength $K$, the strain hardening exponent $n$, and the strain sensitivity constant $m$ in the equation

$$
\sigma(\text { true stress })=K \varepsilon^{n}\left(\frac{\dot{\varepsilon}}{10^{-3 / 5 e c}}\right)^{m}
$$

where $\dot{\varepsilon}$ is the true strain rate. For fully annealed material, the temperature- and strain-rate dependent values of $n$ and $K$ are given for different temperature ranges in MATPRO.

Strain is calculated as a function of true stress, true stress rate of change, cladding temperature, maximum previous cladding temperature, cold work, and fast neutron fluence. Both elastic and plastic stress-strain 
curves are said ${ }^{1}$ to be consistent with either of the two methods to calculate true stress.

Two MATPRO subroutines describe Zircaloy cladding mechanical limits and strain to failure. One calculates true and engineering values of stress at yield, instability strain, strain at rupture, yield strength, and ultimate strength. The required input is cladding temperature, maximum previous cladding temperature, cold work, fast neutron fluence $(>1 \mathrm{Mev})$, and strain rate. The other subroutine repeats the correlation for strain at rupture and adds expressions for the uncertainty of the correlation.

A MATPRO subroutine is also provided for calculating cladding shear modulus in terms of the elastic modulus and Poisson's ratio, which are calculated by other subcodes as a function of temperature. Only one report ${ }^{2}$ was found which presents data on the shear modulus of Zircaloy-2 and -4 , based on tests with solid and tube specimens.

\subsubsection{Sources of Information on Properties of Irradiated Zircaloy}

An attempt to compile and correlate information on the properties of Zircaloy as well as fuel and gap gas properties was made in MATPRO. There appears, however, to be a scarcity of data on the properties of irradiated Zircaloy cladding in general and, in particular, from tests under spent fuel shipping conditions. A continuing program at Battelle's Columbus Laboratory is directed toward evaluating the strength and ductility of irradiated Zircaloy. Results are reported in quarterly progress reports. ${ }^{3}$ This program is designed primarily to evaluate behavior of Zircaloy fuel cladding under reactor transient and accident conditions, but four-point bending tests ${ }^{3}$ do provide data relevant to fuel shipping accidents. Some data have been produced at the 0ak Ridge National Laboratory. 4 . 5 Agin, these experiments were directed toward evaluating the consequences of reactor accidents rather than fuel shipment accidents, and the results are probably not relevant to fuel shipping accidents.

\subsubsection{Fuel Assembly Behavior in Cask Accident Tests}

Several tests of fuel shipment casks have been made at Sandia under simulated shipping accident conditions. ${ }^{6,7,8}$ Fuel assemblies were placed in the casks during these tests, and the effects of the tests on the fuel were observed. The fuel assemblies used in these tests had unirradiated stainless-steel-clad fuel rods (N.S. Savannah fuel); therefore, the applicability of these tests to fully irradiated Zircaloy-clad fuel rods is questionable. Bowing of fuel rods was observed in some of the tests, but failure of the fuel cladding did not occur even under the most drastic test conditions. More recently, the same type of fuel as sembly was placed in a cask that was tested at ORNL by dropping it from a height of thirty feet onto an essentially unyielding surface. 9 The fuel support structure was extensively damaged, and some bowing of the fuel rods was noted, but failure of the fuel cladding was not observed in the preliminary examination of the fuel assembly. 


\subsection{THERMAL/MECHANICAL PROPERTIES OF SPENT FUEL RODS AND THEIR}

\section{BEHAVIOR IN FIRE AND LOSS OF COOLANT ENVIRONMENTS}

A spent fuel shipping cask involved in circumstances in which it is exposed to an external fire, loss of its coolant, or both will experience a temperature excursion. The principal concern in this instance is the release of radionuclides to the cask and subsequently to the environment. Therefore, of primary importance is the ability to predict the behavior of the fuel rod cladding, especially its integrity, and the behavior of the cask in an escalating temperature environment. If the cladding maintains its integrity, then the primary barrier to radionuclide release remains intact, and the impact of the accident is minimized.

\subsubsection{Limiting Temperature and Stress for Zircaloy Cladding Integrity}

Data on unirradiated Zircaloy tube burst has been generated by three different experimental techniques in the United States and abroad. The results of placing Zircaloy tubes in furnaces, ${ }^{10}$ testing them directly by passing electric current through them, ${ }^{11}$ and heating them indirectly by placing resistance heaters inside them ${ }^{12}$ show markedly different stressstrain burst shapes. However, although the data were taken under different heating methods and encompass both single rod and bundle geometry, they do not differ significantly in reported rupture temperature and stress. ${ }^{13}$ This relationship was presented in an empirical formulation by Chapman ${ }^{14}$ as

$$
T=3960-\frac{0.024 \Delta P}{1+H}-\frac{10000 \Delta P}{100(1+H)+3.28 \Delta P}
$$

where

$$
\begin{aligned}
& T=\text { Highest recorded thermocouple indicated temperature, }{ }^{\circ} \mathrm{C} \\
& \Delta \mathrm{P}=\text { Differential pressure, } \mathrm{kPa} \\
& \mathrm{H}=\mathrm{Cl} \text { adding heating rate normalized to } 28^{\circ} \mathrm{C} / \mathrm{sec}
\end{aligned}
$$

No applicable irradiated tube burst data were found; however, the BCL data discussed in Section 3.1.3.2 indicates that irradiated Zircaloy ductility varies little from that of unirradiated Zircaloy.

The pressure dependence was obtained from data which were reported in engineering stress units by using a "standard tube" with a $1.0922 \mathrm{~cm} \mathrm{o.d.}$ and $0.063246 \mathrm{~cm}$ wall thickness. If this same information is used to reformulate the equation in terms of engineering stress, then it should be directly applicable to any currently used fuel rod cladding involved in the cask accidents under consideration. Once this has been done, it will then be necessary to compute the thermal response of the cladding and the engineering stress across it during the accident scenario and compare the 
predicted cladding temperature with the rupture temperature predicted by Chapman's equation to determine if the tube has failed and if radionuclides have been released to the interior of the cask.

\subsubsection{Deterministic Simulation of the Fuel Rods}

In order to assess the thermal response of the cladding and the engineering stress across it, a simulation of the thermal forcing functions of fire and/or loss of coolant and the fuel rod internal heat generation must be performed. The effect of the fire on the cask heat load can be determined at several levels of sophistication; $15,16,17$ similarly, the loss-of-coolant accident can be analyzed to whatever degree desired.16,17 Therefore, with these forcing functions taken independently or superimposed, the initial and boundary conditions for the analysis of the fuel rods can be determined.

Due to the emphasis placed on the loss-of-coolant accident in light water reactors, a large amount of research, both experimental and analytical, has been perfomed to characterize the behavior of nuclear fuel rods in steady state and reactor accident situations. A significant portion of this research has been utilized in the production of the FRAP 19,20 series of computer codes which digitally simulate the behavior of the fuel rods in accident scenarios. If a detailed evaluation of the Zircaloy cladding behavior during a cask fire or loss-of-coolant accident were deemed necessary, modifications to this code series could be made to replace the reactor water/steam boundary conditions with those established by cask accident analyses. However, this is a costly and time-consuming approach and is probably not justifiable unless less sophisticated analyses produce unacceptable results or large uncertainties.

Less sophisticated analyses will require basic physical property data for the fuel rod constituents and a fission gas plenum/gap behavioral model. Data, correlations, and FORTRAN subroutines for specific heat capacity, thermal conductivity, and spectral emmissivity for $\mathrm{UO}_{2}$ and $(\mathrm{U}, \mathrm{Pu}) \mathrm{O}_{2}$ fuels, and Zircaloy-2 and -4 cladding are contained in the MATPRO package for the parameter ranges of interest. MATPRO also has models for more detailed analyses, such as fuel swelling and densification and cladding elastic and plastic deformation. Information is also provided for fission gas properties and parameters for use in fission gas plenum/gap behavioral models such as Ross-Stoute. ${ }^{21}$ MATPRO is the primary data base for the FRAP code series. 


\section{REFERENCES}

1. P. E. MacDonald et a1., "MATPRO-Version 10, A Handbook of Material Properties for Use in the Analysis of Light Water Reactor Fuel Rod Behavior," TREE-NUREG-1180 (February, 1978).

2. R. E. Johnson, "The Torsional Properties of Zircaloy-2 and Zircaloy4," WAPD-BT-10, (October, 1958).

3. L. M. Lowry, et al., "Quarterly Progress Report on Evaluating Strength and Ductility of Irradiated Zircaioy, for the period: January through March 1978," NUREG/CR-0085, BMI-2000 (June, 1978).

4. D. O. Hobson and P. L. Rittenhouse, "Deformation and Rupture of LightWater Reactor Fuel Cladding," ORNL-4727 (October, 1971).

5. D. 0. Hobson, M. F. Osborne and G. W. Parker, "Comparison of Rupture Data From Irradiated Fuel Rods and Unirradiated Cladding," Nucl. Technology 17, 502 (1971).

6. H. R. Yoshimura and M. Huerta, "Ful1-Scale Tests of Spent Nuclear Fuel Shipping Systems," SAND-76-5707 (JuTy, 1976).

7. R. M. Jefferson and H. R. Yoshimura, "Crash Testing of Nuclear Fuel Shipping Containers," SAND-77-1462C (August, 1977).

8. R. M. Jefferson and H. R. Yoshimura, "Crash Testing of Nuclear Fuel Shipping Containers," SAND-77-1461 (February, 1978).

9. R. D. Seagren, "Drop Testing of the Knapp Mills Spent Fuel Cask," ORNL-TM-6908 (In Preparation).

10. D. G. Hardy, "High Temperature Expansion and Rupture Behavior of Zircaloy Tubing," Topical Meeting on Water Reactor Safety, Salt Lake City, American Nuclear Society, CoNF-730304 (March, 1973).

11. H. M. Chung, A. M. Garde and T. F. Kassner, "Light Water Reactor Safety Research Program: Quarterly Progress Report, January, March, 1976," ANL-76-49 (June, 1976).

12. R. H. Chapman, "Multirod Burst Test Program Quarterly Progress Report for October-December, 1975," ORNL/NUREG/TM-10 (May, 1976).

13. M. L. Picklesimer, Nuclear Regulatory Commission, personal communication.

14. R. H. Chapman, "Preliminary Multirod Burst Test Program Results and Implications of Interest to Reactor Safety Evaluations," Sixth Water Reactor Safety Research Information Meeting, November 6-9, 1978. 
15. International Atomic Energy Agency, "Transport Packaging for Radioactive Materials," in four papers, IAEA-SR-10/30, IAEA-SR-10/1, IAEA-SR-10/32 and IAEA-SR-10/47, Vienna (1976).

16. F. Kreith, Principles of Heat Transfer, 2nd ed., International Text Book Company: Scranton, Pennsylvania (January, 1966).

17. H. C. Hotte1, Heat Transmission, 3rd ed., McGraw Hill Book Company: New York, New York (1954).

18. W. D. Turner, D. C. Elrod and I. I. SimonTov, "HEATING5: An IBM360 Heat Conduction Program," ORNL/CSD/TM-15 (March 1977).

19. J. A. Dearien et al, "FRAPS2: A Computer Code for the Steady State Analysis of Oxide Fuel Rods, Report 1, Analytical Models and Input Manual," TREE-NUREG-1107 (July 1977).

20. J. A. Dearien et al, "FRAPT2: A Computer Code for the Transient Analysis of Oxide Fuel Rods, Report 1, Analytical Model and Input Manual," TREE-NUREG-1040 (August 1977).

21. A. M. Ross and R. L. Stoute, "Heat Transfer Coefficient Between $\mathrm{UO}_{2}$ and Zircaloy," AECL-1552 (June 1962). 


\subsection{REVIEW OF. ACCIDENT SCENARIOS AND CATEGORIZATIONS}

The literature was reviewed for correlations between accident severity and radionuclide release and for useful accident scenarios. The scope of the review was limited to the time period after 1972, the publication date of WASH-1238, and several other pertinent documents, since those publications preceding 1972 seemed to be only preliminary versions of the 1972 publications. Nine documents contained scenarios and/or categorizations of interest, which are summarized below and in Table 4.1. The categorizations are evaluated in Section 7.1, and the scenarios are used in Section 8.2.

\section{1 WASH-1238}

The AEC analysis of the environmental impact of the transportation of radioactive materials to and from nuclear power plants was presented in WASH-1238 ${ }^{1}$ in December 1972. Five categories of accident severity were defined for Type $B$ packages as a function of vehicle speed and fire duration as shown in Table 4.2. An associated set of probabilities was also presented in WASH-1238 and cited later in a number of other reports, some of which are summarized below.

Package damage was not correlated with accident severity, but five postulated accidents were described for a rail cask, and these are summarized in Table 4.3. In the first case, severe impact and fire, ten percent of the rods were assumed to experience cladding failure upon impact, thereby releasing the activity in the fuel rod void space (plenum and fuel-cladding gap) tabulated in Table 4.4. These values are still widely referenced. The fire subsequently drives off all of the coolant so that, of the radionuclides in the cavity, 100 percent of the krypton and iodine, but only one percent of the gross fission products, become airborne. The basis for the one percent value was not given.

In the second and third cases, the initial release is limited to the normal coolant activity, but eventually fifty percent of the rods undergo cladding failure due to thermally induced overpressurization of the rod void. The void activity is then released to the cask cavity, but the analysis is carried no further. The fourth case results are the same as the second and/or third depending on the time interval involved. The fifth case was not presented as a postulated accident, but rather as a separate event in which the cask contents are somehow ejected from the cask. The direct dose due to the lack of shielding material was presented.

\subsection{BROBST}

A November 1972 paper ${ }^{2}$ presented by $W$. A. Brobst was published in Nuclear News in May $1972^{3}$ which contained the same accident severity categories as WASH-1238 (Table 4.2). In addition, a correlation between accident severity and cask damage was cited as shown in Table 4.5. These values were based on "gross judgment and the very limited data available." The last 
TABLE 4.1

SUMMARY OF ACCIDENT CLASSIFICATIONS AND SCENARIOS

References

Comments

$\begin{array}{ll} & \text { *Accident severity classified by vehicle speed and fire } \\ \text { WASH-12381 } & \text { *Release fraction not correlated with accident severity }\end{array}$

$12-72$

* Several postulated accident scenarios of interest described

*Fuel rod void activity values widely used

*Accident severity classification as in WASH- 1238

Brobst ${ }^{2,3} \quad{ }^{*} A$ correlation between accident severity and cask damage was

11-72 given based on engineering judgement

*Accident severity classification based on AEC incident reports

Yadigarogl $u^{4} \quad$ *Release fraction assumed to be equally probable within two

$11-72$ categories

$\operatorname{Ross}^{8}$

$1-74$

*WASH-1238 loss-of-coolant scenario critiqued with respect to possible cesium release

*An increase in cesium release of more than a factor of 100 was projected

WASH $-1238^{9}$

Supp 1 II

(NUREG-0069)

7-76
*Cesium release calculation revised upward from WASH-1238 by about a factor of three but lower than Ross's value by a factor of thirty-five
Hodge \&

Jarrett 10

$11-74$
*WASH-1238 accident severity classification collapsed in higher ranges

*Engineering judgment used to relate release fraction to accident severity
WASH- $1400^{11}$

1975
*Void activity projections lower than WASH-1238 and then further modified by an escape fraction

*Based on WASH-1238, $10 \%$ cladding failure on impact was used

${ }^{*} A$ cask plateout factor of 2 was used except for noble gases 
TABLE 4.1 (Continued)

References Comments

*Accident severity classification based on wide data base

NUREG-017012 *Release fraction correlation with accident severity intended 1977 to be simplistic and relatively conservative

Heaberlin 14 10-77

*Three fire damage categories defined, but no attempt made to relate damage to fire intensity and duration

*WASH-1400 based void acitvities used with additional Cs and I fractional release due to extended fire 
TABLE 4.2

ACCIDENT SEVERITY CATEGORIES*

\begin{tabular}{lrc}
\hline Severity & $\begin{array}{c}\text { Vehicle } \\
\text { Speed, mph }\end{array}$ & $\begin{array}{c}\text { Fire } \\
\text { Duration, hr }\end{array}$ \\
\hline Minor & $0-30$ & $0-1 / 2$ \\
& $30-50$ & 0 \\
Moderate & $0-30$ & $1 / 2-1$ \\
& $30-70$ & $<1 / 2$ \\
Severe & & $>1$ \\
& $0-50$ & $1 / 2-1$ \\
& $30-70$ & $0-1 / 2$ \\
Extra Severe & $>70$ & $>1$ \\
& & $1 / 2-1$ \\
\hline
\end{tabular}

*Used in References 1 and 3. 
TABLE 4.3

SUMMARY OF WASH-1238 POSTULATED ACCIDENTS

Accident

Effects

1. SEVERE IMPACT \& FIRE

${ }^{*} 10 \%$ of the rods failed on impact

*Gap fraction released to cavity

* $100 \%$ coolant release

*all $\mathrm{Kr} \& \mathrm{I}$ released to cask cavity dispersed into atmosphere

${ }^{*} 1 \%$ of fission products released to cask cavity dispersed in atmosphere

2. LOSS OF EXTERNAL MECHANICAL COOLING

*release of $50 \%$ of cavity coolant through relief valve due to thermally induced overpressurization

* radionuclide release limited to normal coolant activities

3. CONTINUED LOSS OF EXTERNAL MECHANICAL COOLING

* $50 \%$ cladding failure several hours into the scenario

${ }^{*}$ gap fraction released to cavity

4. LOSS OF HEAT TRANSFER SURFACE AREA

* same as (2) and/or (3) depending on the time interval

5. RELEASE OF FUEL ASSEMBLY

*7 fue 1 assemblies released from cask

*direct dose calculated 
TABLE 4.4

RADIONUCLIDE INVENTORY IN FUEL ROD VOID SPACE

\begin{tabular}{|c|c|c|c|c|c|}
\hline \multirow[t]{3}{*}{ Radionuclide } & \multicolumn{5}{|c|}{ Percent of Total Inventory Released to Rod Void } \\
\hline & \multirow[t]{2}{*}{ WASH- $1238^{*}$} & \multicolumn{3}{|c|}{ Hodge and Jarrett } & \multirow[t]{2}{*}{ Yadigarogl $u^{\star * x}$} \\
\hline & & Large $e^{\star \star}$ & Medium & Smal1 & \\
\hline $\mathrm{kr}-85$ & 30 & 30 & 15 & 0.3 & 35 \\
\hline$I-131$ & 2 & 2 & 1 & 0.02 & 3 \\
\hline $\begin{array}{l}\text { Other Fission } \\
\text { Products }\end{array}$ & 0.01 & 0.1 & 0.05 & 0.001 & \\
\hline $\mathrm{Xe}-131 \mathrm{~m}$ & 2 & & & & \\
\hline$H-3$ & 1 & & & & \\
\hline Actinides & $\begin{array}{c}\text { Essentially } \\
\text { None }\end{array}$ & & & & \\
\hline
\end{tabular}

*Values reported in WASH-1238 as realistic but believed to be based on the peak rather than average rod.

${ }^{* *}$ A medium release is defined as $50 \%$ of a large release and a small release is defined as $1 \%$ of a large release. The large release values were taken from WASH-1238.

***Values taken from IF300 Cask SAR and are an upper limit for a typical LWR. 
TABLE 4.5

PREDICTED FRACTION OF CASKS DAMAGED VS ACCIDENT SEVERITY

\begin{tabular}{|c|c|c|c|c|c|}
\hline \multirow[b]{2}{*}{ Damage* $^{\star}$} & \multicolumn{5}{|c|}{ Accident Severity Category } \\
\hline & Minor & Moderate & Severe & Extra Severe & Extreme \\
\hline $\begin{array}{l}\text { None to Moderate } \\
\text { (No Breach) }\end{array}$ & $0.99+$ & $0.99+$ & 0.99 & 0.95 & 0.90 \\
\hline $\begin{array}{l}\text { Severe } \\
\qquad(\text { Sma } 11 \text { Breach) }\end{array}$ & 0.001 & 0.01 & 0.01 & 0.04 & 0.07 \\
\hline $\begin{array}{l}\text { Extra-Severe } \\
\text { (Medium Breach) }\end{array}$ & --- & --- & 0.001 & 0.01 & 0.02 \\
\hline $\begin{array}{l}\text { Extreme } \\
\text { (Large Breach) }\end{array}$ & --- & --- & --- & 0.001 & 0.01 \\
\hline
\end{tabular}

*Small Breach--Containment not breached, material safely confined for a substantial period of time (perhaps weeks) without repair.

Medium Breach--At least partial loss of coolant and perhaps a small fraction of the available contents.

Large Breach--Up to a total loss of containment, release of a few percent of the available contents. 
two columns of the table illustrate the difficulty in correlating package damage to accident severity in that the damage depends on the form and amount of energy delivered to the cask, the ability of the cask to withstand these forces, the part of the cask that fails, and the type of failure. These depend on the accident circumstances and the specific cask design; therefore, there will be a distribution in damage effects for the same accident environment.

\section{3 YADIGAROGLU}

In the November 1972 issue of Nuclear News ${ }^{4}$, G. Yadigaroglu and colleagues published their part of a larger study of nuclear power risk by Starr and Greenfield ${ }^{5}$. An accident classification originated by Morgan, et al. ${ }^{6}$ was presented, and the relative frequency was determined from AEC incident statistics $^{7}$ for 1949 thru 1970. The classifications were:

$$
\begin{aligned}
& \text { I - - No loss of package integrity } \\
& \text { II -- Package breached--no release } \\
& \text { III -- Release confined to vehicle } \\
& \text { IV -- Release to the ground--no aerial dispersal } \\
& \text { V - Aerial dispersal } \\
& \text { VI -- Radioactive material enters a watercourse }
\end{aligned}
$$

The activity in the rod void space was taken from the IF300 Cask Safety Analysis Report and is given in Table 4.4. These values were cited as upper limits for a typical LWR. The release probabilities for classes $V$ and VI were arbitrarily assumed to be evenly distributed between zero and 10CFR71 values and between the 10CFR71 values and the rod void values given in Table 4.4 .

\subsection{ROSS}

In 1974 M. Ross published his version of the analysis of the WASH-1238 postulated accident involving loss of cask coolant (case 3 of Section 4.1). His version was primarily concerned with cesium and is summarized in Table 4.6. The resulting cesium release was estimated to be a factor of 117 greater than that reported in WASH-1238.

\subsection{WASH-1238, SUPPLEMENT I I}

The NRC revised the cesium release calculation in a supplement 9 to WASH1238. The revised scenario is also summarized in Table 4.6. The WASH-1238 cesium release values were revised upward by a factor of about three. 
TABLE 4.6

COMPARISON OF CESIUM RELEASE SCENARIOS

\begin{tabular}{|c|c|c|}
\hline Source & & Scenarios \\
\hline \multirow[t]{10}{*}{ Ross } & (a) & Cask Blowdown \\
\hline & & $10 \%$ cladding failure on impact \\
\hline & & $20 \%$ Cs produced is in the void \\
\hline & & $\begin{array}{l}\text { another } 1 \% \text { Cs leached from pellet surface } \\
\text { at initial cladding failure }\end{array}$ \\
\hline & & $\begin{array}{l}10 \% \text { in cask cavity escapes to atmosphere } \\
\text { with blowdown }\end{array}$ \\
\hline & (b) & Cask Outgassing \\
\hline & & $50 \%$ creep rupture cladding failure \\
\hline & & $\begin{array}{l}20 \% \text { Cs produced is in the void ( } 1 / 2 \text { vola- } \\
\text { tile, } 1 / 2 \text { aerosolized) }\end{array}$ \\
\hline & & $\begin{array}{l}10 \% \text { in cask cavity escapes to atmosphere } \\
\text { due to pressure buildup }\end{array}$ \\
\hline & & Cesium is $2 / 3 \mathrm{Cs}-134 \& 1 / 3 \mathrm{Cs}-137$ \\
\hline
\end{tabular}

WASH-1238,

Supplement II

(a) Cask Blowdown

$10 \%$ cladding failure on impact

$10 \%$ of fuel from failed rods exposed to water coolant

$0.3 \%$ of cesium can be leached by fuel exposed to water

$10 \%$ coolant released during blowdown

(b) Cask Outgassing

$50 \%$ cladding failure due to thermal effects

$50 \%$ void gas released from failed rods

$0.6 \%$ of total cesium is in void in metallic form

$10 \%$ void metallic cesium remains uncombined at time of cladding failure

No plateout or recombining on contact with colder metals in release path 


\subsection{HODGE AND JARRETT}

In 1974 Hodge and Jarrett ${ }^{10}$ performed an evaluation of the transportation accident risks in the nuclear power industry for the EPA. They defined three accident severity categories essentially by combining the last three categories of WASH-1238. Three damage categories were also defined as follows:

Smal1--microscopic openings, e.g. hairline cracks and pinholes

Medium--openings the size of a fill port

Large--openings several times the size of a fill port

The damage categories were assumed to be directly related to three release categories shown in Table 4.4 where the large release values were taken from WASH-1238. Using engineering judgment, a damage probability for each release category was then assigned to each accident severity category.

\subsection{WASH- 1400}

This 1975 NRC report ${ }^{11}$ considered spent fuel shipping cask accidents inside PWR and BWR plants. Inside the typical PWR plant, no possibility arises in which a cask could be dropped more than thirty feet; therefore, the probability of cask rupture was considered too low to be significant. Inside the typical BWR plant, the cask could be dropped one hundred feet; therefore, a probability of 0.1 was arbitrarily assumed for loss of cask coolant upon impact. Based upon WASH-1238, ten percent of the cladding was assumed to fail. Rod void activities lower than those of Table 4.4 were used (discussed in Section 6.2.1.1), and the gap activity was further reduced by a rod escape fraction. For the spent fuel cask accident, the escape fraction was lowered by an unspecified amount in order to account for lower temperatures in the cask accident versus a reactor accident. (Section 6.2.1.2 contains a further discussion of the applicability of the escape fraction of WASH-1400.) A cask plate-out factor of two was used for radionuclides other than the noble gases.

\subsection{NUREG-0170.}

This 1977 report 12 presented eight accident severity classifications for each of three transportation modes, air, truck, and rail. Figure 4.1 shows the rail mode but is i liustrative of the general scheme. The values are from Reference 13 and are primarily concerned with relatively small containers. However, this approach can be applied to spent fuel shipping casks. A companion report ${ }^{14}$ discusses accident environments for large packages. The first two values on the ordinate of Figure 4.1 relate to the drop tests specified by the regulations (one-half of the test velocity for the rail mode), and the other ordinates are chosen so that a given percentage of the accidents are included. The first abscissa value is chosen so that even minor accident environments include some exposure to fire (See also Table 4.2.). Subsequent abscissa values are chosen so that 


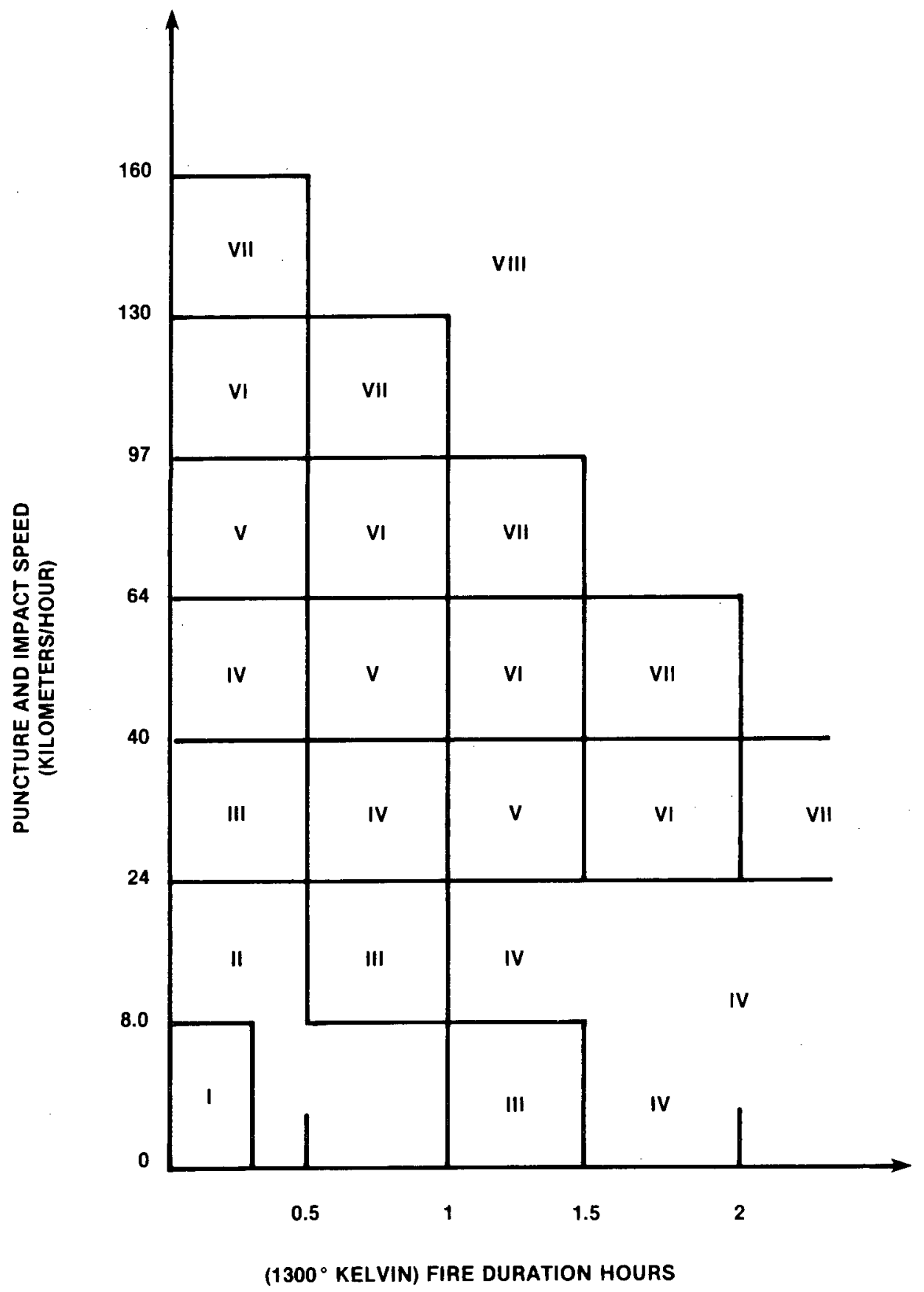

FIGURE 4.1. ACCIDENT SEVERITY CATEGORY CLASSIFICATION SCHEME -- RAIL 
increasing the duration of the fire by thirty minutes is equivalent to increasing the ordinate to the next higher level.

Using the above classification scheme, two release fraction models based on engineering judgment ${ }^{15}$ were defined as shown in Table 4.7. Model I involves zero release up to the regulatory testing level (the definition of the interface between categories II and III) and $100 \%$ release after that. Model II allows a more gradual increase in release fraction, much like the Brobst approach shown in Table 4.5. Model I is characterized as simplistic and overly conservative, and Model II is characterized as more realistic but with inherent conservatisms ${ }^{12}$. The interim drafts of the Urban GEIS ${ }^{16}$ use these values also.

\subsection{HEABERLIN}

Heaberlin and colleagues published ${ }^{17}$ in 1977 an analysis of spent fuel cask accidents at sea. Three degrees of fire damage were defined as fol.lows:

$$
\begin{aligned}
& \text { Minor--no damage } \\
& \text { Moderate--relief valve actuated } \\
& \text { Severe--relief valve actuated leading to loss of all } \\
& \text { cooling water and eventual rod failure. }
\end{aligned}
$$

No attempt was made to relate damage to the fire intensity and duration which would be required to produce it.

Five accident scenarios were evaluated. Two involved immediate failure due to severe fire, one involved immediate failure due to hydrostatic failure of cask and fuel rods at depths greater than 10,000 feet, and two involved corrosive failures occurring thousands of years later. Rod void activities values based on WASH-1400 were used. Since fires at sea may last many days, additional cesium and iodine release fractions due to thermally activated diffusion of 0.89 and 0.62 were used respectively. (Thermally activated diffusion is further discussed in Section 6.2.2.1.) 
TABLE 4.7

NUREG-0170 CORRELATION OF RELEASE FRACTION WITH ACCIDENT SEVERITY

\begin{tabular}{ccc}
\hline \multirow{2}{*}{$\begin{array}{c}\text { Severity } \\
\text { Category }\end{array}$} & \multicolumn{2}{c}{ Release Fraction } \\
\cline { 2 - 3 } I & Model I & Model II \\
\hline II & 0 & 0 \\
III & 0 & 0 \\
IV & 1 & 0.01 \\
V & 1 & 0.1 \\
VI & 1 & 1 \\
VII & 1 & 1 \\
VIII & 1 & 1 \\
\hline
\end{tabular}




\section{REFERENCES}

1. USAEC, "Environmental Survey of Transportation of Radioactive Materials To and From Nuclear Power Plants," WASH-1238 (December, 1972).

2. W. A. Brobst, unpublished paper presented before the Department of Defense Explosives Safety Board, 14th Annual Explosives Safety Seminar, New Orleans, LA (November 10, 1972).

3. W. A. Brobst, "Transportation Accidents: How probable?" Nuclear News, 16, 48-54 (May, 1973).

4. G. Yadigarolgu, A. G. Reinking, and V. E. Schrock, "Spent Fuel Transportation Risks," Nuclear News, 15, 71-75 (November, 1972).

5. C. Starr and M. A. Greenfield, "Public Health Risks of Thermal Power Plants," UCLA-ENG-7242 (May, 1972).

6. J. M. Morgan, Jr., J. W. Knapp, and J. T. Thompson, A Study of the Possible Consequences and Costs of Accidents in the Transportation of High-Level Radioactive Materials, The Johns Hopkins Press, Battimore (1961).

7. W. C. MCCluggage, "The AEC Accident Record and Recent Changes in the AEC Manual, Chapter 0529," CONF-710801 (1971).

8. M. Ross, "The Possibility of Release of Cesium in a Spent-Fuel Transportation Accident," Proceedings of the Fourth International Symposium on Packaging and Transportation of Radioactive Materials, Miami Beach, FLA, September 22-27, 1974, 830-847, CONF-740901 (1974).

9. USNRC, "Potential Releases of Cesium from Irradiated Fuel in a Transportation Accident, Supplement II to WASH-1238," NUREG-0069 (July, 1976).

10. C. V. Hodge and A. A. Jarrett, "Transportation Accident Risks in the Nuclear Power Industry 1975-2000," EPA-520/3-75-023 (Apri1, 1975).

11. USNRC, "Reactor Safety Study--An Assessment of Accident Risks in U.S. Commercial Power Plants," WASH-1400 (October, 1975).

12. USNRC, "Final Environmental Statement on the Transportation of Radioactive Material by Air and Other Modes," NUREG-0170 (December, 1977).

13. R. K. Clarke, et al., "Severities of Transportation Accidents," SLA-74-0001 (July, 1976). 
14. A. W. Dennis, "Severities of Transportation Accidents Involving Large Packages," SAND77-0001 (May 1978).

15. R. E. Luna, Sandia Laboratories, Personal Communication (October, 1978).

16. A. R. Du Charme, et al., "Transport of Radionuclides in Urban Environs: Working Draft Assessment," SAND77-1927 (May, 1978).

17. S. W. Heaberlin, et al., "Consequences of Postulated Losses of LWR Spent Fuel and Plutonium Shipping Packages at Sea," PNL-2093 (October, 1977). 


\section{0 CASK RESPONSE TO ACCIDENT ENVIRONMENTS}

\subsection{INTRODUCTION}

The structural and thermal analysis methodology that has been applied to the design of spent fuel shipping casks has been guided by licensing precedent and work performed at a number of National Laboratories, to date, primarily Sandia and ORNL. It has been widely recognized by cask structural designers that certain phenomena, especially those involved with the dynamic response of casks under impact loadings, are not very well understood, and hence there have been analysis and test programs sponsored both by DOE and NRC to enhance the knowledge of these phenomena.

This section summarizes the structural and thermal analyses and tests performed by license applicants and various researchers that were found as a result of a literature search.

\subsection{SAFETY ANALYSIS REPORTS BY LICENSE APPLICANTS}

The Safety Analysis Reports ${ }^{1-6}$ for each of the currently licensed Type B casks were reviewed. Without exception, the designers performed and documented analyses that could be correlated directly back to requirements in 10CFR71, and little was reported beyond those requirements. The structural calculations were based on conventional strength-of-materials or elasticity theory methods, and can be traced to textbooks, handbooks, or applicable national standards such as the ASME Boiler and Pressure Vessel Code. Table 5.1 provides an abbreviated summary of the analyses.

The thermal analysis methods employed by each cask designer are essentially the same: finite element solutions of the heat conduction field equations subject to specific convective and radiative heat transfer boundary conditions. Each organization used a proven computer program of its choice. These programs are also shown in Table 5.1.

There were three test programs conducted by license applicants in support of their respective analyses that are worthy of note. The IF-300 SAR described a combined testing and anaiysis program to derive and support a correlation for impact energy absorption by plastic deformation of the cooling fins. The TN-8/9 SAR contained descriptions of scale model impact and fire tests that demonstrated the compliance of the designs to the then existing licensing criteria. The NLI-10/24 tests consisted of static crush tests of scale model impact limiters to confirm the limiter design, lead slumping tests to confirm impact analysis, and scale model puncture tests.

\section{3 NATIONAL LABORATORY TESTING AND ANALYSIS PROGRAMS}

The following paragraphs summarize the work done to date by various organizations involved with spent fuel shipping cask design, testing, and analysis. Test programs and pertinent results to date are displayed in Table 5. 2 . 
TABLE 5.1

SUMMARY OF CASK SAR STRUCTURAL AND THERMAL ANALYSES

\begin{tabular}{|c|c|c|c|}
\hline Cask & $\begin{array}{c}\text { Structural } \\
\text { Analysis Method }\end{array}$ & Thermal Analysis & $\begin{array}{l}\text { Tests and } \\
\text { Summary Results }\end{array}$ \\
\hline $\begin{array}{l}\text { NSF- } 4 \text { \& } \\
\text { NAC-1 }\end{array}$ & $\begin{array}{l}\text { Normal conditions: } \\
\text { classical elasticity, } \\
\text { plate and shell } \\
\text { theory. Hand calcu- } \\
\text { lations. } \\
\text { Accident conditions: } \\
\text { crush-energy deter- } \\
\text { mination of decelera- } \\
\text { tion. Hand calcula- } \\
\text { tions. }\end{array}$ & $\begin{array}{l}\text { TAP-N code. Finite } \\
\text { element method for } \\
\text { calculating conduc- } \\
\text { tive, convective, } \\
\text { and radiative heat } \\
\text { transfer. }\end{array}$ & None \\
\hline$N L I-1 / 2$ & $\begin{array}{l}\text { Normal conditions: } \\
\text { classical theory. } \\
\text { Hand calculations. } \\
\text { Accident conditions: } \\
\text { crush-energy and } \\
\text { plastic hinge deter- } \\
\text { mination of decelera- } \\
\text { tion. Hand calcula- } \\
\text { tions. }\end{array}$ & $\begin{array}{l}\text { TRUMP-FED and FETA } \\
\text { codes. Finite ele- } \\
\text { ment heat transfer } \\
\text { calculations. }\end{array}$ & None \\
\hline
\end{tabular}

IF-300 Normal conditions: classical theory. Hand calculations.

Accident conditions: plastic hinge energy absorption by fins. Hand calculations.
THTD code. Finite Tests to determine element heat trans- plastic hinge fer calculations. energy absorption from crushing of cask cooling fins. 
TABLE 5.1

(Continued)

\begin{tabular}{|c|c|c|c|}
\hline Cask & $\begin{array}{c}\text { Structural } \\
\text { Analysis Method }\end{array}$ & Thermal Analysis & $\begin{array}{c}\text { Tests and } \\
\text { Summary Results }\end{array}$ \\
\hline $\begin{array}{l}T N-8 \& \\
T N-9\end{array}$ & $\begin{array}{l}\text { Normal conditions: } \\
\text { classical theory. } \\
\text { Hand calculations. } \\
\text { Accident conditions: } \\
\text { crush-energy calcu- } \\
\text { lation of decelera- } \\
\text { tion. }\end{array}$ & $\begin{array}{l}\text { Closed form solu- } \\
\text { tion of Fourier } \\
\text { equation. Hand } \\
\text { calculations. }\end{array}$ & $\begin{array}{l}\text { Confirmatory } \\
\text { quarter- and half- } \\
\text { scale model drop } \\
\text { tests and fire } \\
\text { test. }\end{array}$ \\
\hline $\begin{array}{l}\text { NLI- } \\
10 / 24\end{array}$ & $\begin{array}{l}\text { Hand calculations } \\
\text { using classical } \\
\text { theory supplemented } \\
\text { by ANSYS finite ele- } \\
\text { ment calculations. } \\
\text { Included fatigue } \\
\text { evaluations of shell } \\
\text { and appurtenances. }\end{array}$ & $\begin{array}{l}\text { ANSYS finite ele- } \\
\text { ment heat transfer } \\
\text { calculations. }\end{array}$ & $\begin{array}{l}\text { 1/8-scale impact } \\
\text { limiter test to } \\
\text { confirm sizing. } \\
\text { Test of impact } \\
\text { slumping of lead } \\
\text { run by Battelle. } \\
\text { 1/4-scale puncture } \\
\text { test to confirm } \\
\text { design against } \\
\text { 10CFR71 criteria. }\end{array}$ \\
\hline
\end{tabular}


TABLE 5.2

SUMMARY OF CASK RESPONSE TESTS

\begin{tabular}{|c|c|c|c|}
\hline Test and Site & Test Article & $\begin{array}{l}\text { Pertinent } \\
\text { Parameters }\end{array}$ & Results/Comments \\
\hline $\begin{array}{l}\text { ORNL Obsolete } \\
\text { Cask Program }\end{array}$ & $\begin{array}{l}\text { The Savannah River } \\
\text { HWCTR Cask used is } \\
4.3 \mathrm{~m} \text { long, } 0.78 \mathrm{~m} \\
\text { in diameter, and } \\
\text { weighs } 21,000 \mathrm{~kg} \text {. } \\
\text { The outer shell } \\
\text { is } 1.25-\mathrm{cm} 1 \mathrm{mi-} \\
\text { nated steel, with } \\
24-\mathrm{cm} \text { lead shiel- } \\
\text { ding and } 9.4-\mathrm{mm} \\
\text { inner vesse } 1 \text {. } \\
\text { Bolted closure. }\end{array}$ & $\begin{array}{l}\text { Two 9-m drops on- } \\
\text { to a concrete pad } \\
\text { at } 11 \text { and } 30 \text { de- } \\
\text { grees from verti- } \\
\text { cal on different } \\
\text { ends of the cask. }\end{array}$ & $\begin{array}{l}\text { Superficial } \\
\text { damage, although } \\
\text { cracks appeared } \\
\text { in the corner } \\
\text { welds. oblique } \\
\text { drop appeared to } \\
\text { be less severe. } \\
\text { Cask was air- } \\
\text { tignt after both } \\
\text { tests. }\end{array}$ \\
\hline $\begin{array}{l}\text { Battelle Scale } \\
\text { Mode? Tests }\end{array}$ & $\begin{array}{l}\text { This test uses } \\
1 / 8-\text {, } 1 / 4-\text {, and } \\
1 / 2-\text { scale models } \\
\text { of a typical full- } \\
\text { scale spent fuel } \\
\text { cask. }\end{array}$ & $\begin{array}{l}\text { Each model was } \\
\text { dropped from } \\
9 \mathrm{~m} \text { at tempera- } \\
\text { tures of }-40 \text { and } \\
175^{\circ} \mathrm{C} \text {. }\end{array}$ & $\begin{array}{l}\text { It was found } \\
\text { that strain } \\
\text { rates are not } \\
\text { significant in } \\
\text { the leadoslump- } \\
\text { ing process. }\end{array}$ \\
\hline $\begin{array}{l}\text { SANDIA Scale } \\
\text { Model and } \\
\text { Full-Scale } \\
\text { Crash Tests }\end{array}$ & $\begin{array}{l}\text { This test utilized } \\
\text { scale models and } \\
\text { three out-of-ser- } \\
\text { vice full-scale } \\
\text { casks. } \\
\text { An approximate } \\
1 / 8 \text {-scale model } \\
\text { was used to } \\
\text { determine para- } \\
\text { maters for the } \\
\text { full-scale tests } \\
\text { and calibrate the } \\
\text { analytical models. } \\
\text { To date, five } \\
\text { fuil-scale tests } \\
\text { have been run. }\end{array}$ & $\begin{array}{l}\text { 100-km/h truck } \\
\text { impact with } 20.5- \\
\text { ton cask; } 130-\mathrm{km} / \mathrm{h} \\
\text { truck impact with } \\
20.5-\text { ton cask; } \\
130-\mathrm{km} / \mathrm{h} \text { grade } \\
\text { crossing test } \\
\text { with } 22.7-\text { ton } \\
\text { cask; } 130-\mathrm{km} / \mathrm{h} \\
\text { rail car impact } \\
\text { test with } 61.8- \\
\text { ton cask; rail } \\
\text { car pool fire } \\
\text { test with } 61.8- \\
\text { ton cask. }\end{array}$ & $\begin{array}{l}\text { The casks have } \\
\text { been shown to be } \\
\text { durable, with no } \\
\text { significant } \\
\text { failure during } \\
\text { the tests. }\end{array}$ \\
\hline
\end{tabular}


Oak Ridge National. Laboratory: ORNL has been. involved for a number of years with programs regarding spent fuel shipping casks. The Cask Designer's Guide 8 was published in 1970 and contains a comprehensive set of guidelines for designing and analyzing casks. A number of tests were run in support of the preparation of this guide which resulted in various correlations with information as to how they may be used by the cask designer. More recently, the Obsolete Cask Program ${ }^{7}$ was initiated, which involved dropping an out-of-service cask (the Savannah River HWCTR cask) at various orientations from a height of 30 feet. The cask survived the drops with only minor damage (some cracking in corner areas), and the data was used for benchmarking structural analyses.

Los Alamos Scientific Laboratory(LASL): Los Alamos has also been involved for some years with the development of analytical techniques and code development for analysis of impact damage to casks. The IMPACI, CEIR, NONSAP, and IMPAC2 ${ }^{9} 13$ programs were developed over the last several years in coordination with ORNL personnel and have been used to predict test programs and analyze experiments run under the Obsolete Cask Program at ORNL and the Battelle Columbus Scale Model Tests. ${ }^{23}$

Specifically, IMPACl is a spring-mass element computer program that solves transient dynamic problems that are modeled as lumped mass systems. There is a provision for using nonlinear springs, and correlations with experiments have shown reasonable predictions for decelerations and shielding deformation. CEIR calculates shielding deformation upon impact by matching impact kinetic energy with the material flow energy. It, too, has shown reasonable capability for predicting shielding material deformation, but because it contains no provision for inertia, it cannot predict the acceleration-time histories. 12 NONSAP is a finite element program, and as such is capable of good accuracy when applied with the proper mesh sizes and when the materiais properties used are accurate. IMPAC2 is an improved version of IMPAC1. ${ }^{13}$

Sandia Laboratories: Sandia has recently been quite activeiy invoived with both code developinent and full-scale tests of large spent fuel shipping casks. The SHOCK and HONDO codes were developed and used to pre-predict the dynamic response of both scale models and the full scale cask crash tests. SHOCK is a lumped-parameter computer program that solves for the dynamic structural response of a lumped mass-spring model. HONDO is a finite element program that can calculate the two-dimensional deformation of solids under impact conditions. Both have been shown to provide reasonably good results when correlated with the experiments. $15,17,18,20,21$

A program of full-scale crash testing and analysis has been recently completed at Sandia.19. This program involved the testing of three out-ofservice casks under a series of severe impact and fire conditions, including truck/cask crashes into an essentially rigid barrier at $130 \mathrm{~km} / \mathrm{h}$ and a high-speed impact of a locomotive into a truck/cask rig at a grade crossing. Test results are being used to benchmark and aid in development of the computer programs mentioned above, as well as to gain specific knowledge as to the behavior of casks under such severe conditions. Five tests were run, and these are summarized in Table 5.2. No significant 
failures have been reported, but one cask did leak about $100 \mathrm{cc}$ 's of coolant following the grade-crossing impact.

An earlier series of tests was run on containers for air transport of Plutonium, 22,23 and these are reported because they were used for early benchmarking of the analytical tools under development noted above.

Recently, Sandia published 27 a survey of available shipping cask materials data that is a valuable contribution to the literature. Data for steel, aluminum, lead and depleted uranium is provided, and gaps in materials data availability are pointed out. There is a confirmed lack of high strain-rate structural materials data.

Battelle Columbus Laboratories: Battelle has run drop tests on several scale models (1/8,1/4, and 1/2) of typical shipping casks at both high (175C) and low $(-40 \mathrm{C})$ temperatures. ${ }^{24}$ These tests were also used for comparative purposes with the Sandia and LASL analytical tools under development, and yielded information regarding the behavior of lead shielding material under impact conditions, which indicated that strain rates are not a significant factor.

Battelle also conducted a survey 25 into the dynamic materials properties of commonly used shipping cask materials; lead, depleted uranium, stainless steel, carbon steel, aluminum, and copper. The results of this study indicated that there is a significant lack of such data. This presents a hindrance to the utilization of more sophisticated analytical techniques than have heretofore been employed.

Pacific Northwest Laboratory: PNL has recently published a report ${ }^{26}$ that contains a set of scoping calculations for establishing certain cask failure thresholds, including end drops, side drops, and various fuel loading mechanisms. This work proved valuable as a comparison for the gauging studies performed for this study.

Other Sources: In the penetration mechanics area, Wilkins of Livermore and Backmon and Goldsmith of the U.S. Naval Weapons Center have recently published survey articles 28,29 that discuss the state of the art. Extensive bibliographies are provided. 


\section{REFERENCES}

1. "Safety Analysis Report for NFS-4 Spent Fuel Shipping Cask,". Docket No. 71-6698, Nuclear Fuel Services, Inc., Rockville, MD. (September, 1972).

2. "Safety Analysis Report for NLI 1/1 Truck Cask," Docket No. 71-9010, National Lead Industries, Inc., Wilmington, DE. (November, 1972).

3. "Safety Analysis Report for TN-8 Shipping Cask," Docket No. 71-9015, Transnuclear, Inc., White Plains, NY (October, 1976).

4. "Safety Analysis Report for TN-9 Shipping Cask," Docket No. 70-9016, Transnuclear, Inc., White Plains, NY (October, 1976).

5. "Design and Analysis Report IF-300 Shipping Cask," Docket No. 70-1220, General Electric Company, San Jose, CA (January, 1971).

6. "Safety Analysis Report for the NLI-10/24 Shipping Cask," Docket No. 70-9023, prepared by NLI Industries, Wilmington, DE (February, 1976).

7. L. B. Shappert, et a1., "The Ful1-Scale Cask Program at ORNL," Proceedings of the IAEA Seminar on Transport Packaging for Radioactive Materials; Vienna, Aưstria (August, 1976).

8. L. B. Shappert, et al., "Cask Designer's Guide," ORNL-NSIC-68 (February, 1970).

9. Bob J. Donham, "Prediction of Maximum Damage to Shielded Shipping Containers," LA-4649 (January, 1971).

10. J. Counts and J. B. Payne, "Comparison of Predicted and Measured Drop Test Responses of Type B Shipping Containers," LA-6642-MS (January, 1977).

11. R. J. Bartholomew, "Cargo Response to Railcar Impact and Tiedown Load Analys is," LA-7469-MS, Informal Report (September, 1978).

12. J. Counts and J: B. Payne, "Evaluation of Analysis Methods for Type B Shipping Container Impact Prob7ems, LA-6640-MS, Informal Report (January, 1977).

13. J. Counts and J. B. Payne, "IMPAC2-A Lumped-Mass Nonlinear Spring Computer Program to Analyze Type B Shipping Container Impact Problems," LA-6643-MS, Informal Report (January, 1977):

14. C. F. Magnuson, "Shock and Vibration Environments for a Large Shipping Container During Trúck Transport, NUREG/CR-0128 (May, 1978). 
15. R. M. Jefferson and H. R. Yoshimura, "Crash Testing of Nuclear Fuel Shipping Containers," SAND77-1462 (February, 1978).

16. A. W. Dennis, et al., "Severties of Transportation Accidents Involving Large Packages," SAND77-0001 (May, 1978).

17. M. Huerta and H. R. Yoshimura, "A Crash Test of a Nuclear Spent Fuel Cask and Truck Transport System," SAND77-0419 (January, 1978).

18. M. Huerta, "Analysis, Scale Modeling, and. Full Scale Tests of a Truck Spent-Nuclear-Fuel Shipping System in High Velocity Impacts Against a Rigid Barrier," SAND77-0270 (Apri1, 1978).

19. H. R. Yoshimura, "Crash Testing of Spent-Nuclear-Fuel Shipping Systems," SAND78-0451C (Apri1, 1978).

20. M. Huerta and H. R. Yoshimura, "A Crash Test of a Nuclear Spent Fuel Cask and Truck Transport System," SAND77-419 (January, 1978).

21. M. Huerta, A. W. Dennis, and H. R. Yoshimura, "Impact Analysis of Spent Nuclear Fuel Shipping Casks," SAND77-0466 (July, 1978).

22. L. L. Bonzon and J. T. Schamaun, "Container Damage Correlation with Impact Velocity and Target Hardness," Proceedings of the IAEA Seminar on Transport Packaging for Radioactive Materials, Vienna, Austria (1976).

23. L. L. Bonzon and M. McWhirter, "Special Tests of Plutonium Shipping Containers," Proceedings of the IAEA Seminar on Transport Packaging for Radioactive Materials, Vienna, Austria (1976).

24. R. A. Robinson, W. J. Zielenbach and A. A. Lawrence, "Strain-Rate Effects for some Common Structural Materials used in Radioactive Material Packaging and Transportation Systems," Battelle Columbus Laboratories, Proceedings of the IAEA Seminar on Transport Packaging for Radioactive Materials, Vienna, Austria (August, 1976).

25. R. A. Robinson, S. J. Basham and E. C. Lusk, "Use of Scale Models to Assess Structural Response of Nuclear Shipping Containers Under Acci-. dent Conditions," Battelle Columbus Laboratories, Proceedings of the IAEA Seminar on Transport Packaging for Radioactive Materials, Vienna, Austria (August, 1976).

26. H. K. Elder, et a1., "An Assessment of the Risk of Transporting Spent Nuclear Fue 1 by Truck," PNL-2588 (November, 1978).

27. H. J. Rack and G. A. Knorovsky, "An Assessment of Stress-Strain Data Suitable for Finite Element Elastic-Plastic Analysis of Shipping Containers," NUREG/CR-0481 (September, 1978). 
28. Mark L. Wilkins, "Mechanics of Penetration and Perforation," Int. J. Engng. Sci., 16 (1978).

29. M. E. Backman and Werner Goldsmith, "The Mechanics of Penetration of Projectiles into Targets," U. S. Naval Weapons Center, Int. J. Engng. Sci., 16, No. 1-A (1978) 


\subsection{FISSION PRODUCT BEHAVIOR CHARACTERIZATION}

\subsection{INTRODUCTION}

This section presents a survey and discussion of the present collection of technical information that may be used to characterize the dynamic behavior of fission product and actinide radionuclides in a postulated spent fuel transport accident (SFTA). The principal objective of such characterizations is the development of accurate radionuclide source terms for use in analyses of accident consequences. The section is divided into two major subsections which address the subject of radionuclide release in terms of the two physical barriers in the shipping cask system: (1) the spent fuel rods (fuel and cladding) and (2) the cask body (cavity and cask walls). The survey in each section concentrates on descriptions of available methods and data which contribute to definition of release magnitudes and the physical and chemical characteristics of released species.

\subsection{RELEASE OF RADIONUCLIDES FROM FAILED FUEL RODS}

Earlier parts of this report have indicated that spent fuel rod claddings may be breached by one or more types of applied stress in a transport accident. The breaches may be large or small, but the event itself is a necessary condition for the release of fission product or actinide species from the rods. Several factors and phenomena can be identified which are important to characterization of the radionuclide source that results from the release step. A categorized listing of such factors and phenomena is presented in Table 6.1. Four key factors are identified in the table for each of two release modes, and specific results are listed for the rapid release mode and the extended release mode.

The rapid release mode corresponds to the "prompt release" that is expected at the time of cladding failure for pressurized rods. Depressurization flow should always constitute a driving force for release when failure occurs, while the inertial ejection of solid debris from the rods would provide an additional driving force in cases where accident impact forces were sufficiently severe to cause gross cladding damage. The fuel and cladding debris ejected by the latter process is anticipated to be more massive than the fuel dust that would be expected to be carried out during the depressurization process. In each of these cases, however, the particle size distribution of the released material is an important factor in subsequent analysis of the consequences of the accident event.

The extended release mode applies to the period following the initial rapid release to that time when release from the failed rod(s) is complete. The principal driving forces here appear to be either elevated temperatures, which increase migration and volatilization rates of radionuclide species or aqueous leaching processes, which liberate some radionuclides from fuel rod solid phases. The two types of driving forces lead to very different source characteristics: a gasborne source. in the thermal case versus a liquid source in the leaching case. In either case, potential chemical 
TABLE 6.1

FACTORS AND PHENOMENA IMPORTANT TO

CHARACTERIZING FUEL ROD RELEASES

\begin{tabular}{|c|c|c|}
\hline & $\begin{array}{l}\text { Rapid Release } \\
\text { Mode }\end{array}$ & $\begin{array}{c}\text { Extended Release } \\
\text { Mode }\end{array}$ \\
\hline \multirow[t]{2}{*}{ Driving Forces } & Depressurization & Thermal activation \\
\hline & Impact inertia & Aqueous leaching \\
\hline \multirow[t]{2}{*}{ Available Inventory } & $\begin{array}{l}\text { Plenum and gap } \\
\text { activity }\end{array}$ & $\begin{array}{l}\text { Nuclides in/on gap } \\
\text { surfaces }\end{array}$ \\
\hline & $\begin{array}{l}\text { Nuclides in the } \\
\text { released particles }\end{array}$ & $\begin{array}{l}\text { Nuclides in the fuel } \\
\text { matrix }\end{array}$ \\
\hline \multirow[t]{3}{*}{ Release Forms } & Gases \& vapors & Gases \& vapors \\
\hline & Aerosols (dust) & Recondensed aerosols \\
\hline & $\begin{array}{l}\text { Fuel and cladding } \\
\text { debris }\end{array}$ & Aqueous solutions \\
\hline \multirow[t]{3}{*}{ Release Species } & Elements \& compounds & Elements \& compounds \\
\hline & $\begin{array}{l}\text { Particles of various } \\
\text { sizes }\end{array}$ & $\begin{array}{l}\text { Particles of various } \\
\text { sizes }\end{array}$ \\
\hline & & $\begin{array}{l}\text { Dissolved \& suspended } \\
\text { species }\end{array}$ \\
\hline
\end{tabular}
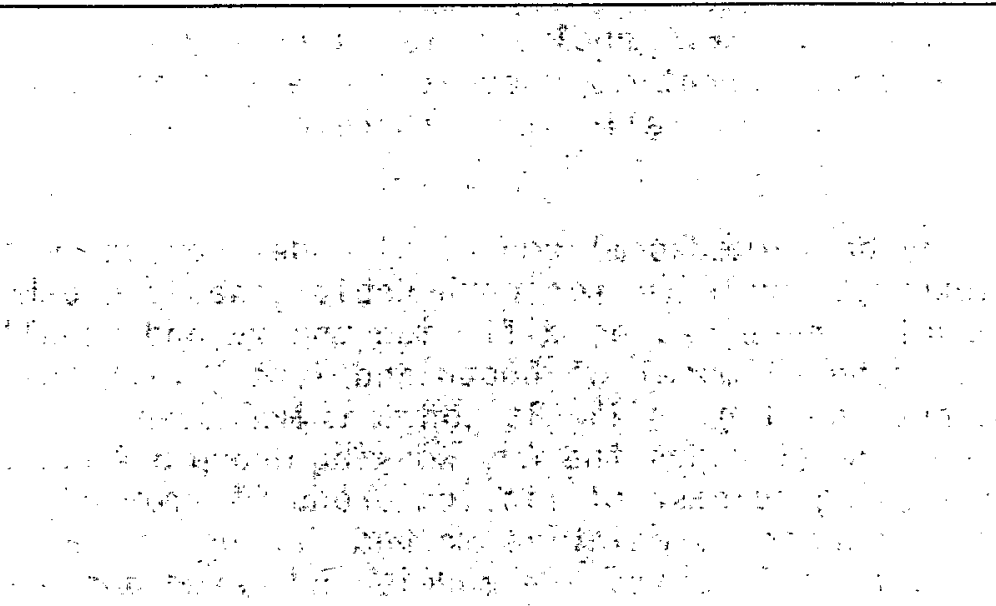
reactions with the bulk fluid (gas or liquid) will influence the particular species that are released from the failed rods.

A survey of the current data and methods which are available for characterizing fuel rod releases by each of the two principal modes is given below. The rapid release mode is considered first, followed by a review for the extended mode. Each of these discussions is organized along the lines of the topics given in Table 6.1.

\subsubsection{Rapid Release Mode Information Survey}

The topics of importance regarding the rapid release mode include the distribution of radionuclide inventory in the fuel rods, in particular the quantity and composition of the plenum/gap activity, the amount of this that escapes during depressurization, and the physical and chemical forms of the escaped species.

\subsubsection{Plenum/Gap Activity}

Plenum gap activity is of considerable interest in nuclear reactor technology because it is clearly associated with fuel performance. Much attention has been given to understanding and predicting the behavior of the noble gas fission products in operating reactor fuel, including their release to the gap and plenum regions of the rods. Since this release is an important parameter in fuel rod design, many experimental studies and calculational models have appeared over the last two or three decades which can or are being used to estimate noble gas release. The models range from simple empirical correlations, such as the Lewis model, 1 to sophisticated computer codes, such as BUBL-1 or GRASS, ${ }^{2}$ which contain detailed mechanistic models of several rate processes. A number of good reviews of the technical subject have appeared from time to time. Reviews by Lustman, ${ }^{3}$ Childs, 4 . Morrison, et al., 5 and Parker and Barton ${ }^{6}$ may be consulted, but a very useful synopsis of available models may be found in a recent USNRC report. ${ }^{7}$ The major shortcoming of most of the empirical and mechanistic models with respect to SFTA analysis is that they are specific to noble gas release and thus cannot be used for other volatile fission products such as iodine, cesium, or tellurium. Therefore, these models will not be described here.

A set of what may be termed semi-empirical models exists which can be used to predict plenum/gap release for both noble gases and other fission products. The models are based on diffusion theory and usually derived from the "equivalent sphere" model of Booth and Rymer 8 with the exception of a mode 1 that was developed by Yui 11 , Baston, and McFadden. ${ }^{9}$

During the past several years the ANS Working Group 5.4 has spent considerable effort examining release of fission products from $\mathrm{UO}_{2}$ for the purpose of developing a standard predictive method for use in accident analyses. In the process the various release models indicated above were critically reviewed, and one approach was selected to form the basis of the standard method. 10 The approach selected was a diffusion-type (Booth) model because 
most of the existing fission gas release information is generally compatible with such a model, and because release data for other fission products can be applied in a relatively straightforward manner. On this basis the Booth-type model should be considered the accepted approach for correlating data and predicting fission product release from $\mathrm{UO}_{2}$ fuel at elevated temperatures.

The governing equation of the Booth model for diffusion of a nuclide in a sphere is:

$$
\frac{\partial C}{\partial t}=\frac{1}{r^{2}} \frac{\partial}{\partial r}\left(r^{2} D \frac{\partial C}{\partial r}\right)+B-\lambda C
$$

where,

$$
\begin{aligned}
& \left.C=\text { the nuclide concentration (atoms } / \mathrm{cm}^{3}\right) \\
& t=\text { the time }(\mathrm{sec}) \\
& r=\text { radial coordinate of sphere }(\mathrm{cm}) \\
& D=\text { the nuclide diffusion coefficient }\left(\mathrm{cm}^{2} / \mathrm{sec}\right) \\
& \left.B=\text { the nuclide production rate (atoms } / \mathrm{cm}^{3}, \mathrm{sec}\right) \\
& \lambda=\text { the radioactive decay constant }\left(\mathrm{sec}^{-1}\right)
\end{aligned}
$$

The diffusion coefficient is a function of temperature and follows the familiar Arrhenius expression:

$$
D_{T}=D_{0} \exp (-Q / R T)
$$

where,

$$
\begin{aligned}
& D_{T}=\text { diffusion coefficient at } T\left(\mathrm{~cm}^{2} / \mathrm{sec}\right) \\
& D_{0}=1 \text { imiting diffusion coefficient }\left(\mathrm{cm}^{2} / \mathrm{sec}\right) \\
& Q=\text { activation energy for diffusion (cal } / \mathrm{g}-\mathrm{atom}) \\
& T=\text { absolute temperature }\left({ }^{0} \mathrm{~K}\right)
\end{aligned}
$$

Numerous solutions have been published for Equation $(6-1)$ for different conditions; i.e., for both stable $(\lambda=0)$ and radioactive $(\lambda>0)$ species with $B$ and $D$ constant or varying with time: $3,10,11$. These solutions contain the quantity $D / a^{2}$, in which "a" is the equivalent sphere radius. Since this radius depends on the structure of the $\mathrm{UO}_{2}$ fuel, interpretations of release data are usually made in terms of the parameter $D / a^{2}$. The parameter is labeled $D^{\prime}\left(i . e ., D^{\prime}=D / a^{2}\right.$ ) and carries the units of $\mathrm{sec}^{-1}$. The temperature dependence of ' $D^{\prime}$ follows an Arrhenius expression in the same 
manner as $D$ given in Equation (6-2). Recent evidence has indicated that $D^{\prime}$ is also a function of fuel burnup. 10,12 The ANS Working Group 5.4 has taken both these effects into consideration in obtaining an empirical fit of the diffusion model to selected sets of reactor high-temperature noble gas release data to obtain reference noble gas diffusion parameters. The Group is in the process of extending the method to iodine, cesium, and tellurium fission products by obtaining ratios of diffusion parameters from the limited studies in the literature where the release of these fission products and of noble gases were measured simultaneously.

When the ANS 5.4 model is complete it should represent the best generalized method for plenum/gap activity prediction. In practice the empirical diffusion model must be used in conjunction with a fuel thermal performance mode ${ }^{13}$ which will predict the radial and axial temperature profiles in operating fuel rods. The high temperature portions of the fuel will exhibit much greater diffusion release than the low temperature portions. Temperature profiles depend on the power output along a rod, the conductivity of materials in the system (particularly the $\mathrm{UO}_{2}$ fuel and the gas gap), and heat transfer at the cladding surface. Each of these vary to some extent during the operating history. The power output is the most important, and the release of stable or long-lived radioactive species is sensitive to the entire power history of the rods. ${ }^{14}$ On the other hand, the plenum/gap activity of short-lived radioactive species depends only on conditions near the end of core life for the rods. At low power outputs, where a large fraction of the fuel remains at relatively low temperatures (less than about $1000^{\circ} \mathrm{C}$ ), other release mechanisms such as recoil and knockout, which are temperature independent, can dominate. Models exist for these processes, ${ }^{6,7}$ and the ANS Working Group 5.4 is also developing a method for use at these conditions. The need for such a model in SFTA applications is marginal because it is common to assume that a shipping cask contains the higher performance fuel assèmblies.

Models which are similar to the forthcoming ANS 5.4 model are available. These include the REGAP15 method developed at BCL and the D-Prime Empirical method developed at ORNL. ${ }^{16}$ These methods utilize diffusion parameters obtained at those sites from analyses of the open literature. The results of using each method for plenum/gap activity calculations appear in Appendices $A$ and $C$ of Appendix VII in WASH-1400.17 Values range from fractions of a percent to about $20 \%$ for a core-averaged rod at discharge, depending on the fission product and the nuclide half-life. No experimental data are available from actual power reactor assemblies for comparison with these estimates. Some noble gas measurements may be available from postirradiation rod puncture tests, but the power histories are usually too poorly known for the data to be of value. A recent measurement on some average to low power rods from the H.B. Robinson reactor showed noble gas $\mathrm{plenum} / \mathrm{gap}$ inventories corresponding to release of about $0.3 \%$ from the fuel during operation. ${ }^{18}$ This amount is much smaller than the $30 \%$ usually assumed for fuel handling accident and SFTA analyses 19,20 given in Table 4.4.

The conditions of an SFTA may be such that the plenum/gap activity may consist of more material than was released from the fuel during reactor oper- 
ation. For example, the scenario leading to cladding perforation might involve an extended heating period during which additional fission products could conceivably be released from the fuel or cladding. Since the temperatures would be low $\left(<1200^{\circ} \mathrm{F}\right)$, this particular release would probably be trivial. Recent $0 R{ }^{2}$ tests ${ }^{18}$ e suggest release of noble gases imbedded in cladding during irradiation could reach $1 \%$ of the rod inventory if temperatures exceed $500^{\circ} \mathrm{C}\left(932^{\circ} \mathrm{F}\right)$. Diffusion models exist ${ }^{21}, 22$ which could be applied to estimate release from the fuel, but diffusion parameters would have to be obtained by reverse extrapolation of data obtained at higher temperatures.

The above discussions have emphasized the behavior of volatile or semivolatile fission products. The plenum/gap region could also contain particulate material originating from mechanical damage to the fuel pellets. Fuel restructuring and thermal cycling processes promote cracking and other mechanical effects which would be expected to result in the generation of some level of particulate material. The particulates should contain the whole range of fission product and actinide activities. No work has been located which defines the level of fuel dust (particulates) that would be present in discharged fuel rods, but recent reports have provided some indication about how much dust might escape during rod depressurizations. This is discussed below.

\subsubsection{Escape of Plenum/Gap Activity}

The previous discussion was concerned with specifying the quantity of radioactivity that can be present in the plenum/gap region in a mobile form. The fraction of this inventory which actually is mobile enough to escape with the depressurizing flow depends on a number of factors. These include chemical reactions of the fission products with each other, the Zircaloy cladding, the $\mathrm{UO}_{2}$ fuel, and perhaps impurity gases in the rods, which produce compounds or a mixture of compounds having variable volatilities. The chemical and thermal stability of the reaction products can result in their non-uniform distribution along the lengths of the rods. The precise character of the thermal transient that precedes cladding perforation will determine the vapor fraction of these compounds or their decomposition products. "In addition, the location and size of the cladding rupture can affect the escape fraction.

In the Reactor Safety Study (RSS) some rough escape fraction estimates were used to specify gap releases for reactor LOCA conditions. ${ }^{23}$ These fractions are of doubtful applicability for SFTA analyses because conditions may be quite different. The heatup transient could be considerably longer (more time for reactions to occur), or the claddings could fail under the initial impact forces (no time for reactions). Even if heatup should cause cladding perforation, the peak temperatures may be lower in SFTA events. This condition was a significant element in deducing a potential cesium source term for an SFTA in report NUREG-0069, 24 where the cesium release corresponded to an escape fraction that was considerably lower than the value selected in the RSS. 
Due to their chemical inertness, it would be proper to assume that all noble gas plenum/gap activity would escape within a few seconds after cladding failure, regardless of the nature of the thermal transient. The chemical reactivity of the other volatiles, accompanied by the probable inhibition of fuel dust entrainment in the depressurization flow, suggest less than total. escape of the plenum/gap inventories of these forms. However, quantitative values must come from experimental measurements. Almost no such experimental data are known to exist. Some recent work has been done at ORNL on the subject, but the only high-burnup rod rupture tests were confined to one rupture temperature $\left(900^{\circ} \mathrm{C}=1652^{\circ} \mathrm{F}\right)$, and three of the four tests included post-rupture heating release contributions. ${ }^{25} \mathrm{c}, 25 \mathrm{~d}$ The single test which could be classified a measure of only the "prompt" release suggests cesium and iodine escape fractions of less than unity, but the total plenum/gap inventories of these fission products were not measured. The four tests also gave useful measurements of the amount of fuel dust that escaped (probably during depressurization) but again the fraction these represented of the total dust content in the $\mathrm{p}$ lenum/gap region was not known.

In a postulated extreme SFTA, where extensive structural damage to fuel rods could occur, the quantity of fuel and fission products that would be ejected from the rods is poorly known, if at all. No experimental data pertaining to this particular phenomenon was identified in the present study.

\subsubsection{Physical and Chemical Forms of Escaped Species}

The forms of the species which escape fuel rods in an SFTA likeiy range from gases and vapors to liquid or solid aerosols, consisting of chemical elements in the simplest case to a variable mixture of chemical compounds in complex cases. As indicated earlier, the noble gases shouid exist in the $\mathrm{plenum} / \mathrm{gap}$ region as the elemental mono-atomic gases and should escape with no change in form. Fission product iodine may exist as a variety of species. Thermodynamic analyses often indicate cesium iodide (CsI) would be the most stable species in operating fuel rods. 23

Experimental work has shown that iodine can react with Zircaioy cladding at temperatures of several hundred degrees to form a series of zirconium iodides of varying volatility and thermal stability. ${ }^{26}$ Iodine might also escape the fuel rod as the element $\left(I_{2}\right)$, as a hydrolysis product (HOI), as an organic jodide $\left(\mathrm{CH}_{3}\right)$, or perhaps as hydrogen iodide (HI). ${ }^{23}, 27$ Iodine contained in fuel dust would exhibit particulate behavior. The composition of the plenum/gap iodine forms and species at the time of cladding failure depends on the thermal and chemical history of the fue $i$ rods, including the transient that occurs in the SFTA. No systematic study of the composition of the prompt release has been made. The recent ORNL work on fission product release from LWR fuel provides some characterization of the combined prompt and delayed iodine release, but not for the prompt release separately. These data will be discussed more fuliy in the section on the extended release mode. 
Cesium and tellurium fission products may also exist as a variety of species. Some portion of these may be present as the metallic elements, but a series of reaction products appears more likely. The known possibilities for cesium include CsI, cesium oxides, ${ }^{23}$ and $\mathrm{CsOH},{ }^{28}$ plus cesium uranates, molybdates, or zirconates. ${ }^{29}$ The latter group represent reactions of cesium with $\mathrm{UO}_{2}$ and refractory fission products in hyperstoichiometric fuel. Tellurium compounds are expected to be tellurium oxides and reaction products with the Zircaloy cladding (tellurides). 23 The comments made above about the importance of the thermal history in determining iodine species applies to cesium and tellurium species as well. Again, the recent ORNL studies do not differentiate between species released in the prompt mode and those released in the extended time mode.

The physical form of the fuel dust that can escape during rod depressurization is of course a particulate aerosol. The size distribution of the material released in the ORNL tests ${ }^{25}, 25$ is not well known. Preliminary estimates indicate particle sizes of 200 microns or less with one to two percent by mass of the particles being less than about 10 microns. ${ }^{30}$ Experimental measurements are probably essential in defining this parameter, but little or no data appear to exist. In cases where severe impact damages the fuel rods so that bulk pieces of fuel would be ejected, the size of the pieces could range from fuel pellet dimensions down to a few microns. No direct measurements of debris sizes for the conditions outlined above were located during this study. Pellet cracking during irradiation might eliminate the presence of full-sized pellets, and if strong crushing forces occur in the SFTA, extensive intergranular fracture might produce grain-sized debris. Grain sizes vary across pellet radii from a few microns near the surface to perhaps hundreds of microns in the interiors $^{31}$ of pellets that operate at high-power ratings. Some recent information gathered during the shearing of LWR spent fuel rods ${ }^{55}$ suggests that most of the debris would be reiatively large particles. However, a small percentage of the debris mass could have been in the form of fine particulates.

\subsubsection{Extended Release Mode Information Survey}

This release mode begins when rod depressurization is over and lasts until escape of activity from the fuel rod ends. Important factors include the distribution and state of the radionuclide inventory that remains after depressurization, the amount of this that escapes during heating or leaching, and the physical and chemical form of the escaped species.

\subsubsection{Inventory and Escape Fractions}

The possible conditions and factors which determine these quantities are varied and complex. Since this is a general survey of the topic, an effort will be made to address a ful 1 range of conditions even though some may be very unlikely for an SFTA. At the end of fuel rod depressurization, interior surfaces of the rod probably contain some residual plenumi gap activity as condensed deposits or reaction products which may be un- 
evenly distributed along the rod. The cladding also contains imbedded radionuclides, and the fuel matrix contains the remaining inventory in the rod. At this point the rod interior is also open to whatever fluid exists outside the rod. Possibilities are helium, steam, air, water, or combinations of these. The size of the failure in the rod cladding influences the extent of contact with the external fluid. Rod temperatures may be low or elevated, and in some accidents the temperatures would be increasing.

Increasing temperatures combined with the gaseous atmospheres outside the failed rod constitute a set of conditions for which certain information is available regarding radionuclide release. Fission product diffusion models exist that might be used to calculate release from the fuel pellets at elevated temperatures. 21,22 However, available diffusion coefficients apply to inert atmospheres at the fuel surface. The values themselves are widely scattered, and values have not been determined for all fission products. Nevertheless, diffusion coefficient expressions have been tabulated for the volatile and semi-volatile fission products for temperatures ranging from about $500^{\circ} \mathrm{C}$ to near the melting temperature of $\mathrm{UO}_{2} \cdot{ }^{5}$

In an air atmosphere $\mathrm{UO}_{2}$ undergoes oxidation to $\mathrm{U}_{3} \mathrm{O}_{8}$ from room temperature to about $1550^{\circ} \mathrm{C} .{ }^{32}$ The kinetics are slow until the temperature reaches a few hundred degrees, but the oxidation process causes accelerated release of some fission products, notably ruthenium. ${ }^{23}$ In recent ORNL studies $18 \mathrm{C}, 25^{\mathrm{b}}$ of fission product release from defected simultant rods and actual high-burnup fuel rods in air at $500^{\circ} \mathrm{C}$ and $700^{\circ} \mathrm{C} ; \mathrm{UO}_{2}$ oxidation was observed along with increased release of ruthenium, iodine, and cesium, compared with observations made when steam atmospheres were used. The releases from the high-burnup rods were less than one percent of the total inventory, and the $\mathrm{UO}_{2}$ oxidation process tended to $\mathrm{plug}$ the defect hole in the cladding. These studies provide very useful qualitative data regarding the release potential of the measured fission products, but too few experiments were conducted to develop a quantitative model. The actual amount of fuel oxidation is probably the critical factor, and this is a complex issue involving the aecessibility of air to the fuel along with the temperature-time history in the reaction zone.

Steam atmospheres are much more neutral toward $\mathrm{UO}_{2}$, but Zircaloy undergoes an oxidation reaction with water vapor which can become appreciable as temperatures approach $1000^{\circ} \mathrm{C} .{ }^{23}$ (Air also oxidizes Zircaloy at elevated temperatures.) Most of the recent ORNL studies involved fission product release measurements from defected rods in steam atmospheres. The results were applied to develop empirical expressions for the release of the iodine and cesium inventory that would remain in fuel rods after depressurization. ${ }^{33}$ The $O R N L$ investigators refer to this release as the diffusional component which is equivalent to the extended release mode being discussed here. The ORNL expressions are applicable in the temperature range 500 to $1200^{\circ} \mathrm{C}$, for the cladding perforation dimensions experienced in the tests, and for an external steam atmosphere. This effectively means the expressions are quite useful for reactor LOCA analyses, but of limited applicability for SFTA analyses unless the SFTA conditions correspond to the ORNL experimental conditions. 
Although it is very unlikely that fuel rod temperatures would reach cladding and/or fuel melting points, some information is summarized in the RSS $^{23}$ which could be used to estimate radionuclide releases during rod meltdown. The RSS approach is based on the limited experimental data that is available, ${ }^{32}$ and it probably overestimates the release from a large array of rods but not necessarily from a single rod. Application of the approach should provide no more than a bounding estimate of releases for melting conditions.

Exposure of fuel rod interiors to water may occur in an SFTA. The presence of water would suggest rather modest temperatures. Radionuclide deposits on accessible interior surfaces should react with and/or dissolve in the water according to their chemical properties and aqueous solubilities. Iodine forms would probably dissolve, while cesium and tellurium forms might dissolve with reaction. Solubility data can be obtained from standard compilations such as that of Linke. ${ }^{34}$ Fission products within the solid fuel matrix could be leached to various degrees depending on the exposed area, the water temperature, and the particular fission product. The only known experimental work on aqueous leaching of high-burnup spent fuel is the recent work of Katayama. 35,36 He has measured leach fractions for cesium, strontium, plutonium, and curium radionuclides for times up to about 600 days with several types of water (deionized, natural groundwater, and sea brine) at room temperature $\left(25^{\circ} \mathrm{C}\right)$. While the various leach curves were generally similar, quantitative differences demonstrated that no single mechanism would describe the leach process of all species. Thus, extrapolation of the data to other conditions would be unwise. For example, higher temperatures might cause significant increases in leach rates, as apparently occurs when industrial glasses are exposed to distilled water. ${ }^{37}$ The available leach data for spent fuel are quite useful, but their application in SFTA analyses should be done with an appreciation for the uncertainties involved.

\subsubsection{Physical and Chemical Forms}

The wide range of conditions outlined above for radionuclide release during the extended mode raise many possibilities regarding the physical states and chemical forms of the released materials. Only the noble gases are an exception to this observation:

The ORNL work on fission product release at elevated temperatures from defective or ruptured fuel rods obtained some information on released forms. Two series of experiments, one using implanted and heat-treated simulants ${ }^{18}$ and the other using sections of actual fuel rods, 25 were conducted at temperatures of $500^{\circ} \mathrm{C}$ to $1200^{\circ} \mathrm{C}$ in flowing steàm or air atmospheres. Attempts were made to classify evolved cesium, iodine, and ruthenium from deposition patterns in a thermal gradient tube, on downstream filters, or on other parts of the experimental apparatus. Quantitative deposition distribution data were obtained, but species identification was more qualitative The results obtained in the collection of steam atmosphere tests can be summarized as follows. Rêleased cesium appeared to exist mostly as $\mathrm{CsOH}$ in steam with some $\mathrm{CsI}$, but the proportions 
of each could not be determined. Some evidence for another less volatile species was obtained, but it was not identified. Cesium species characterization was also inhibited by reactions that occurred with the quartz furnace tube. Released iodine appeared to exist mostly as CsI in steam with some $I_{2}$ (roughly $1 \%$ to $10 \%$ ). Ruthenium release was too low in the steam tests to obtain species characterization data.

In the air atmosphere tests at $500^{\circ} \mathrm{C}$ and $700^{\circ} \mathrm{C}$, the investigators did not interpret the released cesium characterization data, although metallic cesium, cesium oxides, cesium iodide, and perhaps a cesium-fuel reaction product seem to be possibilities. It was concluded that most (maybe all) of the released iodine occurred as $I_{2}$ from the implant test specimens. Iodine release information apparently was not obtained for the high-burnup specimens. Ruthenium released in the air atmosphere tests was observed to be quite volatile, which suggested the volatile oxide, RuO 4 . In summary, the ORNL test series provides some useful information on released species and forms, but a complete characterization was not obtained.

In the unlikely event that fuel rod temperatures increase to the melting range in an SFTA, the task of characterizing forms of released radionuclides becomes formidable. A few thermodynamic analyses exist $23,38,39$ for the fuel/fission product/atmosphere system at these temperatures, which may be used to infer the composition of released (vaporized) forms, but the analyses are mostly confined to elemental or oxide species. At such temperatures the structural components of the rods (fuel and cladding) undergo vaporization loss, resulting in the appearance of rather dense aerosol clouds above the vaporizing surfaces. ${ }^{23}$ The particle size distribution of these recondensed aerosols is poorly known, but most of the particulates are probably sub-micron in size. ${ }^{5}$ The less volatile fission products would be expected to associate with this aerosol and thus exhibit aerosol properties in the space above the melted/vaporizing material. The thermodynamic studies would have to be used to identify possible vapor species of the more volatile fission products which might not be associated with the relatively hot recondensed aerosol material. A description of the form of released species for these conditons would therefore be very tentative.

The aqueous leaching of radionuclides from exposed fuel (SFTA resulting in failed rods immersed in water), should yield dilute aqueous solutions or perhaps aqueous colloidal suspensions of the leached nuclides. Dissolved species could include cationic, anionic, or neutral forms, while suspended material would usually consist of hydrated oxides or hydrates of some other slightly dissociated compound. The specific species would depend on the fission product; the temperature; and the $\mathrm{pH}$, redox potential, and ionic strength of the water leachant. The leaching studies characteristically involve such dilute solutions of the leached radionuclides that identification of aqueous species is not even attempted. If identification studies were made, the results would tend to apply only to the specific conditions used in the study because trace contaminants in the water (perhaps leached from the apparatus) would probably influence the solution properties. Complicating conditions during leaching of fuel in a spent fuel rod would be similar. On this basis a much simpler level of aqueous 
species classification would appear appropriate for SFTA analyses. Standard chemical texts, handbooks, and monographs $40,41,42$ provide information for estimating general species, i.e., dissolved versus suspended forms and ionic versus neutral species for many elements and compounds. These sources could be supplemented with some specific data such as the iodine hydrolysis equilibria paper by Eggleton 43 and the plutonium hydrolysis products discussion of Andleman and Rozze11.44 Such an approach might bracket possible forms or species so that parameter effects calculations could be used to determine the best assumption for accident analysis.

\subsection{TRANSPORT AND DEPOSITION OF RADIONUCLIDES WITHIN CASKS}

After radionuclides have been released from the failed fuel rods they will experience a combination of transport and deposition processes in the shipping cask cavity and the leakage path which may limit the amounts that escape to the natural environment. Possible reactions in the fluid phase or with cask internal surfaces can modify the forms which would escape. Several factors and phenomena which are important to describing the release source term are tabulated in Table 6.2. The table is divided into the two principal processes, transport and deposition, with important factors and phenomena listed for each. The two processes are very closely coupled in the cask release problem, since radionuclides released from failed fuel rods must travel through the fluid phase to reach a deposition surface. Also, fluid leakage from the failed cask would compete with surface deposition in reducing the concentration of radionuclide forms in the fluid phase. An exception to the importance of fluid phase transport could occur in extremely severe hypothetical accidents in which impact forces might be sufficient to cause inertial ejection of spent fuel rods through a massive breach in the cask wall. In the discussion below, transport and deposition data and models will be surveyed together rather than separately.

\subsubsection{Integral Experimental Tests}

Review of the existing literature disclosed no reports of integral studies of radionuclide transport and deposition in spent fuel shipping casks under accident or non-accident conditions. Integral tests refer to experimental work in which actual or simulated cask geometries were used, and fission product (real or simulant) leakage was characterized for a range of thermal, fluid flow, and leakage conditions. Therefore there is no cask deposition information, and it is understandable that current scenarios for SFTA analyses 20,24 assume essentially complete escape from the cask of radioactivity that is postulated to undergo release from failed fuel rods. The absence of such integral test data presents a severe handicap to deve1oping an acceptable analytical model because no real test of the model's validity, or range of validity, exists. Nevertheless, the following two subsections will survey methods and data that might be applied in an analytical development effort for the cask transport and deposition problem. 
TABLE 6.2

FACTORS AND PHENOMENA IMPORTANT TO

CHARACTERIZING FAILED CASK RELEASES

\begin{tabular}{|c|c|c|}
\hline & Transport & Deposition Process \\
\hline Basic phenomena & $\begin{array}{l}\text { Fluid flow } \\
\quad \text { (gas or liquid) } \\
\text { Inertial ejection } \\
\quad \text { (bulk solids) }\end{array}$ & $\begin{array}{l}\text { Physical sorption } \\
\text { Chemisorption } \\
\text { Vapor condensation } \\
\text { Particulate settling/ } \\
\text { plateout }\end{array}$ \\
\hline Forms and species & $\begin{array}{l}\text { Gases, aerosols, } \\
\text { bulky solids, } \\
\text { aqueous species }\end{array}$ & $\begin{array}{l}\text { Reaction products } \\
\text { Condensed phases }\end{array}$ \\
\hline Special factors & $\begin{array}{l}\text { Flow and leak path } \\
\text { geometry } \\
\text { Leak rates }\end{array}$ & $\begin{array}{l}\text { Deposition coefficients } \\
\text { or efficiencies } \\
\text { Surface materials } \\
\text { Surface areas }\end{array}$ \\
\hline
\end{tabular}




\subsubsection{Potential Analytical Models}

Several general approaches exist that might be applied to modeling radionuclide transport and deposition (T\&D) in leaking shipping casks. The T\&D model should be linked to the heat-transfer and fluid flow analysis that is done for the accident scenario so that temperatures of bulk materials, and the flow and leakage behavior of the bulk fluid would be available. The TRACK computer code, 45 recently developed at BCL for analys is of fission product T\&D in a shipping cask, might be used. The code utilizes a series of control volumes to model different regions of the cask internal geometry, but these have been defined only for the case of a cask standing on end. Thermal hydraulic information was estimated from analyses by Fields. ${ }^{46}$ Fission product deposition mechanisms modeled include particle deposition on dry walls from turbulent flaw, deposition of some vapor forms on surfaces, condensation/evaporation of condensable forms on surfaces, and capture of certain soluble vapor forms by a water phase.

A somewhat simpler model might be developed in which the central cavity of the shipping cask is treated as a we11-mixed chamber with leakage. Vapor deposition on surfaces could be assumed controlled by available deposition velocities, and condensation/evaporation of condensable forms would be treated as instantaneous processes. Particle deposition might be modeled in terms of gravitational settling. Deposition in the leakage path could be ignored or treated with models that have appeared in the 1iterature which describe deposition of vapor and particulate species in pipes or channels for either laminar or turbulent flow conditions. $47,48,49,50$ The system of coupled equations for treating the combination of cavity and leak path geometries would be similar to models described by Morrison, et a). 51

It should be mentioned again that the use of any of the above modeling approaches would provide only estimates of the radionuclide T\&D behavior in SFTA's. The predictions of these models cannot be verified by comparison with experimental results since the necessary experimental work has not been done.

\subsubsection{Experimental Data for Model Input}

The analytical models outlined above would need input values for a number of model parameters srincipal data needs for vapor species include deposition coefficients, desorption coeffictents, and vapor pressures for various surfaces, temperatures, and atmospheres For species in aqueous solution, deposition coefficients or distribution coefficients between the 1 iquid and solid phases are needed In the case of particulate forms, the key information concerns the particle size distribution of the aerosol or suspended particulate material. 


\subsubsection{Deposition Coefficients}

Considerable experimental work has been reported in the nuclear safety literature on fission product deposition from the vapor phase. Most of the work was directed at elemental iodine deposition on mild steel or stainless steel from steam or steam-air atmospheres at temperatures ranging from about $100^{\circ} \mathrm{C}$ to about $700^{\circ} \mathrm{C}$. Limited data have been reported for other fission products, other surfaces, and other atmospheres (particularly helium). Summaries of available deposition coefficient data have been given by Morrison, et al., 5 Silverman, et a1., 52 and Gieseke, et al. 45 The numerous factors which can affect sorption processes cause considerable uncertainty in deposition coefficient or deposition velocity values. Even for the relatively well-studied iodine, uncertainties of plus or minus an order of magnitude are common.

\subsubsection{Desorption Coefficients}

Desorption refers to the release of a material from a surface which had previously been deposited from the vapor phase. It requires a change in the dynamic conditions at the surface, such as the temperature or the vapor phase concentration of the sorbing species. Desorption has been of most interest in reactor safety research with respect to iodine behavior in containment vessels. Morrison, et a1. ${ }^{5}$ summarized the early work, and later studies were performed by Genco, et al. 53 Studies involving other fission products were not identified in the present literature review process. Therefore, very limited desorption coefficient data would be available for use in an SFTA cask T\&D model.

\subsubsection{Vapor Pressures}

A number of reference sources exist which tabulate equilibrium vapor pressure data for the chemical elements and some of their more common compounds. In other cases vapor pressures may be estimated from basic thermodynamic data. Most vapor pressure and thermodynamic data apply to specific temperature ranges which may or may not correspond to that required for the T\&D model. Gieseke, et al.45 have tabulated vapor pressure data for a few of the more likely chemical forms of the volatile fission products for use in TRAP or TRACK code analysis. The fundamental problem with vapor pressure data is that the chemical form of the fission product must be specified in order to determine which vapor pressure data to use. Also, since vapor pressures are exponential functions of temperature, the thermal conditions must be well known to obtain accurate analyses of the condensation/evaporation equilibria. In general the availability of good vapor pressure data for use in SFTA analytical models would be limited.

\subsubsection{Aqueous Phase Deposition Coefficients}

Almost no data exist that may be used to define deposition on solid surfaces from the aqueous phase. The only approach identified in the present 
study which might be used is the approximate partition coefficient approach described by Gieseke, et al.45 It is based on the experimental work of Herczynskas4 and is specific to ionic species, metallic surfaces, and room temperature. The method is quite general and useful only as a crude indicator of the degree of surface adsorption that might occur. The absence of a temperature function in the approach might represent the greatest deficiency in applying it to SFTA conditions.

\subsubsection{Particle Size Distribution Data}

The only particle size distribution data that could be used in a cask T\&D model are the data discussed in Section 6.2.1.3 regarding the chemical and physical forms that might be released from the failed fuel rods. This includes the limited characterization of fuel dust released in ORNL burst tests, the crude estimates for recondensed aerosols produced during fuel melting, the limited fuel rod shearing data, and the speculations regarding particle sizes that might result from impact shattering of fuel rods. None of these data are complete enough to support a mechanistic treatment of aerosol dynamics in a shipping cask T\&D model.

\subsubsection{Summary of T\&D Data Status}

The available data for use in specifying input values to analytical models of radionuclide $T \& D$ in shipping cask accidents are very limited. Iodine deposition and desorption rate data are available, but the values can vary considerably. Only very crude information exists for other fission product and actinide forms. Consequently, theoretical analyses would tend to be useful only as qualitative indicators of radionuclide T\&D behavior and not as reliable quantitative predictions. 


\section{REFERENCES}

1. W. B. Lewis, "Engineering for Fission Gas in $\mathrm{UO}_{2}$ Fuel," Nucl. Appl, 2, 171-181 (1966).

2. Fast Reactor Fuel Element Technology, Proc. Conf., New Orleans, 1971 (Amer Nucl. Soc, Hinsdale, 1971), p. 267 and 311.

3. B. Lustman "Uranium Dioxide: Properties and Nuclear Applications," J. Belle, editor, USAEC, Washington (1961).

4. B. G. Childs, "Fission Product Effects in Uranium Dioxide," J. Nucl., Mater, 9 , 217-244 (1963).

5. D. L. Morrison, et al., "An Evaluation of the Applicability of Existing Data to the Analytical Description of a Nuclear Reactor Accident," BMI-1779 (August, 1966).

6. G. W. Parker and C. J. Barton, "Fission Product Release," in The Technology of Nuclear Reactor Safety, Vol. 2, T. J. Thompson and J. G. Beckerley, eds., MIT Press, Cambridge (1973).

7. USNRC, "The Role of Fission Gas Release in Reactor Licensing," NUREG75/077 (November, 1975).

8. A. H. Booth, "A Method of Calculating Fission Gas Diffusion from $\mathrm{UO}_{2}$ and Its Application to the $X-2-f$ Loop Test," AECL report CRDC-721 (September, 1957).

9. W. A. Yuil1, V. F. Baston, and J. H. McFadden, "An Analytical Model Describing the Behavior of Fission Products in Operating Fuel Pins," IN-1467 (June, 1971).

10. S. E. Turner, et a1., "Status Report--ANS 5.4 Fuel Plenum Gas Activity" (Apri1, 1977).

11. S. D. Beck, "The Diffusion of Radioactive Fission Products from Porous Fuel Elements," BMI-1433 (Apri1, 1960).

12. R. 0. Meyer, C. E. Beyer, and J. C. Voglewede, "Fission Gas Release from Fuel at High Burnup," NUREG-0418 (March, 1978).

13. D. D. Lanning, et al., "Gapcon-Thermal-3 Code Description," PNL2434 (January, 1978).

14. D. L. Morrison, W. A. Carbiener, and R. L. Ritzman, "An Evaluation of the Applicability of Existing Data to the Analytical Description of A Nuclear Reactor Accident," Quarterly Progress Report for OctoberDecember, 1968, BMI-1856 (January, 1969) p. 37. 
15. D. L. Morrison, et al., "An Evaluation of the Applicability of Existing Data to the Analytical Description of a Nuclear Reactor Accident," Quarterly Progress Report for Apri1-June, 1967, BMI-1810 (July, 1967) p. 15.

16. G. W. Parker, et al., "Calculation of Amount of Volatile Radioactivity in Fuel Rod Void Spaces," in Nuclear Safety Program Annual Progress Report for Period Ending December 31, 1967, ORNL-4228 (April, 1968) p. 11.

17. USNRC, "The Reactor Safety Study--An Assessment of Accident Risks in U.S. Commercial Nuclear Power Plants," WASH-1400 (NUREG-75/014) October, 1975.

18. R. A. Lorenz, J. L. Collins, S. R. Manning, "Quarterly Progress Report on Fission Product Release from LWR Fuel" for the Period:

a) October-December, 1975, ORNL/TM-5290 (March; 1976)

b) January-March, 1976, ORNL/NUREG/TM-30 (July, 1976)

c) Apri7-June, 1976, ORNL/NUREG/TM-44 (August, 1966)

d) July-September, 1976, ORNL/NUREG/TM-73 (December, 1976)

e) October-December, 1976, ORNL/NUREG/TM-88 (March, 1977)

19. USNRC, "Assumptions Used for Evaluating the Potential Radiological Consequences of a Fuel Handling Accident in the Fuel Handling and Storage Facility for Boiling and Pressurized Water Reactors," Regulatory Guide 1.25 (March, 1972).

20. USAEC, "Environmental Survey of Transportation of Radioactive Materials to and from Nuclear Power Plants,"WASH-1238 (December, 1972).

21. R. L. Ritzman and D. L. Morrison, "FRCRL2--A Computer Code for Calculating Fission-Product Release in Reactor Accident Analyses," BMI1913 (August, 1971).

22. J. B. Melehan, et al., "Release of Fission Gases from $\mathrm{UO}_{2}$ During and After Irradiation, BMI-1623 (March, 1963).

23. R. L. Ritzman, et al., "Release of Radioactivity in Reactor Accidents," Appendix VII of WASH-1400" (The Reactor Safety Study) (October, 1975).

24. Supplement II to WASH-7238, Motent Ial Releases of Cesium from Irradiated Fuel in a Transportation Accjent, NUREG-0069 (July, 1976).

25. A. P. Malinauskas, "Quarteriy Prögress Report on Fission Product Behavior in LWR's" for the Period: 

a) January-March, 1977, ORNL/NUREG/TM-122 (June, 1977)
b) Apri1-June, 1977, ORNL/NUREG/TM-139 (September, 1977)
C) July-September, 1977, ORNL/NUREG/TM-170 (January, 1978)
d) October-December, 1977, ORNL/NUREG/TM-186 (March, 1978)
e) January-March, 1978, ORNL/NUREG/TM-208 (June, 1978)
f) April-June, 1978, ORNL/NUREG/TM-242 (September, 1978)

26. H. Feuerstein, "Behavior of Iodine in Zircaloy Capsules," ORNL-4543 (August, 1970).

27. USAEC, "Assumptions Used for Evaluating the Potential Radiological Consequences of a Loss-of-Coolant Accident for Boiling Water Reactors," Regulatory Guide 1.3 (Revision 2) (June, 1974).

28. J. L. Collins, et a1., "Knudsen Ce11--Mass Spectrometer Studies of Cesium-Urania Interactions," ORNL/NUREG/TM-24 (June, 1976).

29. P. A. G. O'Hare, et al., "Chemical Engineering Division ThermochemiCal Studies Annual Report, July 1973--June 1974," ANL-8121 (July, 1974).

30. J. L. Collins, Oak Ridge National Laboratory, Personal Communications (August, 1978).

31. J. Belle, ed., "Uranium Dioxide: Properties and Nuclear Applications," USAEC, Washington (1961).

32. G. W. Parker, et al., "Out-of-Pile Studies of Fission Product Release from Overheated Reactor Fuels at ORNL, 1955--1965," ORNL-3981 (July, 1967).

33. R. A. Lorenz, J. L. Collins, and A. P. Malinauskas, "Fission Product Source Terms for the LWR Loss-of-Coolant Accident: Summary Report," ORNL/NUREG/TM-206 (June, 1978).

34. W. F. Linke, "Solubilities of Inorganic and Metal Organic Compounds," 4th Edition, American Chemical Society, Washington, D.C. (1965).

35. Y. B. Katayama, "Leaching of Irradiated LWR Fuel Pellets in Deionized and Typical Ground Water," BNWL-2057 (July, 1976).

36. Y. B. Katayama and J. E. Mende1, "Leaching of Irradiated LWR Fuel Pellets in Deionized Water, Sea Brine, and Typical Ground Water," PNL-SA-6416 (Presented at ANS Winter Meeting at San Francisco, California, November 22--December 2, 1977).

37. J. E. Mende1, "A Review of Leaching Test Methods and the Leachability of Various Solid Media Containing Radioactive Wastes," BNWL-1765 (July, 1973), p. 11. 
38. S. D. Gabelnick and M. G. Chasanov, "A Calculational approach to the Estimation of Fue 1 and Fission Product Vapor Pressures and Oxidation States to $6000^{\circ} \mathrm{K}, " \mathrm{ANL}-7867$ (October, 1972).

39. R. G. Bedford and D. D. Jackson, "Volatilities of the Fission Product and Uranium Oxides," UCRL-12314 (January, 1965).

40. T. Moeller, "Inorganic Chemistry," John Wiley and Sons, Inc., New York (1952).

41. R. C. Weast, editor, "Handbook of Chemistry and Physics," 51 st Edition, The Chemical Rubber Co., Cleveland, Ohio (1970).

42. T. Erdey-Gruz, "Transport Phenomena in Aqueous Solutions," John Wiley \& Sons, New York (1974).

43. A. E. J. Eggleton, "A Theoretical Examination of Iodine-Water Partition Coefficients," AERE-R-4887 (February, 1967).

44. J. B. Andelman and T. C. Rozze11, "Plutonium in the Water Environment. I. Characteristics of Aqueous Plutonium," in Radionuclides in the Environment, American Chemical Society, Washington, D.C. (1970).

45. J. A. Gieseke, et al.; "Analysis of Fission Product Transport Under Terminated LOCA Conditions," BMI-NUREG-1990 (December, 1977).

46. S. R. Fields, "Spent Fuel Shipping Cask Accident Evaluation," Draft report, Hanford Engineering Development Laboratory (June, 1975).

47. T. S. Kress and F. H. Nei11, "A Model for Fission Product Transport and Deposition Under Isothermal Conditions," ORNL-TM-1274 (October, 1965).

48. G. E. Raines, et al., "Experimental and Theoretical Studies of Fission Product Deposition in Flowing Helium," BMI-1688 (August, 1964).

49. S. K. Beal, "Deposition of Particles in Turbulent Flow on Channel or Pipe Walls," Nucl. Sci Engr, 40, 1 (1970).

50. H. Matsui, et al., "Measurement of Deposition Fraction of Aerosol Particles in a Horizontal Straight Metal Pipe," J. Nucl. Sci and Tech, 11, 300 (1974).

51. D. L. Morrison, et al., "An Evaluation of the Applicability of Existing Data to the Analytical Description of a Nuclear Reactor Accident," Quarterly Progress Report for January-March, 1968, BMI-1835 (Apri1, 1968) p. 19.

52. L. Silverman, et al., "Fission Product Behavior and Retention in Containment Systems," in The Technology of Nuclear Reactor Safety, Vol. 2, T. J. Thompson and J. G. Beckerley, editors, The MIT Press, Cambridge, Massachusetts (1973) pp. 619-697. 
53. J. M. Genco, et al., "Fission Product Deposition and Its Enhancement Under Reactor Accident Conditions, Depositon on Primary-System Surfaces," BMI-1863 (March, 1969).

54. E. Herczynska, "Adsorption of Ions on Metal and Metal Oxide Surfaces in Aqueous Solution," Translated from Polish, AEC-tr-6776 (1965).

55. J. H. Goode and R. G. Stacy, "Head-End Reprocessing Studies With H. B. Robinson-2 Fuel," ORNL/TM-6037 (June, 1978), p. 20. 


\subsection{EVALUATION OF THE ADEQUACY OF EXISTING DATA}

The data summarized in Sections 3.0 through 6.0 are evaluated in this section. The evaluation of the ability to correlate fission product release with accident severity is presented first and includes an accident severity classification scheme which eliminates some of the difficulties with current schemes. An evaluation of fuel response data is contained in Section 7.2 , the cask response data evaluation is contained in Section 7.3 , and the release and behavior of radionuclides is contained in Section 7.4. A summary of the evaluation is presented in tabular form in Section 7.5.

\subsection{ABILITY TO CORRELATE FISSION PRODUCT RELEASE TO ACCIDENT}

\section{CATEGORIZATION}

Two of the four approaches to accident categorization presented in Section 4.0 may be useful, the WASH- $1238^{1}$ and the NUREG-0170 ${ }^{2}$ schemes. The Hodge and Jarrett ${ }^{3}$ approach is an oversimplification of the WASH-1238 approach, and the Yadigaroglu ${ }^{4}$ approach is not sufficiently generic. The WASH-1238 and NUREG-0170 approaches appear to be quite similar, if Figure 7.1 is compared with Figure 4.1. However, the basis for the ordinate values is different. The four WASH-1238 values were reduced, apparently in an arbitrary manner, from a set of ten values from published ${ }^{5}$ data on truck accidents at various speeds. The first two NUREG-0170 values were selected to relate to performance test values. (For the rail case, one half of the test velocity was used.) The other values are convenient, but apparently arbitrary, values of the percentage of accidents occurring at a lower speed. The abscissas of both schemes apparently were chosen similarly (i.e., with increments of one-half hour). The least severe NUREG0170 categorization however, includes up to fifteen minutes of fire.

The NUREG-0170 classification scheme, in which the first few ordinate values are chosen by considering the Type B performance tests, appears to be particularly meaningful. The method for the remaining ordinate values appears reasonable, provided that the data. used as a basis are applicable and statistically meaningful. The method for selecting the abscissa also appears as reasonable as possible.

The correlation of the accident classification scheme with cask response and then to fuel assembly response is the problem. First, regarding the above accident classification schemes, the cask and cask contents are not likely to respond in the same manner to the two different ranges of impact and fire values (for the "severe" category of Figure 7.1 , or category "IV" of Figure 4.1), i.e., a situation involving high impact and a short-duration fire as opposed to a situation with low impact and a long-duration fire. In the NUREG-0170 case, the classiffication scheme (Figure 4.1) is subordinate to the assumed release fraction (Table 4.7). The logic is that a category IV release ( $10 \%$ release fraction) might result from either a $40-64 \mathrm{~km} / \mathrm{hr}$ impact plus a fire of less than one-half hour, a $8-24 \mathrm{~km} / \mathrm{hr}$ impact plus a fire of 1-1.5 hr, or an impact less than $24 \mathrm{~km} / \mathrm{hr}$ plus a fire greater than $1.5 \mathrm{hr}$. 


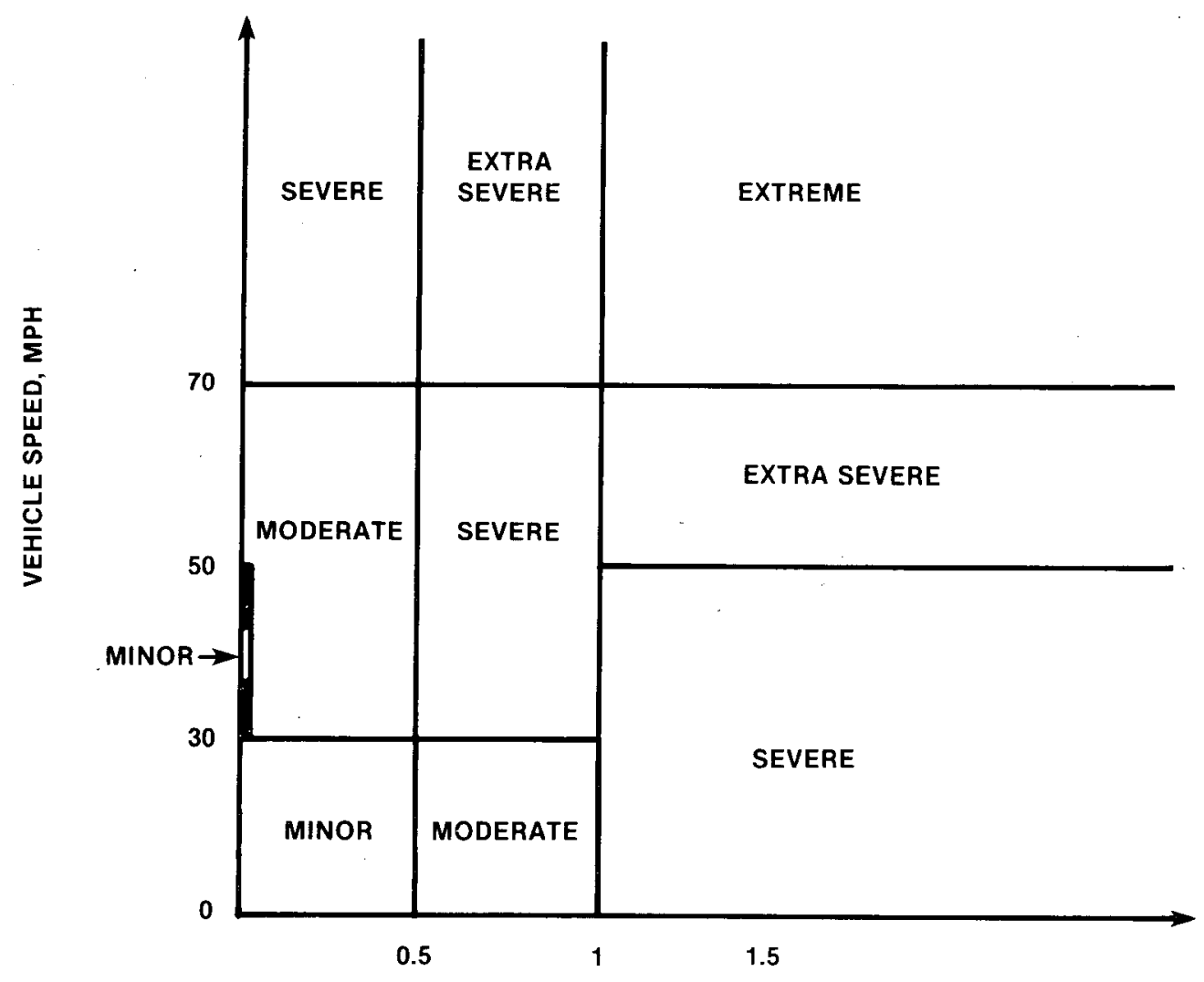

FIRE DURATION HOURS

FIGURE 7.1. GRAPHIC DISPLAY OF WASH-1238 ACCIDENT SEVERITY CATEGORIES 
In order to establish a correlation between accident environment and radionuclide release, it appears that an approach which looks for release information given the accident environment has a better chance for success. Therefore, an accident scheme is shown in Figure 7.2 which separates highimpact, short-duration fire events from low-impact, long-duration fire events. The first category includes the most probable type of accidents-minor package damage and no release of radionuclides. The second category is based on the performance tests, where it is demonstrated that there is very little release (generally none). The values for $I_{T}$ and $H_{T}$ are based on the thirty-foot drop test and the thirty-minute fire test respectively.

The performance test specifies an unyielding surface, whereas "real" accidents generally involve a surface that yields or deforms. In addition, real fires would seldom be described by exposure of the entire cask to a fire resulting in a high, constant, thermal input to the cask; rather, part of the cask surface would be shielded by the ground and/or the transport vehicle and the thermal input to the cask will likely be less due to lower flame temperatures, emissivity, and so forth. Therefore, another region can be defined by $I_{R}$ and $H_{R}$ in which the probable radionuclide release will be uniformly low.

Beyond $I_{R}$ and $H_{R}$, cask integrity progressively deteriorates, and the highimpact, Short-duration fire versus low-impact, long-duration fire question arises. Therefore, separate categories are defined as shown in Figure 7.2 for these extremes and for the common high impact, long-duration fire case. An additional high-impact, short-duration fire category is also shown. Other classifications would be added as necessary. The values for $I_{1}, I_{2}, H_{1}$, etc. are chosen as in NUREG-0170. Sufficient information appears available in References 6 and 7 for choosing the values in Figure 7.2.

The estimates of cask damage (or release fraction) given in Chapter 4 were all based on well-considered engineering judgment. Brobst's estimate (Table 4.5) was probably the most thoroughly conceived, and Model II of NUREG-0170 was probably intended to be fairly realistic but more defensible in the adversary arena. Neither would be considered appropriate as a reasonably realistic correlation between the accident environment and radionuclide release.

The difficulty in obtaining the desired correlation rests with the damage evaluation and subsequent radionuclide release from the failed cask. Both the energy associated with the accident environment and the energy absorption ability of the cask and its contents must be considered. The energy absorption capability depends strongly on a number of variables, including failure mode, orientation of the cask, (and contents) with respect to the applied force, and cask design. Section 5 presents the current cask response methodology, and Section $7: 3$ contains a discussion of the adequacy of that methodology. Even though dynamic analysis capability is not fully developed, the analytical models generally are sufficient to permit a reasonable correlation. (This correlation could improve as the dynamic analysis capability matures.) However, as presented in Section 7.3 , the input data required for the analytical models are inadequate, especially in the area of dynamic analysis. 


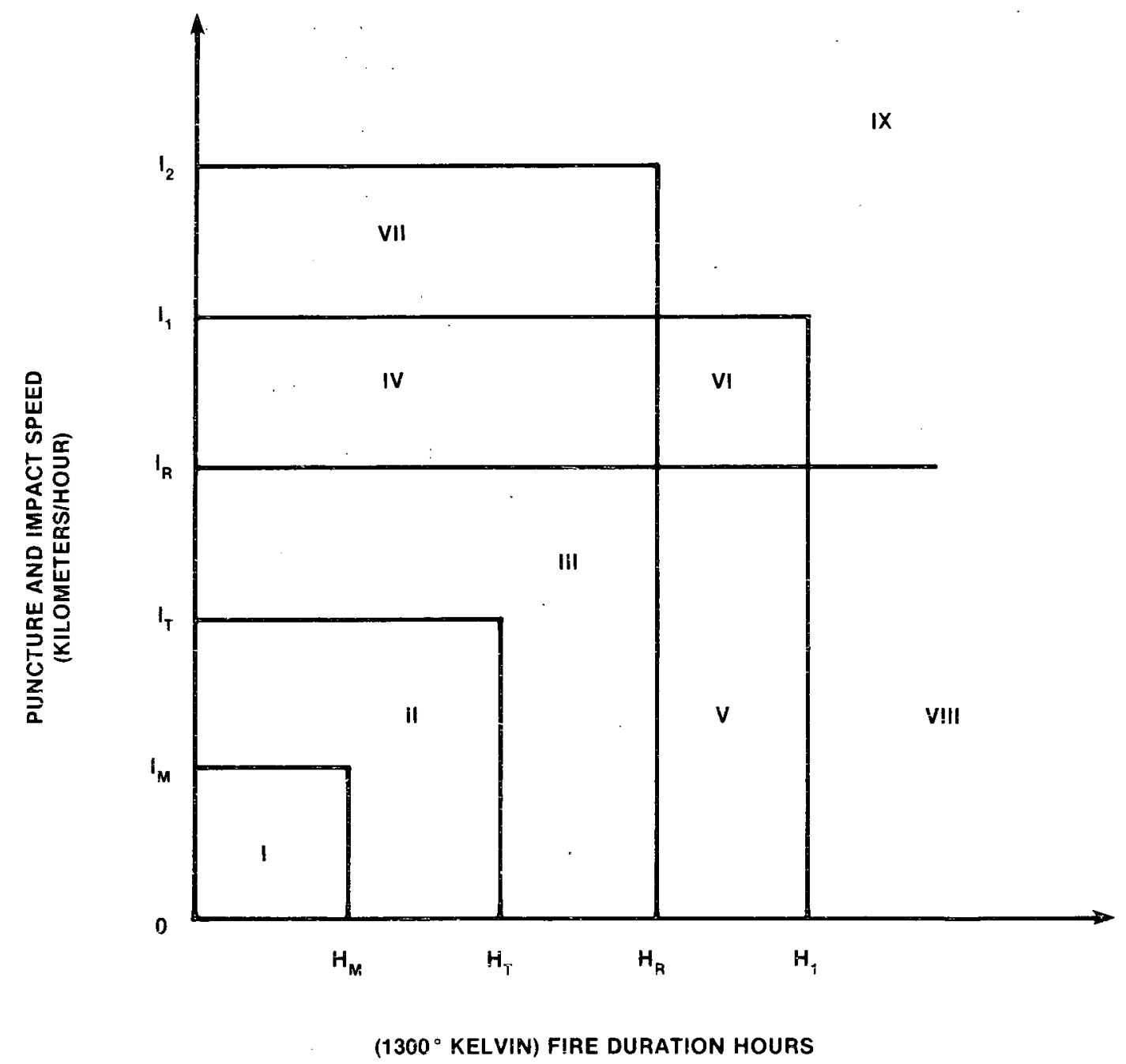

FIGURE 7.2. ACCIDENT SEVERITY CATEGORY CLASSIFICATION SCHEME 
The above correlation would be applicable for a specific class of failure modes for a specific cask design. To obtain a generic correlation of cask damage to accident severity, the results from a spectrum of failure modes and cask designs would have to be systematically determined and combined.

Knowledge of the cask failure mechanism is a necessary but not sufficient step. An equally important, and perhaps more difficult step is the evaluation of the radionuclide release through a cask breach. Fuel mechanical response is discussed in Section 7.2 and the resulting radionuclide behavior is discussed in Section 7.4

\subsection{ADEQUACY OF EXISTING DATA FOR EVALUATING FUEL RESPONSE}

Briefly stated, existing data are inadequate for realistic evaluation of fuel response in LWR spent fuel shipping accidents. While MATPRO offers models dealing with stress-strain relationships in Zircaloy cladding, these models do not deal adequately with impact. Furthermore, most of the mechanical/ structural property measurements on irradiated Zircaloy cladding are being made to help evaluate the consequences of reactor transients and accidents. The only available information on the effect of impact-induced bowing of spent fuel rods comes from four-point bending tests with irradiated Zircaloy cladding at Battelle Memorial Institute.

The observations of the behavior of unirradiated N.S. Savannah stainless steel-clad fuel assemblies in cask accidents are interesting, but they are certainly inconclusive in terms of evaluating the possible behavior of fully irradiated LWR Zircaloy-clad fuel assemblies. The fact that the unirradiated, stainless steel-clad fuel rods showed no evidence of cladding failure in cask-impact tests is not very comforting in view of the large differences in strength and ductility between unirradiated stainless steel and irradiated Zircaloy cladding. Because of the bowing of stainless steel-clad fuel rods in severe impact cask tests, the question arises of whether the usual maximum of ten percent cladding failure due to impact in severe shipping accidents is sufficiently conservative. The results of the above-mentioned four-point bending tests ${ }^{8}$ with irradiated Zircaloy (from the H. B. Robinson Nuclear Plant) indicate that the ten percent prediction is conservative because bending to a four-inch radius did not cause cladding failure. The irradiated Zircaloy cladding appears to be sufficiently ductile that a moderate amount of fuel rod bowing is unlikely to cause cladding failure. Bending tests with spent fuel rods woutd give more convincing data than rods filled with other ceramic material but, until tests with sections of irradiated fuel rods are performed, it seems reasonable to assume that only a small fraction of the fuel rods will fail from impact in a spent fue shipping accident.

For the cask accidents jnvolving loss of coolant and fire, either independently or superimposed, an adequate data base exists to perform thermalhydraulic evaluations on the cask and on the fuel rods at several levels of sophistication. However, existing analytical simulations for these ac- 
cidents are not directly applicable. The best simulation, FRAPT2, is probably more detailed than necessary and would require modification. Although these modifications are feasible, analytical techniques are also available to perform less sophisticated, but probably adequate, analyses.

\subsection{ADEQUACY OF EXISTING DATA ON CASK RESPONSE}

Review of existing documentation regarding the structural and thermal analysis and testing methods for spent fuel shipping casks indicates that the area most urgently needing attention is in the dynamic response of casks and their contents to impact. Finite-element solution of transient heat transfer problems for the geometries in question is a state-of-the-art technique and only requires that appropriate boundary conditions be applied, which is normally not an especially difficult task. The techniques for static structural analysis that have been applied in the past for licensing casks are adequate and demonstrably conservative.

Evaluation of the dynamic response of casks to severe impact environments, however, is minimal to date. While the large-scale test programs that have already been conducted indicate that a gross failure of a cask is highly unlikely, it is possible to postulate failure modes that could lead to a breach of cask integrity, e.g., cracks emanating from an inadequately designed weld joint such as a corner weld where stress risers occur. In order to deal with this situation adequately, additional testing is required. The judicious application of sophisticated finite element analytical techniques is needed also. This effort will be hampered by a lack of adequate materials properties under high strain rates.

Additionally, little work has been done in the area of the transmission of impacts through the cask inner structure to the fuel assemblies within. A. better understanding of this area will also be required to obtain a basis for determining adequate but not overly conservative criteria for design adequacy substantiation. The judicious testing and analysis approach described above is the appropriate direction for further research in this area also.

\subsection{ADEQUACY OF FISSION PRODUCT RELEASE AND BEHAVIOR INFORMATION}

The review of the present collection of technical information that might be used to characterize the dynamic behavior of fission products in severe spent fuel transportation accidents has indicated oniy a few areas in which the data base is sufficient to permit development of reasonably accurate predictions. Many areas are best described as containing some useful qualitative information for the design of analyticai models, but little or no quantitative data for applying or testing potential models.

Information items which seem to be generally adequate tend to be connected with the prediction of noble gas behavior and with the specification of simple physical data such as radionuclide inventories, system geometry, and very general thermal and flow conditions. However, the data base concerning behavior of other volatile and nonvolatile fission products is 
largely qualitative. That is, some experimental and theoretical evidence exists for estimating potential forms and hence properties of fission products, but little quantitative data exists for specifying accurate volatiles or mobilities over ranges of accident conditions. Little data is available on the temperature dependence of aqueous leaching of spent fuel. In addition, while qualitative information exists on the general mechanical response of fuel rods in potential accidents, detailed data on the shape and size of cladding failures and on the degree of fuel fragmentation do not exist. The availability of generalized analytical models or computer codes of fission product transport and deposition within spent fuel shipping casks is also limited.

Perhaps the area in which lack of information is most critical is that concerning characterization of possible aerosol source terms for severe SFTA scenarios. This includes the amount and the particle size distribution of fuel dust that would be present in spent fuel rods or could be generated by the impact forces associated with an accident. Without particle size distribution data the development of a "respirable aerosol" source term becomes mostly a matter of speculation. A less significant area which also suffers from a general lack of specific information is the characterization of releases from melting fuel. This is not regarded as too important to SFTA analyses, since it is rather doubtful that expected spent fuel shipping conditions and realistic accident environments could ever lead to such high fuel temperatures.

\subsection{SUMMARY OF THE ADEQUACY OF EXISTING INFORMATION}

On the basis of the discussion presented in the preceding portions of this section, a detailed evaluation was prepared of the adequacy of these methods and data for defining SFTA source terms that are needed to perform environmental consequence analyses. The results of the evaluation are given in Table 7.1. The table contains a listing of the numerous items which need to be supplied or defined in order to produce comprehensive sourceterm estimates. In general, items 1 and 2 pertain to starting conditions or assumptions; items 3 and 4 concern the response of the cask and its contents to impact and puncture; item 5 concerns the thermal-hydraulic response; items 6 and 7 - pertain to radionuclide releases from the fuel rods; items 8,9 , and 10 deal with the definition of radionuclide forms and releases from the cask boundary. Each of the detailed items under these main headings was judged for adequacy against four criteria. The criteria are defined as follows:

A - The level of understanding regarding basic phenomena and processes associated with the item

B - The availability of analytical modets, correlations, or codes for the item

C - The availability of key input conditions, property data, and rate parameters for the item 
TABLE 7.1

EVALUATION OF THE ADEQUACY OF EXISTING DATA

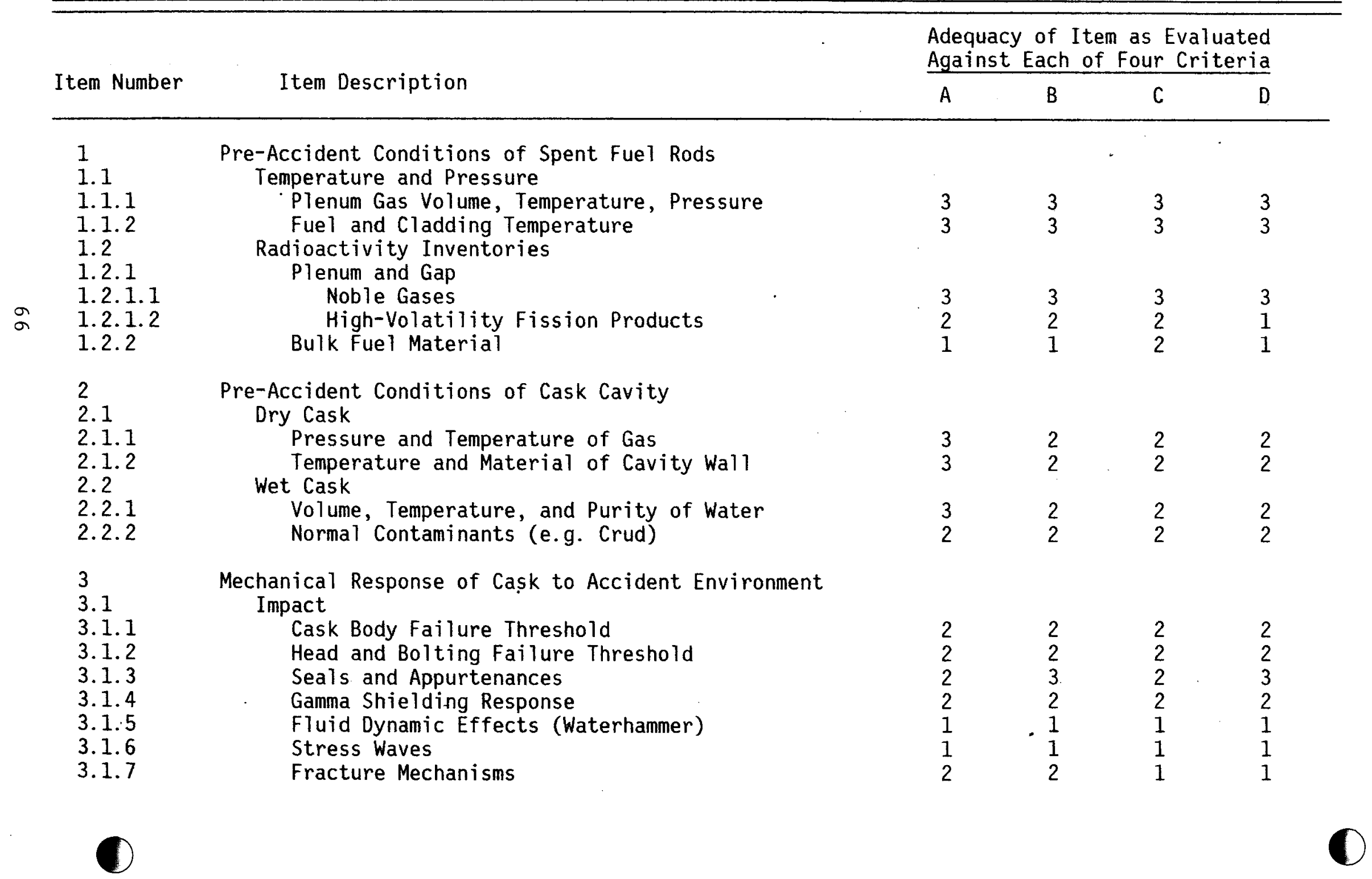


TABLE 7.1 (Cont'd)

EVALUATION OF THE ADEQUACY OF EXISTING DATA

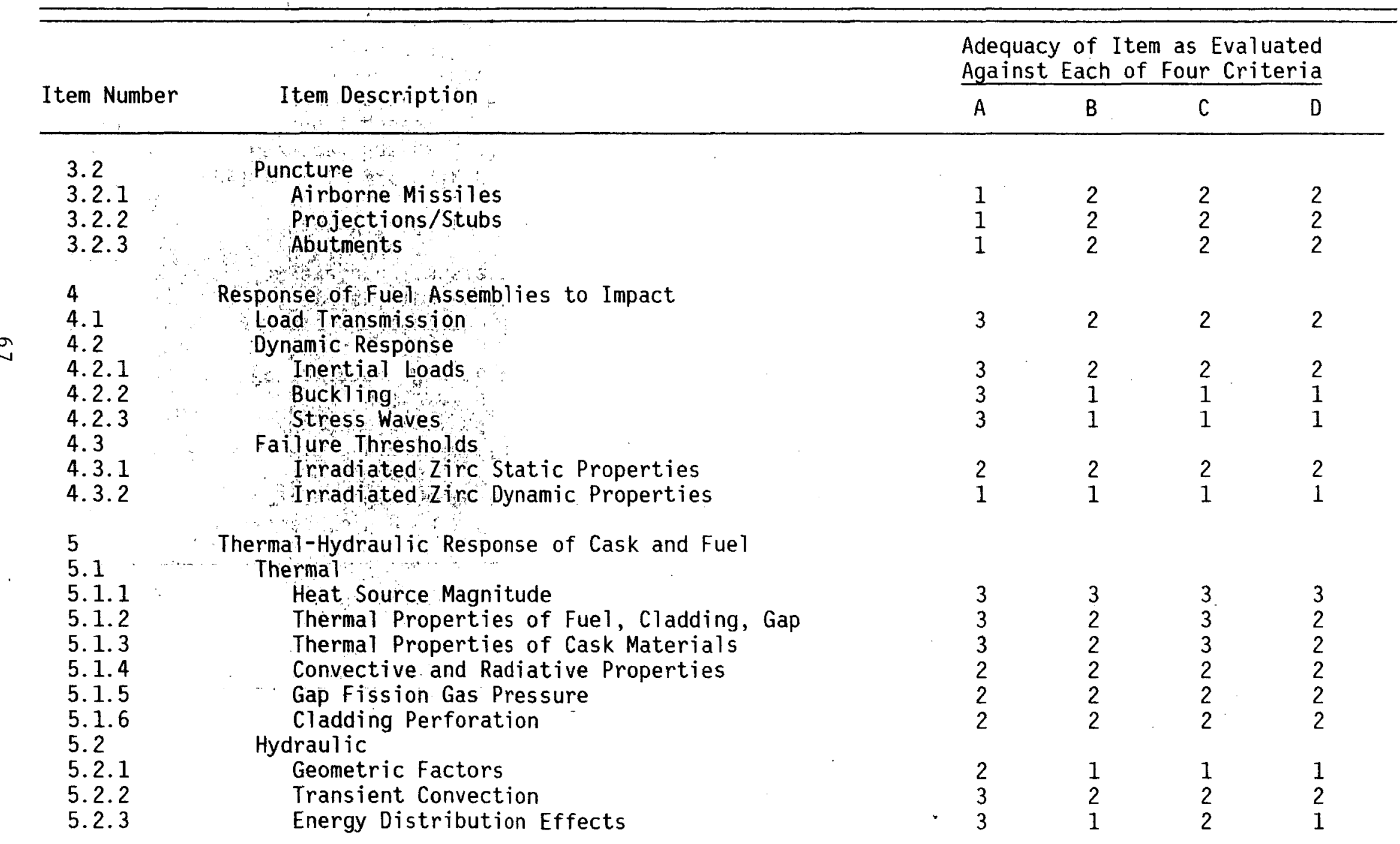




\section{Item Number}

Item Description
Adequacy of Item as Evaluated Against Each of Four Criteria

$\begin{array}{llll}A & B & C & D\end{array}$

\section{D}

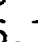

6.1 .1

6.1 .2

6.1 .3

6.1 .4

6.2

6.2 .1

6.2 .2

6.2 .3

6.3

6.3 .1

6. 3.2

7

7.1

7.1.1

7.1.2

7.1.2. 1

7.1.2.2

7.1. 3

7.1.4

7.1 .5

8

8. 1

8.1.1

8.1.2

8.1. 3

Releases to Dry Cask Cavity, (Ci)

Physical Damage to Rods Inflicted by Impact Forces

Noble Gases

High-Volatility Fission Products

Particulate Fuel

Bulk Fuel Debris

Perforations Due to Rod Temperature Transient Noble Gases

High-Volatility Fission Products

Particulate Fuel

Temperature Transient after Perforation Noble Gases

High-Volatility Fission Products

$\begin{array}{lrrr}3 & 2 & 2 & 2 \\ 2 & 1 & 2 & 1 \\ 2 & 1 & 2 & 1 \\ 2 & 1 & 1 & 1 \\ 3 & 3 & 2 & 2 \\ 2 & 2 & 2 & 2 \\ 2 & 1 & 2 & 1 \\ 2 & 2 & 2 & 2 \\ 2 & 2 & 2 & 2\end{array}$

Releases to Wet Cask Cavity, (Ci)

Physical Damage Inflicted by Impact Forces

Noble Gases

High-Volatility Fission Products

Gaseous Fraction

Dissolved Fraction

Particulate Fuel

Bulk Fuel Debris

Leach Rates of Fuel by Water

Characteristics of Species as They Exist in Cavity

Chemical and Physical (Compounds; Gas, Solid, Liquid)

Noble Gases

High-Volatility Fission Products

Low-Volatility Fission Products and Actinides 
TABLE 7.1 (Cont'd)

EVALUATION OF THE ADEQUACY OF EXISTING DATA

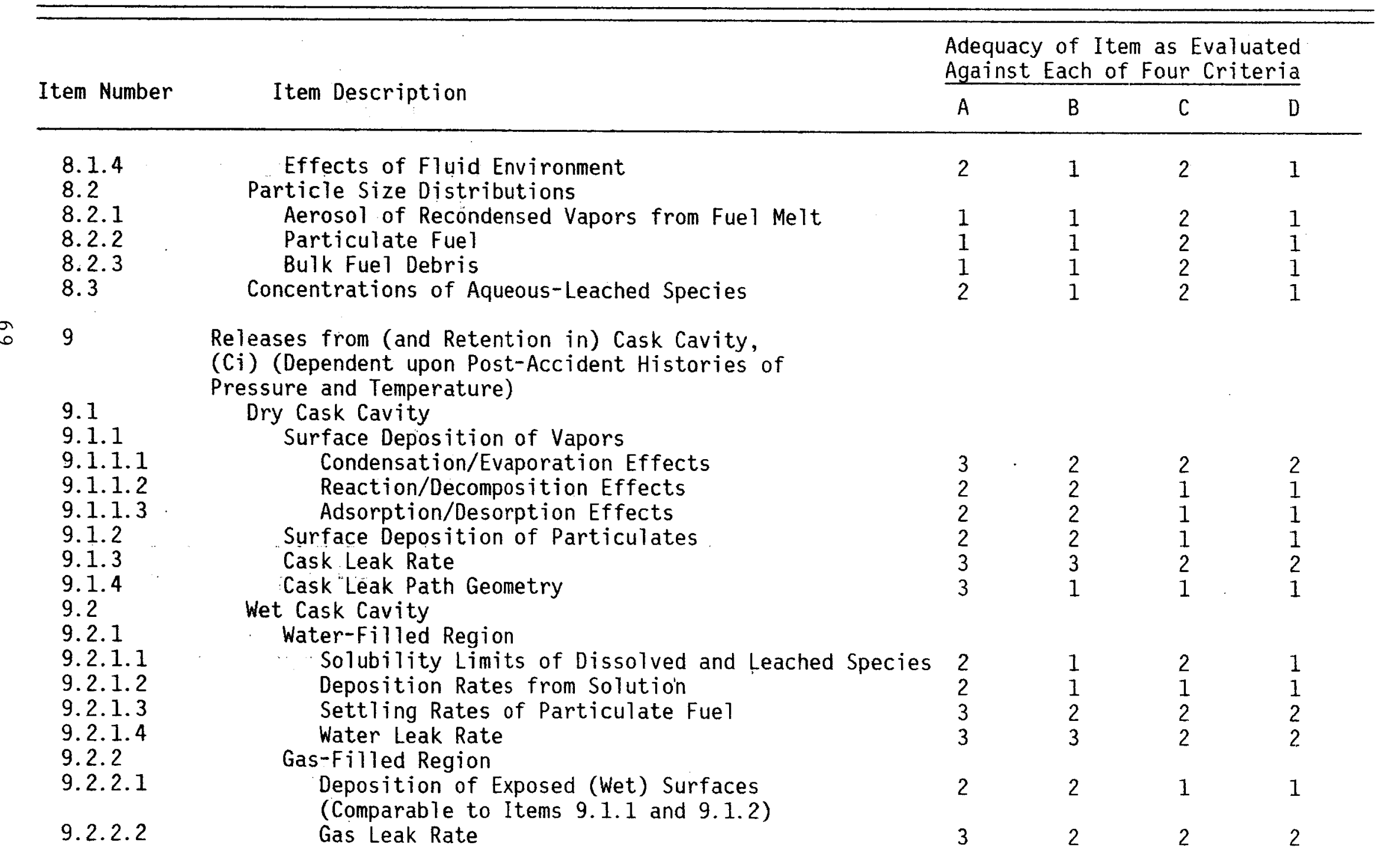


TABLE 7.1 (Cont'd)

EVALUATION OF THE ADEQUACY OF EXISTING DATA

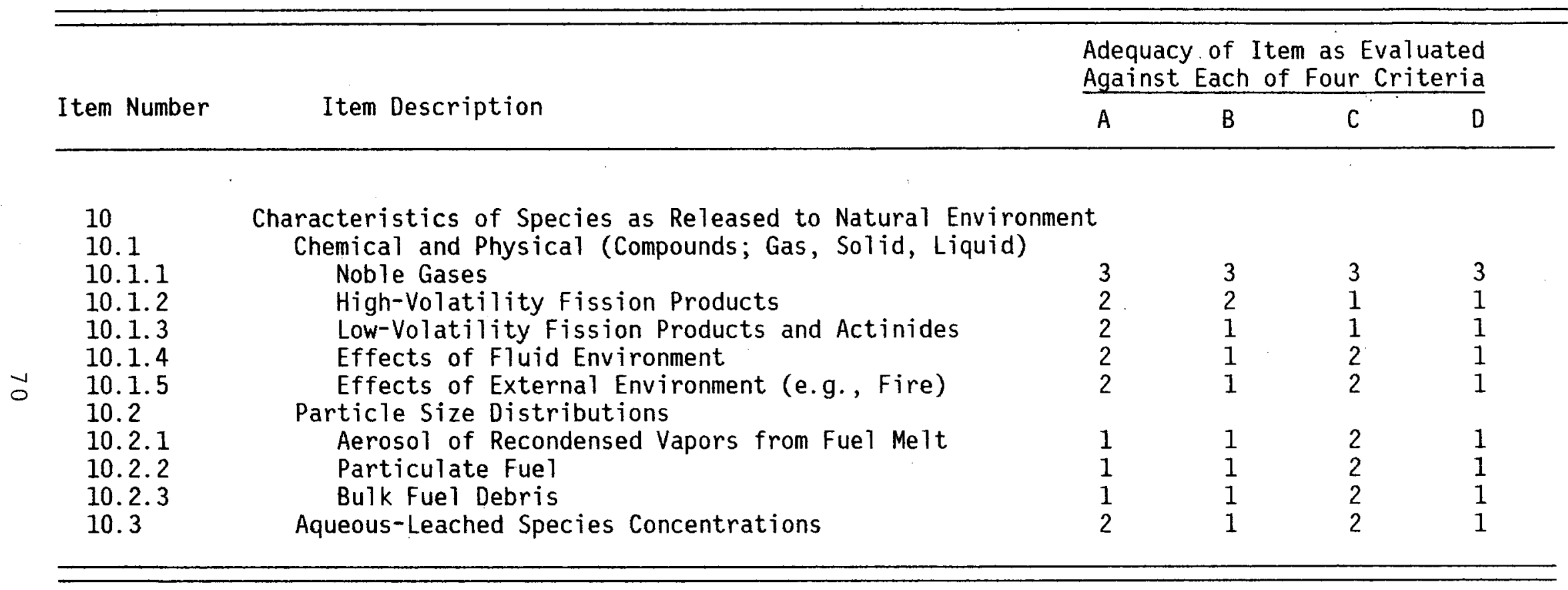




\section{D - The completeness of the output resulting from application of available analytical methods}

Three rankings were used to indicate the relative adequacy of the information base for each item-criterion combination, which is reflected in the following point system:

$\begin{array}{cl}\begin{array}{c}\text { Point } \\ \text { Value }\end{array} & \begin{array}{l}\text { Degree of Adequacy of } \\ \text { the Information Base }\end{array} \\ 1 & \begin{array}{l}\text { Generally inadequate } \\ 2\end{array} \\ 3 & \text { Mixed adequate/inadequate } \\ & \text { Generaliy adequate }\end{array}$

The numerical adequacy rankings assigned to each item-criterion combination are listed on the right-hand side of Table 7.1. Inspection of the rankings reveals that only about $16 \%$ of the total entries 1 ie in the "generally adequate" category, about 50\% 1ie in the "mixed" category, and about $34 \%$ lie in the "generally inadequate" category.

Important to bear in mind is that the adequacy rankings are judgment values. Certain assignments might therefore be questioned by other evaluators, but general trends would not be significantly altered. The evaluation indicates that it is not possible to produce comprehensive and accurate source terms for most SFTA scenarios. Too much important experimental data are missing. However, some source-term estimates of varying uncertainty could be developed. The task is to attempt to evaluate the ranges of uncertainty for different items and to estimate the impact of these on environmental consequence predictions. 


\section{REFERENCES}

1. USAEC, "Environmental Survey of Transportation of Radioactive Materials To and From Nuclear Power Plants," WASH-1238 (December, 1972).

2. USNRC, "Final Environmental Statement on the Transportation of Radioactive Material by Air and Other Modes," NUREG-0170 (December, 1977).

3. C. V. Hodge and A. A. Jarrett, "Transportation Accident Risks in the Nuclear Power Industry 1975-2000," EPA-520/3-75-023 (Apri1, 1975).

4. G. Yadigarolgu, A. G. Reinking, and V. E. Schrock, "Spent Fue T Transportation Risks," Nuclear News, 15, 71-75 (November, 1972).

5. F. F. Leimkuhler, Trucking of Radioactive Materials, Safety vs. Economy in Highway Transport, The Johns Hopkins Press, Baltimore (1963).

6. R. K. Clarke, J. T. Foley, W. F. Hartman, and D. W. Larson, "Severities of Transportation Accidents," SLA-74-0001 (July, 1976).

7. A. W. Dennis, J. T. Foley, W. F. Hartman, and D. W. Larson, "Severities of Transportation Accidents Involving Large Packages," SAND770001 (May, 1978).

8. L. M. Lowry, et al., "Quarterly Progress Report on Evaluating Strength and Ductility of Irradiated Zircaloy for the period: January through March 1978," NUREG/CR-0085, BMI-2000 (June, 1978). 


\subsection{THERMAL-HYDRAULIC GAUGING CALCULATIONS}

The ready availability of deterministic solutions for the cask and its contents to a loss-of-coolant accident and/or a fire accident was covered in Section 3.2.2. Given the initial and the boundary conditions, the geometry, and basic physical property data, calculations can generally be performed to the level of detail desired for either design or gauging purposes. The gauging calculations technique is described in Section 8.1, the gauging results are described in Section 8.2, and the uncertainties and conclusions are discussed in Section 8.3.

\subsection{SOLUTION TECHNIQUE}

The standard heat conduction equation was solved in the radial direction using an implicit finite difference technique. Energy transfer by radiation was modeled at the cask's outer surface and across the water jacket. Energy transfer by convection was modeled in the water jacket and inside the cask. (At the initiation of the accident, the water in the jacket is assumed to be lost, leaving only vapor.) In order to reduce the computer time, two schemes were used to subdivide the space into discrete volumes. A major noding scheme included seven nodes in the aluminum basket/fuel assembly region and six nodes through the cask wall. A minor noding scheme included seventeen nodes in the aluminum basket/fuel assembly region.

Three fuel rod regions were modeled to obtain distinct fuel, cladding, and gas temperatures. These three regions represented fuel rods nearest the center of the cask, at an average location in the cask, and at the outermost position in the cask. The first and last nodes were aluminum, and the remaining nodes were fuel, cladding, and aluminum composites. The minor node scheme was solved at each time step using the wall temperature from the major node scheme.

The transient momentum equation is usually solved for nuclear reactor leak flow calculations; however, flow path inertia, area variation with path length, and length-dependent loss terms are required for the full formulation. For our gauging calculations (and probably for cask design purposes), the Darcy equation appears adequate:

$$
\Delta \mathrm{P}=\mathrm{f} \frac{\mathrm{W}^{2}}{2 \rho g \mathrm{~A}^{2}}
$$

Flow was calculated using the $\Delta P$ from the previous time stép, and a check was made to ensure that sonic velocity was not exceeded. The energy removed by the exiting fluid was assumed to be distributed proportionally to the heat generation rate. 
Chapman's equation (Equation 3-2) was used to calculate the cladding failure temperature. The normalized heating rate, $H$, was calculated from the time rate of change of the cladding temperature, and the force across the cladding, $\Delta P$, was the difference between the cask pressure and the fission gas pressure. The change in fission gas pressure was determined from an ideal gas law formulation.

\subsection{RESULTS}

A thermal-hydraulic analysis was performed on a spent fuel cask representative of a large rail cask. The rationale for selecting the particular cask size and the fuel type are discussed in Section 2. The thermal-hydraulic input parameters are given in Table 8.1. As will be discussed further below, both a helium-cooled and a water-cooled cask were considered, and the helium-cooled values are included in parentheses in Table 8.1.

The reference rail cask selected was helium-cooled; therefore, when water was substituted as a coolant the specific design parameters (primarily the solid fuel basket) were such that the saturation pressure was unrealistically high. Therefore, instead of substituting a complete new set of parameters typical of a water-cooled cask, an external cooling system was assumed to be operational only until the accident is initiated. An external cooling system removing $70 \%$ of the heat generated resulted in initial fuel temperatures typical of water-cooled casks, about $420^{\circ} \mathrm{F}$.

The fuel temperature as a function of time resulting from the severe impact and fire scenario for the water-cooled cask is shown in Figure 10.2. The cask surface temperature rises from about $140^{\circ} \mathrm{F}$ to $1000^{\circ} \mathrm{F}$ in less than 15 minutes, reaches $1200^{\circ} \mathrm{F}$ in about 40 minutes, and is at about $1300^{\circ} \mathrm{F}$. when the fire ends at 2 hours. An initial cooldown period in the cask interior is due to energy removal as a result of escaping coolant. As the blowdown ends (at about 30 minutes), the outer fuel pins begin to heat rapidly due to the energy input from the fire heating the cask cavity wall. The impact of the fire on the fuel pins further inside the massive aluminum basket is delayed. The central pin is cooled largely through heat transfer to the cooled average pins, and subsequent heatup for the first three hours is due largely to its own internal heat generation.

After the fire ends, the cask surface temperature drops $600^{\circ} \mathrm{F}$ in the first hour and then rapidiy reaches a cooling rate of 20 to 40 degrees per hour. The outer fuel pins follow the same trend, although without the sudden initial decrease in temperature. Cooling affects the average pin about two hours after the fire ends and affects the inner pin about five hours after the fire ends.

As discussed in section 2, ten percent of the fuel pins are assumed to be ruptured in the initial impact. Of particular interest is that no additional ruptures were induced by a $1475^{\circ} \mathrm{F}$ fire of two hours 'duration.

The helium-cooled case uses the same basic parameters as the water-cooled case. Helium-cooled casks operate at higher initial temperatures; there- 
TABLE 8.1

THERMAL-HYDRAULIC SCOPING PARAMETERS

Cask

Fuel Basket Material

Initial Heat Removal

Shield Material

Fuel

Number of Fuel Assemblies

Heat Generation Rate/Fuel Assembly

Initial Fission Gas Pressure

Coolant

Medium

Pressure

Convective Heat Transfer Coefficient
Al uminum

$70 \%(20 \%)$

Lead, Steel, Water
$10 \mathrm{PWR}$

$8.4 \mathrm{~kW}$

800 psi (1200 psi)

Scenario

Fire

2 hrs d $1475^{\circ} \mathrm{F}$

Leak Size

$20 \mathrm{~cm}^{2}$

Initial Pin Failures

$10 \%$

Water (Helium)

300 psia (35 psia)

$5 \mathrm{Btu} / \mathrm{hr} / \mathrm{ft}^{2} /{ }^{\circ} \mathrm{F}$ 
fore, the initial fission gas pressure was increased to 1200 psi. Due to the relatively high heat loading of the reference cask ( $84 \mathrm{~kW}$ vs $70 \mathrm{~kW}$ as the licensed limit), the initial maximum temperature was somewhat higher than that of current casks $\left(1270^{\circ} \mathrm{F}\right.$ vs. $\left.1050^{\circ} \mathrm{F}\right)$. Therefore, an external cooling system is assumed to remove $20 \%$ of the generated heat until the time of the accident. Figure 10.1 shows the fuel temperatires as a function of time resulting from the severe impact and fire scenario. Due to the lower heat removal capability of the helium as compared to that of water, no noticeable cooling occurs during cask blowdown. Otherwise, the shapes of the curves are similar.

Because of the higher initial temperatures (and corresponding fission gas pressures), some thermally induced ruptures occur between five and seven hours after the accident. Essentially all of the innermost pins rupture. In a more exact calculation, the thermally induced ruptures might increase or decrease by $20 \%$. This variation is not significant for the scoping purpose of this project.

A recent $P N L$ report ${ }^{1}$ contains thermal analyses of a water-cooled truck cask for several fire temperature/duration combinations. The results are different because the analysis technique (number of nodes, and so forth) appears to be more detailed than that for our gauging calculations, the assumed heat load was higher $(11.4 \mathrm{~kW})$, the fuel was positioned in the cask by four annular spacers one inch thick, and the cladding was assumed to fail when the cladding temperature reached $1050^{\circ} \mathrm{F}$. The PNL analysis of a $1850^{\circ} \mathrm{F}$ fire lasting two hours produced a peak fue 1 temperature of $1600^{\circ} \mathrm{F}$ about 4.5 hours after the accident. The first cladding failures occurred at approximately 1.8 hours from the start of the accident, and all cladding was assumed to fail by 2.1 hours after the accident. The effect of the hotter fire temperature assumed and the difference in cask geometry in the PNL report is reflected in the cask inner wall temperature, which was about $1380^{\circ} \mathrm{F}$ shortiy after the fire ended in the PNL report, compared to about $875^{\circ} \mathrm{F}$ for the gauging calculations. The presence of the massive aluminum basket (versus four annular spacers) in the gauging calculations apparently shielded the majority of the fuel pins from the effects of the fire in the early part of the scenario, but caused a delayed cooling of the fuel pins due to the stored heat and to the reduction in convective cooling capability. The net effect is that the peak gauging fuel temperatures are reached in the 12- to 14-hour time frame (estimated since the calculations were terminated at 10 hours), versus the 4 to 5 hour time frame in the PNL calculations. The peak temperatures are not very different, however. Earlier peak temperatures in the gauging calculations would likely have produced thermally induced cladding failures because at the time of high temperatires, the heating rate, $H$, in Equation 3.2 would have been much higher. The lack of thermally induced cladding failures for the water-cooled cask is not considered important for scoping purposes since the base case for the investigation of radionuclide behavior was the helium-cooled cask for which $40 \%$ thermally induced cladding failure was calculated. 


\subsection{UNCERTAINTIES AND CONCLUSIONS}

The major uncertainties involved in these gauging calculations, or in design calculations, are of several different types: initial and boundary conditions, geometry after impact, and physical properties. Each of these will be discussed below.

As was discussed in Section 2, the basic premise of this project is that, regardless of its extremely low probability, a severe SFTA is assumed to have occurred. Furthermore, this project would not produce very meaningful dialogue unless the cask is assumed to be breached; therefore, the authors defined a set of initial and boundary conditions which would ensure a calculated release of radionuclides. Variations in this definition of the assumed accident may have a significant effect on the calculated consequences. However, once these accident conditions are defined in terms of the regulatory process, no further hypothetical cases need be explored for this project.

For example, currently licensed casks are designed for fuel having a relatively high burnup and specific power and a relatively short cooling time of about three months. (See Section 2.) In practice, fuel is seldom shipped unless it is cooled one year or more and not all fuel has the maximum heat generation rate assumed. These design/licensing conservatisms will generally overshadow attempts to introduce realism later in the accident consequence scenario.

Another example occurs in the definition of accident environment(s). The impact (puncture) and/or fire which the cask must withstand will most likely be defined unambiguously. Thus, while it may be difficult to test a cask for a uniform fire of exactiy $1475^{\circ} \mathrm{F}$ for exactly thirty minutes or to measure the actual fire temperature, these initial and boundary conditions are presupposed for the purposes of this project.

The second type of uncertainty is the definition of the geometry of the cask and contents. The cask wall may be assumed to be deformed, the fuel assemblies can be assumed to be displaced nonsymmetrically, or the fue rods can be assumed to be deformed. Generally these uncertainties would increase the calculated temperatures (or at least in the licensing process the most conservative possibility would be chosen). These uncertainties are incorporated either in the initial accident definition or in the calculation of the response of the cask and its contents. The former was discussed in the preceding paragraphs, and the latter is discussed in Section 9. In any case, these uncertainties are considered as input to the thermal-hydraulic gauging calculation.

The third type of uncertainty originates with the physical properties of the fuel, e.g., conductivity, or of the coolant, e.g., convective heat transfer coefficient. While the cask designer no doubt would prefer increased detail in these data, the effect of such increased knowledge on the thermal-hydrauic calculation, and the subsequent effect on the public health from a severe accident scenario would be relatively small. 
In conclusion, the uncertainties in the thermal-hydraulic portion of SFTA are not significant compared to the uncertainties to be discussed in Sections 9 and 10 . 


\section{REFERENCE}

1. H. K. Elder et al., "An Assessment of the Risk of Transporting Spent Nuclear Fuel by Truck," PNL-2588. (November, 1978). 


\subsection{CASK AND FUEL STRUCTURAL GAUGING CALCULATIONS}

\subsection{GENERAL CONSIDERATIONS}

The subject of cask structural response was assessed with the objective of determining a reasonable approach for raising the overall confidence level in the ability of both existing and future casks to withstand severe accident environments. The present criteria specified in 10CFR71 were not used as bounding events. Rather, a set of gauging calcuations were performed to estimate failure thresholds of a representative "reference" cask under a variety of postulated events, and these results were used with other published findings to formulate a set of conclusions and recommendations. The result of the gauging calculations for both the cask and the fuel, e.g., failure threshold estimates, were used to determine priorities for recommendations for research needs.

For the purposes of this report, threats to cask and/or fuel integrity are arranged in four categories: 1) failure of main body due to impact; 2) response of key design features, such as seals and appurtenances; 3) puncture; and 4) fuel response. While these categories are not mutually exclusive, they provide convenient divisions for addressing failure thresholds and development needs.

Gauging calculations were not performed on the key design features; rather, qualitative assessments were made and are noted in Section 11.

\subsection{APPROACH}

Our review of 1 icensed casks and prior research programs in Section 5 noted that almost a11 work had been performed using either the 10CFR71 criteria as measurements of success or as basic research unrelated to specific cask licensing. Little had been done to establish failure thresholds for casks and transported fuel assemblies.

Knowing those thresholds, or at least establishing a clearly defined approach for determining them, was considered an important result of this project, which would yield a number of benefits, including the following:

1. When compared with the expected occurrence frequencies and severities of various transportation accidents, another input is available for establishing priorities among development needs.

2. Quantitative benchmarks would be available.

3. Improved key design features that could result in an appreciably lower probability of public exposure would be identified. 
The primary exception to the statement above regarding lack of failure threshold information, is the PNL report that was published when this project was approximately half complete. The information provided in that report encompassed areas not undertaken by this project, but the approach was similar to that of this project. The PNL report also corroborated many of our results, thus strengthening the conclusions presented here.

The approach taken here was to devise a simplified cask structural assembly as a reference case and analyze it for numerous static and dynamic loadings using basic strength-of-materials methods or empirical correlations in the case of puncture. The methods used are inexact, and in some cases crude approximations, but by carefully choosing assumptions and failure criteria, reasonable bounding values for failure thresholds can be obtained. In cases where the degree of uncertainty is high, recommendations for further work are indicated.

An understanding of failure criteria is necessary to interpret the results properly. Stainless steel ( 300 series) is used as the structural material in most casks and was used for the reference cask here. Depending on heat treatment, such steels can have an ultimate strength of twice yield strength, with failure occurring at $40 \%$ strain or more. However, large deformations cannot be handled by basic calculational techniques, and failure must be assumed to occur in the proximity of yield. The result is a significant amount of conservatism that in general should outweigh errors inherent in the basic calculational techniques.

\subsubsection{Description of Reference Cask}

The reference cask devised for the purpose of scoping calculations is shown schematically in Figure 9.1. It is representative of a generic cask for the licensed types reviewed, but is sufficiently different that caskspecific conclusions may not be drawn.

Dimensions are as follows:

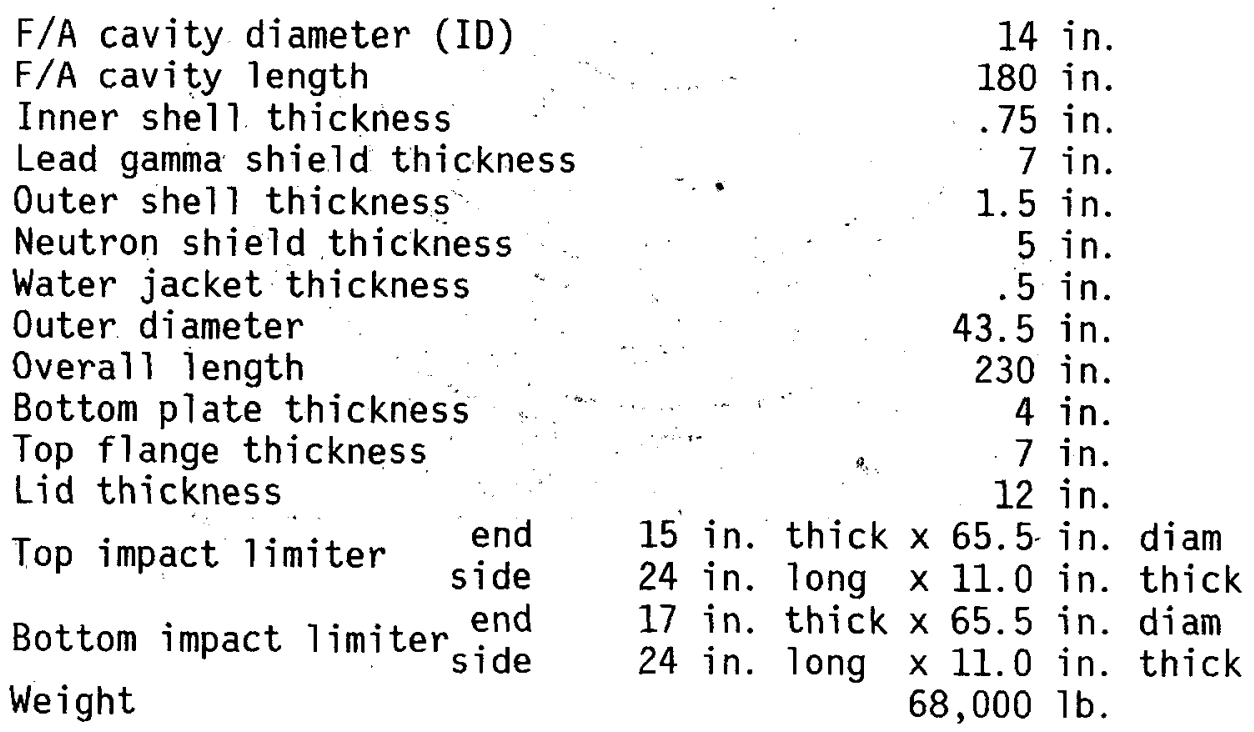



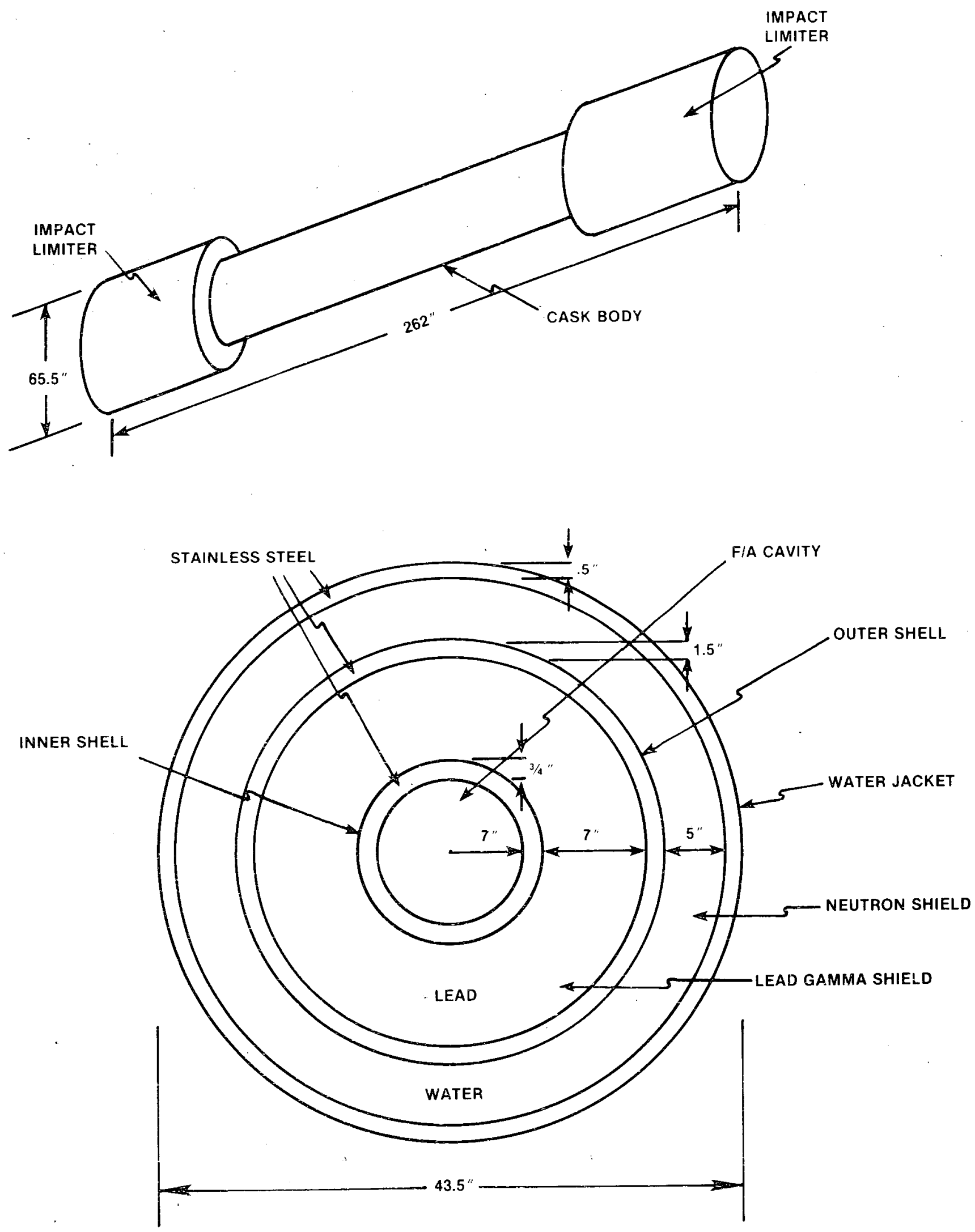

FIGURE 9.1. SCHEMATIC OF REFERENCE CASK 


\subsubsection{Treatment of Fuel Assembly Response}

An LWR fuel assembly geometry is too complex to be treated analyticaliy in detail within the scope of this project. Rather, simple loading conditions were determined that would challenge the integrity of a single rod supported at the spacer grids. A representative rod with the following characteristics is used:
0.D.
0.422 in.
wall thickness
0.024 in.
span between grids
$25.98 \mathrm{in.}$
mass
$0.48 \mathrm{lbm} / \mathrm{in}$.

The cask designs reviewed made no provision for fuel assembly shock absorption, so decelerations were assumed to be transferred directly to the rod. Because a fuel rod is a thin-walled tube, membrane and beam theory should yield good results.

\section{3. CASK-RELATED GAUGING CALCULATIONS}

\subsubsection{Cask Body}

Much work has been done by others in the areas of end and side impact, and this work is not duplicated here. The PNL scoping calculations on a similar reference cask are mentioned in Section 5.

Case 1: Estimate the impact speed necessary to effect gross failure of the cask body through a side-center impact into a rigid abutment.

Using a simple beam formula for stress in the shell

$$
\sigma_{\max }=\frac{M r}{I}
$$

for each of the four shells (jacket, outer; lead, and inner); then superimposing the moments required to yield each, the moment required to fajl the cask is

$$
M_{f}=8.4 \times 10^{6} \mathrm{ft}+\mathrm{b}
$$

using yielding of the inner shelt as a criterion for failure.

To calculate a velocity to fajlure, equate work done in bending the cask to failure to impact energy. As a simple, conservative failure criterion, assume failure if the distance moved off axis by the end of the cask is equal to the gamma shield thickness. 


$$
\begin{gathered}
W=\text { Work }=\frac{2 M}{L_{\text {cask }}} \times t_{\text {lead }}=4.9 \times 10^{6} \mathrm{ft} 1 \mathrm{~b} \\
W=\frac{1}{2} \mathrm{~m}_{\text {cask }} v^{2} \\
v_{\text {failure }}=67 \mathrm{ft} / \mathrm{sec}=46 \mathrm{mph}
\end{gathered}
$$

This result is believed to be extremely conservative because no credit is taken for energy required to displace the lead or for plastic deformation of the shells. Furthermore each cask is actually tested to $30 \mathrm{mph}$ generally with no failure and certainly not gross failure.

An interesting corollary is that if the abutment were a fourfoot diameter concrete column eighteen feet high, the maximum stress induced at midsection by a static load, $2 \mathrm{M} / \mathrm{L}$, is 4,500 psi. This is greater than the average failure strength for concrete, so the abutment is likely to fail before the cask fails.

\subsubsection{Puncture}

Several gauging calculations were run using a puncture correlation found in the literature, 2,3 for blunt steel projectiles impinging normally on flat steel plates. The correlation has been well corroborated by test data and is

$$
v^{2}=\frac{f(D t)^{1.5}}{w^{1.5}}
$$

where

$$
\begin{aligned}
& D \text { is projectile diam. (in.) } \\
& t \text { is target thickness (in.) } \\
& W \text { is projectile weight } \\
& v \text { is impact velocity } \\
& f \text { is a constant }
\end{aligned}
$$

This correlation does not consider the effect of lead backing and is applicable in velocity regimes where the target impact area behaves as a solid, i.e., ordnance velocities.

Case 1: Determine if elastic buckling is a failure mode for high sectional density penetrators.

$$
P_{c r}=\frac{\pi^{2} E I}{L^{2}} \quad \text { for first mode buckling and }
$$

assume the penetrator is cylindrical, then

$$
I=\frac{\pi r^{4}}{2}
$$


Compute L/D for the buckling condition for

$$
\begin{array}{ll}
\text { stee } 1, & L / D=17 \\
\text { al uminum, } & L / D=13 \\
\text { granite, } & L / D=15
\end{array}
$$

These values lead to the conclusion that fixed penetrators are feasible, as penetration distances of only 12-20 inches are required to reach the inner cavity.

Case 2: For typical projectiles, what velocities are required for puncture?

Using the penetration correlation noted earlier, Tables 9.1 and 9.2 give values for the velocity required to puncture a steel plate of thickness $t$ for 8.8 1b., 2 in. diameter and $651 \mathrm{~b}, 4$ in. diameter projectiles respectively.

Because the correlation has been proven to be reasonably accurate for the simple geometry of a blunt projectile onto a flat plate, the values shown in the tables serve to indicate a range of values from which an upper bound for puncture conditions can be selected. Velocity in the range of 400-500 ft/sec or greater would be required for puncture of just the outer shell for the smaller projectile, and greater than $150 \mathrm{ft} / \mathrm{sec}$ for the larger. Generation of such missiles is considered highly unlikely except by military ordnance.

Case 3: If the 68,000 1b. cask drops on a stub or rolls off a vehicle onto a projection at speed, what conditions are required for puncture?

Assuming a total steel thickness of 2.75 in. and ignoring the effect of the lead gamma shield, Table 9.3 gives the velocity required for puncture on a given projection, assuming that the projection doesn't fail, and that incidence is normal. Existence of such low speed accident conditions and penetrator dimensions is considered more likely than the airborne puncture conditions shown in Case 2.

Case 4: How far from normal incidence must the penetrator angle be for the cask to fail the penetrator in bending rather than be punctured?

Assuming a penetrator long enough to reach into the cask inner cavity, Tables 9.4 and 9.5 give the vertical load neces- 
TABLE 9.1

PUNCTURE VELOCITY FOR TARGET THICKNESS

(8.8 1b, 2 in diameter)

\begin{tabular}{ll}
\hline$v\left(\frac{\mathrm{ft}}{\mathrm{sec}}\right)$ & $t(\mathrm{in})$ \\
\hline 50 & 0.07 \\
100 & 0.18 \\
150 & 0.31 \\
200 & 0.46 \\
250 & 0.61 \\
300 & 0.78 \\
400 & 1.2 \\
450 & 1.4 \\
500 & 1.6 \\
550 & 1.8 \\
600 & 2.0 \\
\hline
\end{tabular}

TABLE 9.2

PUNCTURE VELOCITY FOR TARGET THICKNESS

( 65 1b, 4 in diameter)

\begin{tabular}{cc}
\hline \hline$\left(\frac{\mathrm{ft}}{\mathrm{sec}}\right)$ & $t(i n)$ \\
\hline 50 & 0.27 \\
100 & 0.67 \\
150 & 1.01 \\
200 & 1.7 \\
250 & 2.3 \\
300 & 2.9 \\
350 & 3.5 \\
400 & 4.2 \\
450 & 5.0 \\
500 & 5.7 \\
\hline
\end{tabular}


TABLE 9.3

PUNCTURE VELOCITY FOR PENETRATOR DIAMETER (68,000 1b cask, 2.75 in. shel1 thickness)

\begin{tabular}{cr}
\hline \hline$D($ in $)$ & $v\left(\frac{\mathrm{ft}}{\mathrm{sec}}\right)$ \\
\hline 1 & 3.3 \\
2 & 9.4 \\
3 & 17.2 \\
4 & 26.5 \\
5 & 37.0 \\
6 & 48.7 \\
8 & 74.9 \\
9 & 89.4 \\
10 & 105.7 \\
11 & 120.8 \\
12 & 137.6 \\
\hline
\end{tabular}

TABLE 9.4

VERTICAL LOAD TO FAIL, 12-IN. LONG

2-IN. DIAMETER STEEL PROJECTION FOR ANGLE OF INCIDENCE

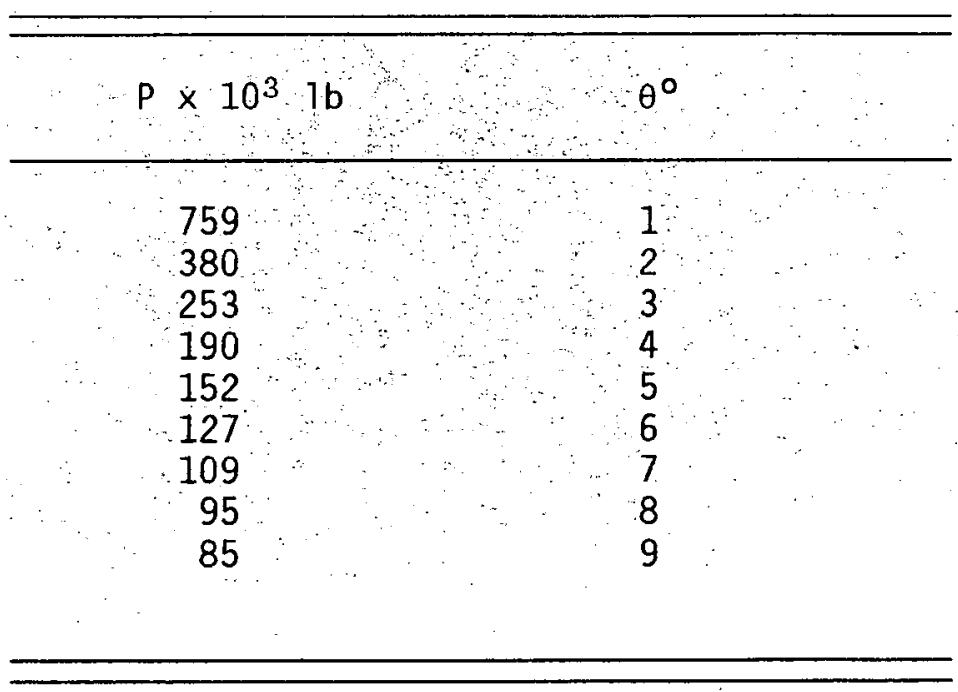


TABLE 9.5

ESTIMATED LOAD IN KIPS TO FAIL STEEL PLATE BY PLUGGING, FOR VARIOUS THICKNESS AND DIAMETER VALUES

\begin{tabular}{|c|c|c|c|c|c|c|c|c|}
\hline$t^{D \rightarrow}$ & 0.5 & 1.0 & 1.5 & 2.0 & 2.5 & 3.0 & 3.5 & 4.0 \\
\hline$\downarrow$ & & & & & & & & \\
\hline 0.5 & 31.4 & 62.8 & 94.2 & 125.6 & 157.0 & 188.0 & 220.0 & 251.0 \\
\hline 1.0 & 62.8 & 125.6 & 188.0 & 251.0 & 314.0 & 378.0 & 440.0 & 503.0 \\
\hline 1.5 & 94.0 & 188.0 & 283.0 & 377.0 & 472.0 & 566.0 & 660.0 & 754.0 \\
\hline 2.0 & 126.0 & 251.0 & 377.0 & 503.0 & 628.0 & 784.0 & 880.0 & 1005.0 \\
\hline \multirow[t]{2}{*}{2.5} & 157.0 & 314.0 & 471.0 & 628.0 & 785.0 & 943.0 & 1100.0 & 1256.0 \\
\hline & & & & & & & & \\
\hline
\end{tabular}


sary to fail the penetrator as a function of angle of incidence and the estimated load required to penetrate a plate for various representative values of plate thickness and penetrator diameter respectively. Plugging failure of the plate is assumed, and the equations are for static conditions.

The tables show, for example, that for a 2-in. diameter penetrator and a 1.5-in. thick target plate, an angle of incidence of less than 2 degrees is required to avoid failing the steel projection.

While Case 3 indicates that a puncture accident may be feasible, the requirement for near-normal incidence significantly diminishes the probability of occurrence.

Conclusions about these four cases are presented in Section 9.5.

\subsection{FUEL ASSEMBLY-RELATED GAUGING CALCULATIONS}

As discussed previously in this section, the fuel assembly calculations dealt primarily with the behavior of one fuel rod subjected to various loadings. Materials data for irradiated Zircaloy were taken from MATPRO assuming a rod temperature of $400^{\circ} \mathrm{F}$ and $800 \mathrm{psi}$ internal pressure. Fuel pellets were assumed not to influence rod behavior except for adding mass.

Case 1: Estimate the deceleration necessary to fail a rod due to side impact.

The rod span between support grids can be treated as a doublecantilevered beam, uniformly loaded. The bending moment at mid-span is

$$
M=\frac{w l^{2}}{12}
$$

Using a failure strength of $58 \mathrm{ksi}$, the acceleration required for failure with no internal pressure is

$$
a_{i}=\frac{12 \sigma I}{r m 1^{2}}
$$

or $79 \mathrm{~g}^{\prime} \mathrm{s}$. Adding internal pressure and using the maximum shear stress yield criterion, the failure deceleration becomes $71 \mathrm{~g}^{\prime} \mathrm{s}$.

Case 2: What deceleration will cause the rod to buckle elastically due to an end drop? 
The equation for elastic buckling is

$$
P_{c r}=\frac{\pi^{2} E I}{L^{2}}
$$

yielding a critical load of $208 \mathrm{lb}$.

Assuming that the rod is held in place vertically by a resistance within the assembly of 105 pounds, the deceleration necessary for buckling is $38 \mathrm{~g}^{\prime} \mathrm{s}$.

Case 3: What loads are required to yield the rod in compression from an on-end drop?

Again assuming an internal pressure of 800 psi and using the maximum shear stress criterion, the failure threshold is found to be $96 \mathrm{~g}^{\prime} \mathrm{s}$., well over the value found for buckling.

\subsection{CONCLUSIONS AND SUMMARY OF UNCERTAINTIES}

The scoping calculations were intended to indicate ranges and upper bounds for failure thresholds for a variety of loads to use as guidelines in formulating recommendations. Conservative assumptions were made in every case, and in some cases, rather crude models were used as the 1 imited scope of this study prohibited use of more sophisticated tools. The process of trying to construct models that were amenable to hand calculations did promote identification of uncertainties as more detailed calculational techniques were considered.

\subsubsection{Cask Body}

Considerable work has been done by others in the area of cask body response, in both the testing and analysis areas. While it is doubtful whether the capability exists to adequately treat the problem of cask response to severe transportation accidents in a general fashion by analysis, it is believed that it is possible to demonstrate beyond a reasonable doubt by a balanced program of testing and analysis that gross failure of a cask body is an extremely unlikely event. Further, it is concluded that the current body of knowledge in this area can be utilized to make a substantial contribution towards achieving this goal.

In the gauging calculations performed for this project, it was decided to attempt to scope the failure threshold for only the broadside impact into a rigid abutment problem because of the extent of work done by Sandia and ORNL in this area. The result was less conservative than the PNL result (which used the low failure criteria of an $8 \mathrm{~cm}$ dent), but still more conservative than the Sandia grade crossing test, in that the latter resulted in only a few $\mathrm{Cc}^{\prime} \mathrm{s}$ of fluid leakage from what appears to be a 
more severe impact. Conservatism in this project includes no consideration of stainless steel ductility or energy absorption in the deformation of materials especially lead.

It is not considered feasible to characterize with a high degree of accuracy the failure thresholds of cask bodies to impact environments by detailed analysis. In addition to the fact that detailed and accurate models for phenomena such as crack propagation, plugging failure, and lead-steel interface slippage are not available, there is an inadequate data base for behavior of the applicable structural materials at high strain rates. It is possible and feasible to perform large deformation dynamic analyses on limited portions of a cask using simplified boundary conditions and failure criteria. It is this capability that can be combined with a program of scale-model and full-scale tests, if necessary, to estabiish conservative failure thresholds.

Based on a review of the aggregate of tests and anaiyses run to date, and on the subjective judgment that impact environments significantly more severe than those considered to date are unlikely, it is our judgment that gross failure of spent fuel casks is unlikely. It is believed that the general issue could be resolved by a balanced program of 1 imited analyses of large deformations with accompanying tests, with the goal of establishing failure thresholds of typical casks, and establishing the likelihood of gross failure by comparing the thresholds with estimates of the probability of accidents of varying severity.

\subsubsection{Cask Puncture}

As noted above, the puncture correlation used here was derived empirically for the case of blunt steel projectiles impinging normally on a flat steel plate, at ordnance velocities. Deviations from those conditions carry reduced credibility, but none of the impact situations considered here deviate widely enough to invalidate the results for bounding purposes.

The literature survey revealed little in the way of purely analytical treatments of penetration phenomena, most work being based on experiments designed for a specific problem. Reference 3 contained a description of a finite element treatment of an oblique penetration problem that correlated surprisingly well. with experiment, but again, the method was not designed for general use. While considerable expertise is believed to exist in DOD-related laboratories, much of the work that has been done is classified. Because of time limitations, a comprehensive search of the penetration mechanics literature was not performed.

Two conclusions were drawn from the gauging puncture calculatons:

1. Airborne missiles generated by means other than military weaponry do not pose a threat to cask integrity. While the probability of a 1- or 2-inch steel bar being propelled at the 300 to $500 \mathrm{ft} / \mathrm{sec}$ necessary for cask puncture at a nearly normal angle to the curved cask surface was not calculated, the effect is believed to be negligible. 
2. The potential for cask puncture from a drop or high-speed impact onto a projection of the necessary material and dimensions cannot be discounted without further evaluations of both the cask's vulnerability to puncture and the probability of such an event.

\subsubsection{Fuel Response}

The area of irradiated fuel assembly response to impact environments was found to entail the greatest uncertainty of the areas surveyed and also to have considerable promise for reduction in the probability of public exposure due to transportation accidents. The complex geometry of a fuel assembly makes it very difficult to treat analytically as a whole, and thus treatment of a single rod was necessitated. Treatment of the buckling problem would probably have to be handled statistically for the complete assembly.

The following conclusions were drawn from the scoping calculations:

1. The reference cask end impact dimension will bottom after a drop of greater than $40 \mathrm{ft}$, resulting in decelerations greater than the $38 \mathrm{~g}$ 's estimated necessary buckle fuel rods. Fuel rod buckling must therefore be considered a credible failure mode.

2. Cask decelerations in the $70 \mathrm{~g}$ range have been calculated and measured for extreme impact conditions such as the grade crossing test at Sandia. As $71 \mathrm{~g}^{\prime} \mathrm{s}$ is estimated to be the fuel rod failure threshold for lateral impacts, this must be considered a credible failure mode if such accidents are considered credible.

3. The direct load transmission path from the cask body results in the fuel assemblies seeing the same loads as the cask body in all cases investigated.

Aside from the uncertainty associated with behavior of the total fuel assembly, the problem of local rod failure due to stress wave propagation is also difficult to calculate with confidence. It is expected that stresses well over yield would be generated near the end of a rod as a result of a credible end impact, but the failure threshold cannot be characterized.

The remaining uncertainty associated with fuel response is in the properties of irradiated Zircaloy. MATPRO contained data for low strain rates, but no data is available for the high strain rates expected under impact conditions. 


\section{REFERENCES}

1. H. K. Elder, et a1., "An Assessment of the Risk of Transporting Spent Nuclear Fuel by Truck," PNL-2588 (November, 1978).

2. R. B. Linderman, J. V. Rotz, G. C. K. Yeh, "Design of Structures for Missile Impact," Bechtel Power Corporation Topical BC-TOP-9A Rev. 2 (September, 1974).

3. Mark L. Wilkins, "Mechanics of Penetration and Perforation," Int. J. Eng. Sci., 16 (1978).

4. M. E. Backman and Werner Goldsmith, "The Mechanics of Penetration of Projectiles into Targets," U. S. Naval Weapons Center, Int. J. Engng. Sci., 16, No. 1-A (1978).

5. E. Limberger, "A Simple Mode1 for Predicting Energy Dissipation of Thin Plates Being Perforated by 'Hard' Missiles," Nuclear Engineering and Design 51 (1979).

6. H. Kolsky, "Stress Waves in Solids," Dover Publishers, 1963.

7. E. F. Bruhn, "Analysis and Design of Flight Vehicle Structures," TriState Offset Co., 1968.

8. Timoshenko and Goodier, "Theory of Elasticity," McGraw-Hi11, Inc., 1951. 


\subsection{FISSION PRODUCT RELEASE, TRANSPORT AND \\ DEPOSITION GAUGING CALCULATIONS}

\subsection{INTRODUCTION}

The potential for cask breach was discussed in Section 9. The next step is to evaluate the release of radionuclides from such a breach. This section presents a series of analytical calculations of the release, transport, and deposition of fission product species and forms under different SFTA conditions. The purpose of carrying out these calculations was to provide insight regarding the sensitivity of various parameters, as well as to help evaluate the importance of the several areas of inadequate information that were identified in Sections 6.0 and 7.0.

The section is divided into three major parts: 1) estimation of volatile releases; 2) estimation of particulate releases; and 3) examination of public health impacts of release variations. The first two parts describe the results of using general cask characteristics and accident conditions, developed in other portions of the study (Sections 8.0 and 9.0), to estimate possible ranges of fission product SFTA releases. The ranges reflect current uncertainties in fission product and fuel behavior with respect to both the prompt (initial) release of radioactive material and the delayed (extended) release of radioactive material from spent fuel shipping casks in postulated severe accidents. The third part of the section employs standard radiation dose analysis methods to estimate public health impacts from the several ranges and modes of potential SFTA releases. Contributions to total radiation doses caused by individual components or parameter assumptions in the release source terms are then used to assess the relative importance of these factors to accurate SFTA radiological source term development. A series of conclusions and recommendations then follows regarding work that is needed for better definition of source term magnitudes.

\subsection{ESTIMATION OF VOLATILE RELEASES}

\subsubsection{Release of Volatiles from Fuel Pellets}

Volatile fission products can be released from the gas space of any fuel rods which are damaged during an SFTA. Accumulation of these volatile species in the rod gaps occurs by release from the fuel pellets during reactor operation and during any significant post-irradiation temperature transient, as may be associated with an SFTA. Both of these sources were considered in the present work. For evaluating in-reactor releases, the operating characteristics of core and fuel were modeled after those of Diablo Canyon, Unit $2^{1}$; some pertinent characteristics are listed in Table 10.1. For the releases during an SFTA, the temperature histories of three representative fuel rods were used, as presented in Section 8.0, and shown in Figure 10.1. 
Reference Nuclear Plant

Total Core Power

Average Linear Power

Average Specific Power

Average Burnup at Discharge

Fuel Assembly Rod Array

Fuel Assembly Loading

Fuel Pellet Diameter

Fuel Cooling Before Transport
Diablo Canyon, Unit 2

3411 MWt

$5.44 \mathrm{~kW} / \mathrm{ft}$

ح $30 \mathrm{MW} / \mathrm{MTU}$

ح 33000 MWD/MTU

$17 \times 17$ (264 Fueled)

0.46 MTU

0.3225 in

180 days 


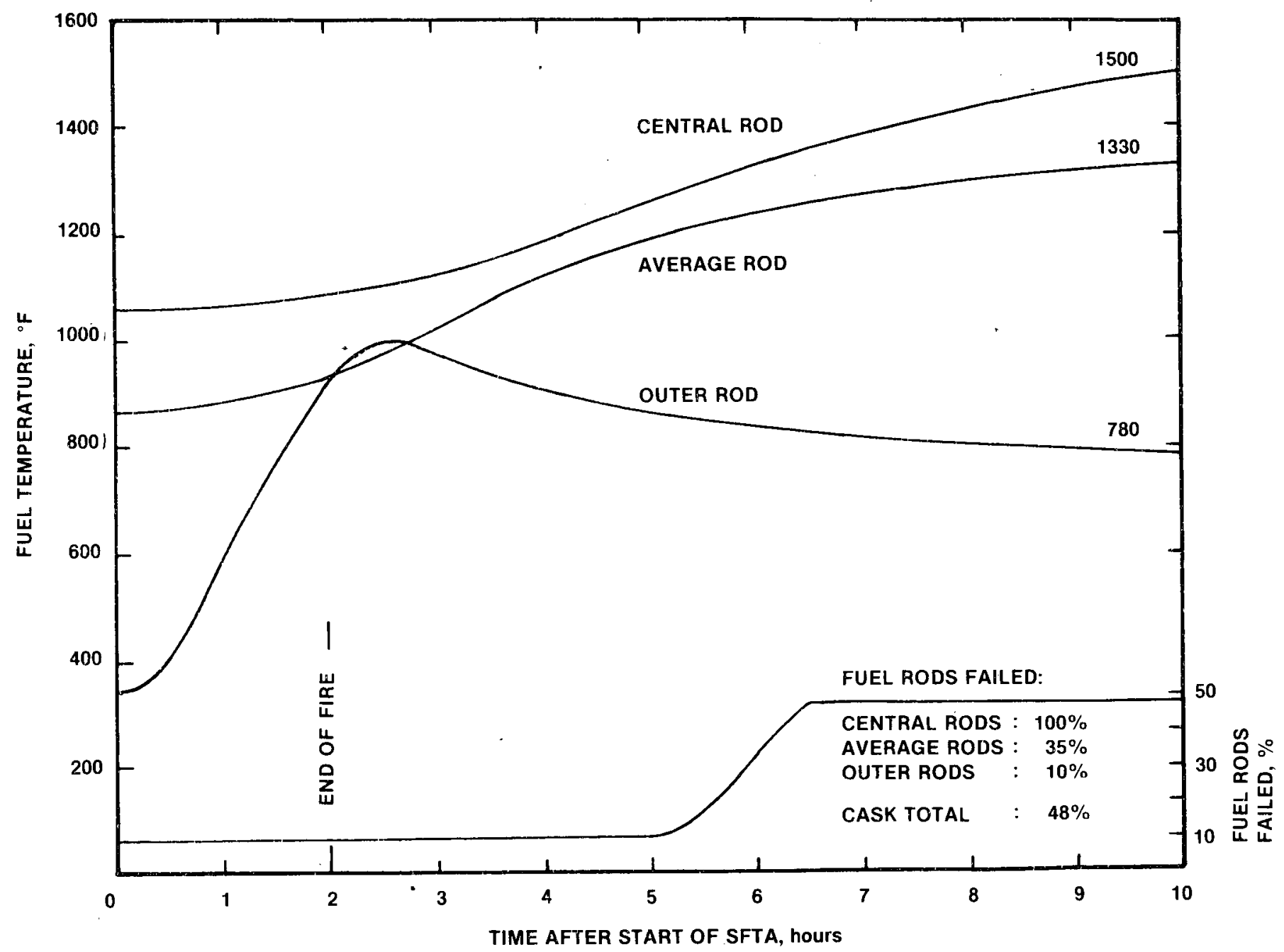

FIGURE 10.1. FUEL TEMPERATURES AND ROD FAILURES FOR THREE REPRESENTATIVE RODS IN HELIUM-COOLED CASK IN SFTA INVOLVING IMPACT AND FIRE 


\subsubsection{FRCRL2/REGAP, Summary of Methods and Inputs}

Releases of the volatile species from the fuel pellets were calculated by use of the computer code FRCRL2 ${ }^{2}$ with some modifications. This is a twopart code: subroutine REGAP determines the fractional releases of stable and radioactive volatiles from fuel during reactor operation; the main routine FRCRL2 determines the fractional releases during the SFTA thermal transient. FRCRL2 and REGAP are gas diffusion-modeled codes in which the fractional release of a volatile species is a function of a diffusion parameter, $D^{\prime}$, defined by the equation

where $\quad D^{\prime}(I, T)$ is the diffusion parameter for gaseous species

$$
D^{\prime}(I, T)=D_{0}^{\prime}(I) e^{-Q(I) / R T(r, Z)} K(B)
$$
I at temperature $T$, $\mathrm{sec}^{-1}$

\begin{tabular}{|c|c|}
\hline$D_{0}^{1}(I)$ & $\begin{array}{l}\text { is the limiting value of the diffusion } \\
\text { paraneter for species I, sec-1 }\end{array}$ \\
\hline$D(I)$ & $\begin{array}{l}\text { is Arrhenius activation energy for species } I \text {, } \\
\text { cal/g-atom }\end{array}$ \\
\hline $\mathrm{R}$ & is universal gas constant, cal/g-atom ${ }^{{ }} \mathrm{K}$ \\
\hline$T(r, z)$ & $\begin{array}{l}\text { is fuel temperature at radius } r \text { and axial } \\
\text { location } z \text { in reactor core or in shipping cask } \\
\text { cavity, }{ }_{K}\end{array}$ \\
\hline$K(B)$ & $\begin{array}{l}\text { is a correction factor for diffusion enhance- } \\
\text { ment due to accumulated burnup } B \text {, defined } \\
\text { below }\end{array}$ \\
\hline
\end{tabular}

The diffusion parameter $D^{\prime}$ is a function of local. fuel temperature. In REGAP, the fuel temperature is calculated as a function of fuel pellet radius (because of the high rate of internal heat generation during reactor operation) at each of 11 axia positions in the core. These calculations are based on the reactor operating power level and the core axial power profile, supplied as inputs to REGAP. Fuel temperatures are treated as constant with time. Temperature variation across the core diameter was neglected because all ten fuel assemblies loaded into the shipping cask are assumed to have been discharged from the same central core zone across which there is little power gradient.

In FRCRL2, temperature data for each of three fuel rods are supplied as code inputs, "based on the results of the heat transfer calculations described in Section 8:0." The three fuel rods are representative of the central, geometric average and outer fuel regions within the loaded spent fuel cask cavity. Fuel temperatures are treated as constant across the pellet diameters and along the lengths of the three rods, but they are variable with time as the thermal transient progresses. 
Two sets of data were employed for the limiting diffusion parameters $D^{\prime}$ and the activation energies Q. One source of data is a proposed standard model for calculation of fission gas releases from $\mathrm{UO}_{2}$, as drafted by Subcommittee 5.4 of the American Nuclear Society. This proposed model has not been adopted formal 1.y.; although the data were published ${ }^{3}$ in May, 1979, they may be subject to change. The second source of data is "Calcuiation of Gap Release of Radioactive Fission Products" in WASH-1400. " These two sets of data, listed in Table 10.2, were used to evaluate the sensitivity of predicted gaseous releases to the values used for the diffusion parameters.

The burnup correction factor $K$ is a multiplier of the diffusion parameter which accounts for an observed fuel burnup enhancement of fission product diffusion. Two expressions were used for the correction, one recommended by ANS Subcommittee 5.4, the other presented in WASH-1400 ${ }^{4}$. The corrections apply an order-of-magnitude increase to the diffusion parameters for each 14000 or 25000 MWD/MTU of accrued burnup and may be expressed as follows:

$$
\begin{array}{ll}
K(B)=10^{\left(\frac{B V(z)}{14000}\right)} & \text { (ANS Subcommittee 5.4) } \\
\left.K(B)=10^{\left(\frac{B V(z)}{25000}\right.}-1\right) & (\text { WASH-1400) }
\end{array}
$$

where $B$ is average accumulated fuel burnup, MWD/MTU $V(z)$ is the local (axial) core power profile factor.

Because accumulated burnup $B$ is a function of time since reactor startup, the correction factor is most influential for the diffusion of those fission product atoms produced late in the period of reactor operation. Therefore, for in-reactor release calculations, the burnup correction is averaged by subroutine REGAP over the last half-life of each species preceding reactor shutdown and fuel discharge, or over the full period of reactor operation, whichever is the shorter time. For example, if two isotopes have half-1ives of 10 days and 500 days, the corrections are 220 and 70 respectively, using the ANS model and an average burnup of 33000 MWD/MTU. For the in-cask release calculations, the correction is evaluated by FRCRL2 at the final accumulated burnup and therefore has a maximum value of 230 .

A low-temperature fission gas release mode ${ }^{3}$ was also incorporated into REGAP to allow for minimum releases due to phenomena such as primary atomic knockout from the fuel surfaces in those core regions where low fuel temperatures inhibit diffusion to the surfaces. This mode ${ }^{3}$ was suggested by the ANS Subcommittee 5.4. 
TABLE 10.2

LIMITING DIFFUSION PARAMETERS AND ACTIVATION

ENERGIES FOR VOLATILE FISSION PRODUCTS

\begin{tabular}{|c|c|c|c|c|c|c|}
\hline \multirow[b]{2}{*}{ Species } & \multicolumn{3}{|c|}{ ANS Subcommittee 5.4} & \multicolumn{3}{|c|}{ WASH- 1400} \\
\hline & $D_{0}^{1}, \sec ^{-1}$ & $\mathrm{Q}$, & cal/g-atom & $D_{0}^{1}, \sec ^{-1}$ & Q & ,cal/g-atom \\
\hline $\mathrm{Kr} \& \mathrm{Xe}$ & 0.610 & & 72300 & 0.206 & & 61400 \\
\hline$I_{2}$ & 0.351 & , & 63400 & 0.00261 & & 40400 \\
\hline $\mathrm{CS}$ & 0.0462 & & 60200 & 0.00122 & & 34000 \\
\hline $\mathrm{Te}$ & 671.0 & & 84800 & 0.0473 & & 48400 \\
\hline
\end{tabular}




\subsubsection{Results of Calculations of Volatile Releases}

Results of REGAP calculations of the releases of volatiles from operating fuel pellets are given in Table 10.3, based on the reactor core characteristics as listed in Table 10.1. The radionuclides considered are those of significant inventory after 180 days of fuel cooling.

Releases were determined using both diffusion models as discussed in Section 10.2.1.1, each with and without its burnup enhancement correction factor. Table 10.3 shows that the burnup corrections are significant in the present analysis, especially for the ANS diffusion model, which generally increases the predicted releases by an order of magnitude for the longer-lived and stable species, and a factor of 20 for the shorter-lived species. Agreement between the burnup-enhanced ANS and WASH-1400 models is good except for $\mathrm{Cs}$ : the releases of noble gases, $\mathrm{I}_{2}$, and Te predicted by the WASH-1400 model average 15 percent less than those predicted by the ANS mode 1; for $\mathrm{Cs}$, it predicts a 150 percent greater release than the ANS model.

The diffusional releases of volatiles from the fuel pellets during an SFTA temperature transient, calculated by FRCRL2, are shown in Table 10.4. The present analysis used only the values of the diffusion parameters and burnup correction as recommended by the ANS Subcommittee 5.4. The releases which occur during the SFTA thermal transient are small compared to those during reactor operation, i.e., about one percent as great. If the loaded shipping cask remains at normal thermal equilibrium for three weeks prior to the SFTA temperature transient, the releases for that time are calculated to be no more than 20 percent of those which occur during the transient (i.e., $\sim 0.2 \%$ ) and so are negligible.

The masses of stable and very long-lived isotopes of the volatile fission products greatly exceed the masses of the short-lived isotopes. Therefore, they dominate certain non-radiological factors such as vapor pressure. When considering the effects of such factors, the total pellet release fractions calculated for the duration of reactor operation and for the SFTA thermal transient may be summarized as in Table 10.5.

The releases of volatiles from fuel pellets discussed in this section are for the case of a passive He-cooled spent fuel shipping cask design. However, the results are also directly applicable to a water-cooled cask design because the dominant releases occur during reactor operation, independent of shipping cask characteristics. As may be seen by comparing Figures 10.1 and 10.2 , the fuel pellet temperature transient for a watercooled cask design involved in the SFTA fire is less severe than for the He-cooled design. Also the normal equilibrium fuel temperatures during shipment are much lower. Therefore, the post-discharge releases of volatiles from the fuel pellets would be much less than one percent of the inreactor releases, an inconsequential increment. 
TABLE 10.3

RESULTS OF REGAP CALCULATIONS OF RELEASES OF

VOLATILES FROM FUEL PELLETS

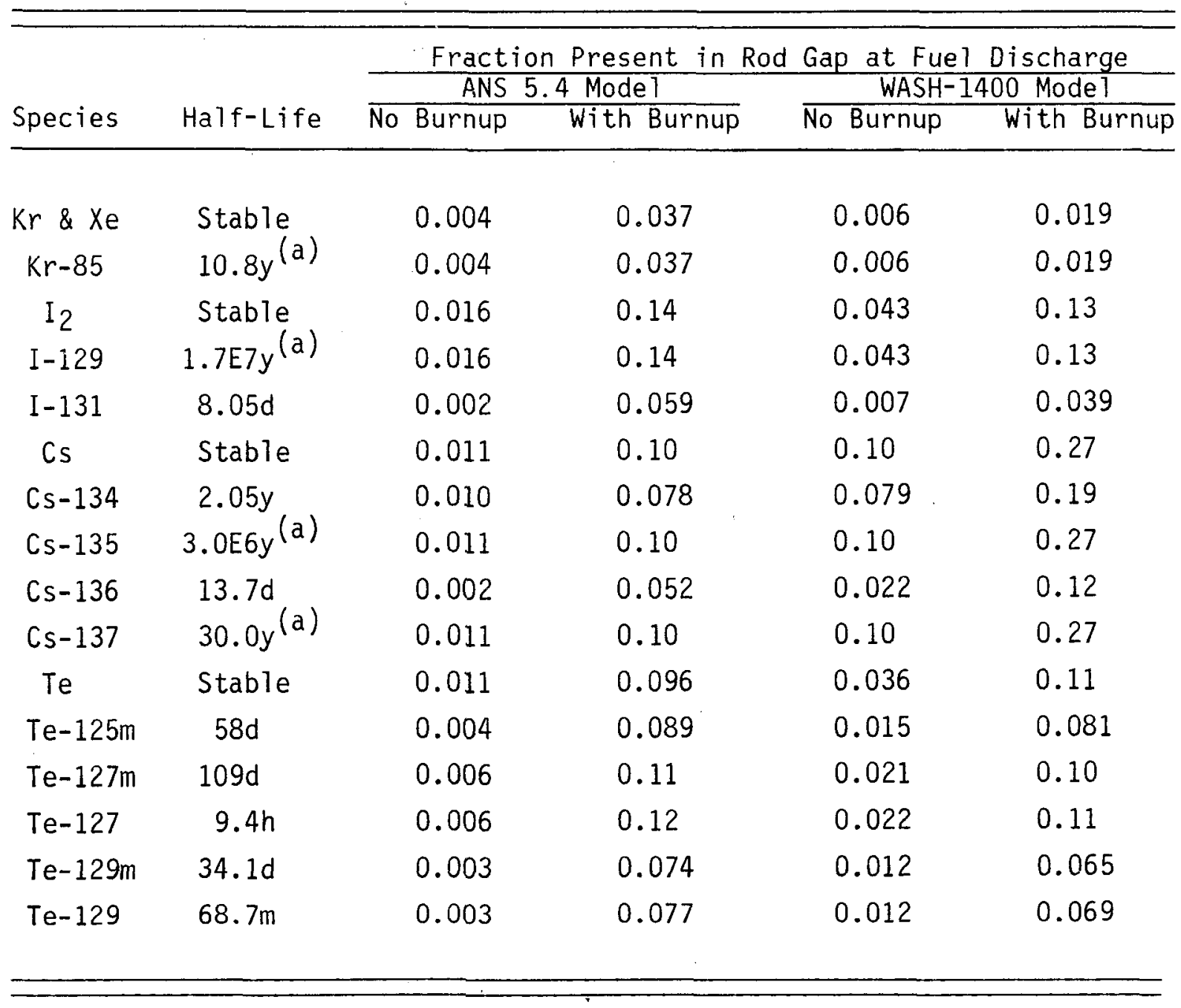

(a) This species was treated as stable in the calculations because of its long half-life. 
TABLE 10.4

RESULTS OF FRCRL2 CALCULATIONS OF RELEASES OF VOLATILES FROM FUEL PELLETS OF THREE REPRESENTATIVE RODS DURING SFTA TEMPERATURE TRANSIENT

\begin{tabular}{ccccccc}
\hline & \multicolumn{5}{c}{ Fractional Release } \\
\cline { 3 - 6 } Species & $\begin{array}{c}\text { Central } \\
\text { Rod }\end{array}$ & $\begin{array}{c}\text { Average } \\
\text { Rod }\end{array}$ & $\begin{array}{c}\text { Outer } \\
\text { Rod }\end{array}$ & $\begin{array}{c}\text { Total Cask } \\
\text { Inventory }\end{array}$ \\
\hline Kr \& Xe & $2 \times 10^{-4}$ & $6 \times 10^{-5}$ & $5 \times 10^{-7}$ & $1 \times 10^{-4}$ \\
$I_{2}$ & $2 \times 10^{-3}$ & $4 \times 10^{-4}$ & $7 \times 10^{-6}$ & $6 \times 10^{-4}$ \\
$C_{s}$ & $1 \times 10^{-3}$ & $3 \times 10^{-4}$ & $7 \times 10^{-6}$ & $5 \times 10^{-4}$ \\
Te & $4 \times 10^{-4}$ & $7 \times 10^{-5}$ & $3 \times 10^{-7}$ & $2 \times 10^{-4}$ \\
\hline
\end{tabular}

(a) Release fraction developed from releases for each type of rod according to an estimated distribution of these rods in a filled shipping cask. 
TABLE 10.5

SUMMARY OF CALCULATED TOTAL RELEASES OF VOLATILES FROM FUEL PELLETS (FRCRL2/REGAP)

\begin{tabular}{ccc}
\hline & Fraction Present In Fuel Rod Gaps \\
\hline Species & $\begin{array}{c}\text { ANS 5.4 Model } \\
\text { With Burnup }\end{array}$ & $\begin{array}{c}\text { WASH-1400 Model } \\
\text { with Burnup }\end{array}$ \\
\hline $\mathrm{Kr} \& \mathrm{Xe}$ & 0.04 & 0.02 \\
$\mathrm{I}_{2}$ & 0.14 & 0.13 \\
$\mathrm{Cs}$ & 0.10 & 0.27 \\
$\mathrm{Te}$ & 0.10 & 0.11 \\
\hline
\end{tabular}




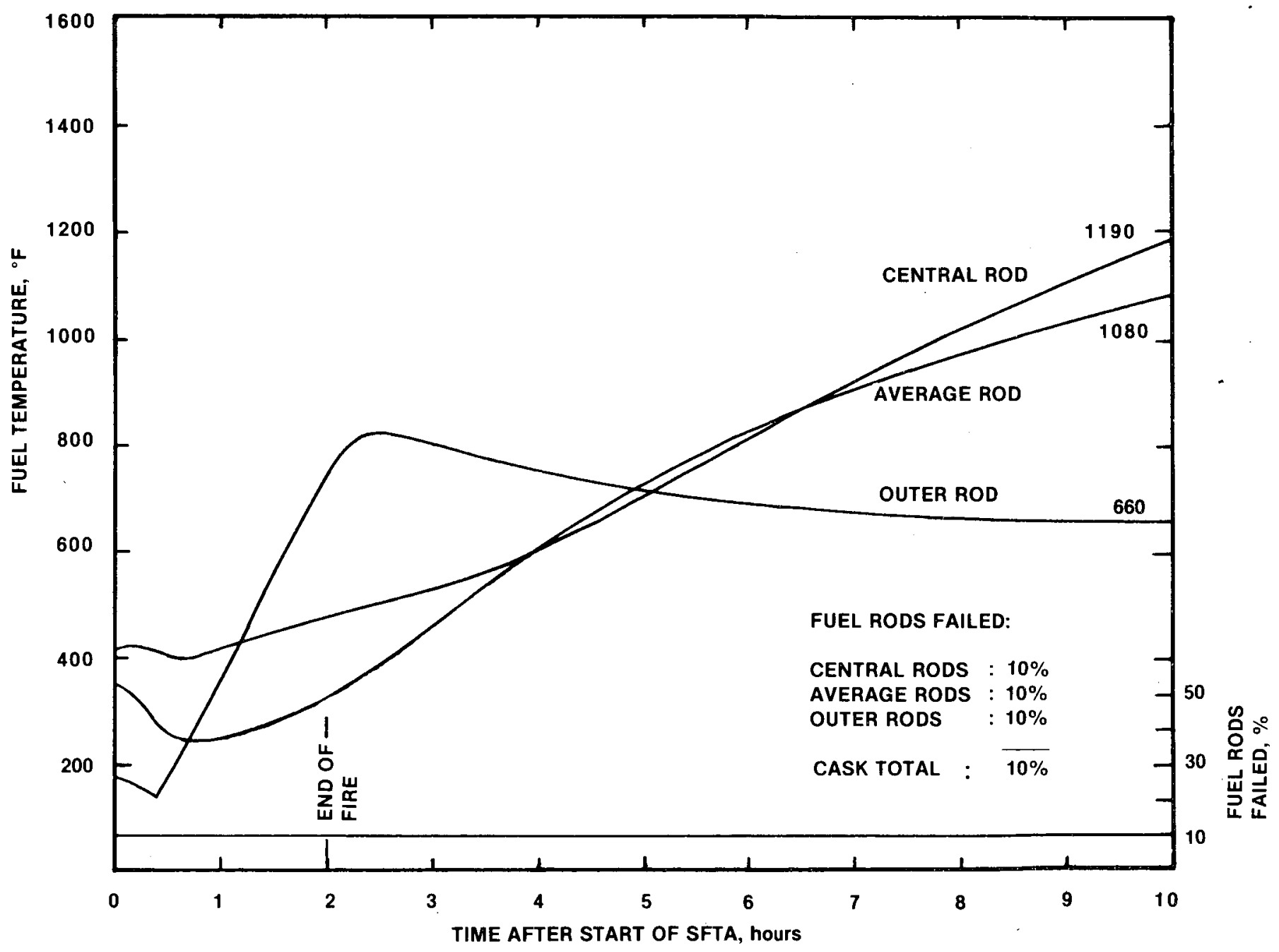

FIGURE 10.2. FUEL TEMPERATURES AND ROD FAILURES FOR THREE REPRESENTATIVE RODS IN WATER-COOLED CASK IN SFTA INVOLVING IMPACT AND FIRE 


\subsubsection{Estimation of Releases from Casks}

Some potential releases of volatile fission products (krypton, iodine, cesium, and tellurium nuclides) from shipping casks during severe SFTA events are developed in this subsection. This required consideration of three basic factors: 1) the fraction of fuel rod cladding failures; 2) the volatility of fission product forms; and 3 ) the discharge characteristics of the bulk fluid from the cask interior. A reference accident scenario was utilized for broad definition of conditions for evaluating these factors, and then the effects of possible variations in the scenario, caused by different accident assumptions or cask characteristics, were examined on an individual basis.

\subsubsection{Basic Accident Scenario and General Conditions}

The basic accident scenario used here corresponds to the scenario for a helium-cooled cask that was used for conducting thermal-hydraulic (Section 8.0) gauging calculations. The scenario involves a severe impact event, causing a $20 \mathrm{~cm}^{2}$ opening through the cask boundary and failure of $10 \%$ of the fuel rods, followed by an extended ( 2 hour) $1475^{\circ} \mathrm{F}$ fire which leads to creep rupture failure of an additional $40 \%$ of the fuel rods. The scenario thus includes most of the features and driving forces that would be important in determining fission product source terms.

The initial fuel cladding failures should result in some escape of the plenum and gap fission product inventories from the damaged rods and from the leaking cask. The driving forces for escape would be provided by depressurization flow of helium fill-gas from the damaged rods and by blowdown of the helium coolant from the cask cavity. Application of standard fluid flow formulas indicates that the depressurization and blowdown processes would probably occur within seconds. Therefore a prompt mode of volatile fission product release should result from the initial impact event. The cask blowdown from an initial pressure of 24 psig would result in discharge of about $60 \%$ of the gaseous or vapor contents of the cask cavity. The portion of the fuel rod gap fission product inventories that would be present as vapors for release would depend on the volatilities of the particular chemical forms that might exist. In the present gauging calculations, widely different assumptions regarding chemical forms were made to determine possible ranges of release values. The assumed chemical forms consisted essentially of an elemental form (high volatility) and a reaction product form (low volatility) for each volatile fission product. The forms considered and the pertinent vapor pressure data for each are listed in Table 10.6.

As the cask blowdown and prompt release are occurring, the cask and its contents begin to experience an extended thermal excursion due to the postulated external fire. A prediction of internal temperatures and of the time schedule for fuel rod cladding failures is given in Figure 10.1. During this time the available volatile fission products from the initially damaged rods, along with the rods which undergo creep rupture, are subject to release from the cask cavity. The driving force for release 
TABLE 10.6

POTENTIAL VOLATILE FISSION PRODUCT CHEMICAL

FORMS AND VAPOR PRESSURE DATA

\begin{tabular}{|c|c|c|c|c|c|}
\hline $\begin{array}{c}\text { Chemical } \\
\text { Form }\end{array}$ & $\frac{\text { Vapor Pressure }}{A}$ & $\frac{\text { Equation }}{B}$ & $\frac{\text { Coeffieients }}{C}$ & $\begin{array}{c}\text { Vapor Pressure } \\
\text { at } 700^{\circ} \mathrm{K} \\
(\mathrm{mm} \mathrm{HG})\end{array}$ & Reference \\
\hline $\mathrm{Kr}$ & Always $G$ & iaseous ${ }^{(2)}$ & & $>760$ & 5 \\
\hline $\mathrm{I}_{2}$ & 3205 & 23.65 & -5.18 & $>760$ & 6 \\
\hline CsI & 9678 & 20.35 & -3.52 & $3.2 \times 10-4$ & 6 \\
\hline Cs & 4075 & 11.38 & -1.45 & $2.7 \times 10^{1}$ & 6 \\
\hline $\mathrm{CsOH}$ & 5953 & 7.63 & 0.0 & $1.3 \times 10^{-1}$ & 7 \\
\hline $\mathrm{Cs}_{2} \mathrm{UO}_{4}$ & $7.6 \times 10^{-6}$ & $\mathrm{mmHG}$ at & $1088^{\circ} \mathrm{KY}(3)$ & $<7.6 \times 10^{-6}$ & 8 \\
\hline$\cdot \mathrm{Te}_{2}$ & 7980 & 22.58 & -4.32 & $7.7 \times 10^{-2}$ & 6 \\
\hline $\mathrm{TeO}_{2}$ & 13940 & 23.51 & -3.52 & $3.8 \times 10^{-7}$ & 6 \\
\hline
\end{tabular}

(1) $\log P(m m H G)=-\frac{A}{T}+B+C \log T$

where $P$ is the vapor pressure in $\mathrm{mmHG}$

$T$ is the temperature in ${ }^{\circ} \mathrm{K}$

(2) Krypton boils at a temperature of $121^{\circ} \mathrm{K}$ at 1 atmosphere.

(3) Only one vapor pressure value was found for a cesium uranate but this indicates quite low volatility at the temperatures of interest in the present study; i.e., below about $1000^{\circ} \mathrm{K}$. 
depends on thermal expansion of the residual cavity gases combined with some helium which is added during cladding ruptures. However, evaluation of these leakage sources indicated that only about $50 \%$ of the gaseous or vapor contents of the cask cavity remaining after blowdown would be discharged over the entire 10-hour period shown in Figure 10.1. The portion of the exposed volatile fission products that would escape by this delayed release mode would depend to a large extent on vaporization equilibria for the different chemical forms of the fission products at the cavity thermal conditions. The same assumptions concerning possible differences in chemical forms were used to scope variations in the delayed release mode as were used for the prompt release mode.

\subsubsection{Helium Cooled Cask Release Fraction Ranges}

On the basis of the above general accident scenario and conditions, a set of release fraction ranges for the volatile fission products was developed. The calculations represent a quasi-steady-state approach, using gross fluid discharge fractions and fission product vaporization equilibria instead of detailed rate process and mass-transfer models. This approach was adopted because of the considerable uncertainties concerning chemical forms of fission products and the complicated internal geometry of typical spent fuel shipping casks. The results of the computations are presented in Table 10.7, and the bases for these results are summarized below.

1) REGAP calculations as reported in Section 10.2.1 were used to specify fuel rod gap inventories of the volatile fission products. These inventories in terms of fraction released from the fuel were,

$$
\begin{aligned}
& \mathrm{Kr}=0.04 \\
& \mathrm{I}=0.14 \\
& \mathrm{Cs}=0.10 \\
& \mathrm{Te}=0.10
\end{aligned}
$$

2) $10 \%$ of the rods were assumed to fail at impact

3) $60 \%$ of the cask cavity gases would be released during helium blowdown

4) The vapor fraction of each fission product form in the cavity during blowdown was determined by its vapor pressure, assuming instantaneous equilibration of the gap inventory from the failed rods throughout the cavity volume and surfaces. A cavity volume of $1.29 \times 10^{6} \mathrm{~cm}^{3}\left(45.6 \mathrm{ft}^{3}\right)$ was used along with a uniform temperature of $800^{\circ} \mathrm{F}\left(700^{\circ} \mathrm{K}\right)$ which represents a reasonable average initial temperature according to figure 10.1 . 
TABLE 10.7

RESULTS OF GAUGING CALCULATIONS OF VOLATILE FISSION PRODUCT RELEASES FOR A SFTA INVOLVING IMPACT PLUS FIRE

\begin{tabular}{|c|c|c|c|c|c|c|}
\hline \multirow[b]{2}{*}{$\begin{array}{l}\text { Fission } \\
\text { Product } \\
\text { Form(1) } \\
\end{array}$} & \multicolumn{4}{|c|}{ Fraction of Cask Inventory Released from the Cask } & \multicolumn{2}{|c|}{ Total Fraction Released $(2)$} \\
\hline & $\begin{array}{l}\text { Prompt } \\
\text { Release }\end{array}$ & \multicolumn{3}{|c|}{$\begin{array}{lrr}\text { Delayed Release vs. Cavity } & \text { Temperature } \\
800^{\circ} \mathrm{F} & 1000^{\circ} \mathrm{F} & 1200^{\circ} \mathrm{F}\end{array}$} & $\begin{array}{l}\text { Low } \\
\text { Limit }\end{array}$ & $\begin{array}{l}\text { High } \\
\text { Limit }\end{array}$ \\
\hline $\mathrm{Kr}$ & $2.5 \times 10^{-3}$ & $8.8 \times 10^{-3}$ & $8.8 \times 10^{-3}$ & $8.8 \times 10^{-3}$ & $1.1 \times 10^{-2}$ & $1.1 \times 10^{-2}$ \\
\hline $\mathrm{I}_{2}$ & $8.7 \times 10^{-3}$ & $3.1 \times 10^{-2}$ & $3.1 \times 10^{-2}$ & $3.1 \times 10^{-2}$ & $4.0 \times 10^{-2}$ & $4.0 \times 10^{-2}$ \\
\hline $\operatorname{CsI}$ & $3.1 \times 10^{-7}$ & $2.5 \times 10^{-7}$ & $1.5 \times 10^{-5}$ & $3.1 \times 10^{-4}$ & $5.6 \times 10^{-7}$ & $3.1 \times 10^{-4}$ \\
\hline $\mathrm{Cs}$ & $5.1 \times 10^{-3}$ & $4.5 \times 10^{-3}$ & $1.8 \times 10^{-2}$ & $2.2 \times 10^{-2}$ & $9.6 \times 10^{-3}$ & $2.7 \times 10^{-2}$ \\
\hline $\mathrm{Cs}_{2} \mathrm{UO}_{4}$ & $<1.5 \times 10^{-9}$ & $<1.0 \times 10^{-9}$ & $<1.0 \times 10^{-9}$ & $<1.0 \times 10^{-9}$ & $<2.5 \times 10^{-9}$ & $<2.5 \times 10^{-9}$ \\
\hline $\mathrm{Te}_{2}$ & $6.2 \times 10^{-4}$ & $5.4 \times 10^{-5}$ & $1.0 \times 10^{-3}$ & $7.9 \times 10^{-3}$ & $6.7 \times 10^{-4}$ & $8.5 \times 10^{-3}$ \\
\hline $\mathrm{TeO}_{2}$ & $2.7 \times 10^{-10}$ & $2.2 \times 10^{-10}$ & $7.7 \times 10^{-8}$ & $4.3 \times 10^{-6}$ & $4.9 \times 10^{-10}$ & $4.3 \times 10^{-6}$ \\
\hline
\end{tabular}

(1) A high volatility and a low volatility form wass assumed for fission products iodine, cesium, and tellurium.

(2) The values under "low $1 \mathrm{imit"}$ " are the sum of the prompt release and the delayed release for $800^{\circ} \mathrm{F}$ cavity temperature. The values under "high limit" are the sum of the prompt release and the delayed release for $1200^{\circ} \mathrm{F}$ cavity temperature. 
5) $40 \%$ of the rods were assumed to fail during the extended thermal excursion

6) $50 \%$ of the cavity volume remaining after blowdown was assumed displaced during the thermal excursion phase

7) The vapor fraction of each fission product form in the cavity during the thermal excursion period was determined by its vapor pressure, assuming equilibration of the gap inventory from all failed rods throughout the cask cavity. Since the cask internal temperatures change somewhat during the 10-hour period, these vapor fractions were evaluated at three temperatures: $800^{\circ} \mathrm{F}, 1000^{\circ} \mathrm{F}$, and $1200^{\circ} \mathrm{F}$.

The data in Table 10.7 include separate prompt and delayed release fractions for several alternate volatile fission product forms; iodine as elemental iodine or as cesium iodide, cesium as elemental cesium or as a cesium uranate, and tellurium as elemental tellurium or as tellurium dioxide. In the last two columns of the table two sets of predicted total releases are given which represent in one case a low estimate (based on vaporization equilibrium at a relatively low cavity temperature during delayed release) and in the other case a high estimate (based on vaporization equilibrium at a relatively high cavity temperature during delayed release). Substantial differences between the two limits occur among the less volatile chemical forms.

\subsubsection{Water Cooled Cask Release Variations}

The water coolant blowdown requires nearly one-half hour and expels effectively all the fluid, leaving a steam atmosphere in the cavity. Fuel rods that rupture on impact would release mobile gap-inventory fission products into liquid water in the cavity. The water at about $400^{\circ} \mathrm{F}$ would then have access to fuel within the damaged rods and to gap fission products that were not liberated during fuel rod depressurization. Water at this temperature would probably dissolve remaining gap iodine, cesium, and tellurium forms if the water could thoroughly infiltrate the broken fuel rods. Water at this temperature might al so rapidiy leach these soluble species from whatever fraction of the fuel it could intimately contact.

If the temperature dependence indicated for the rate of leaching of industrial glasses ${ }^{9}$ would be applicable to aqueous leaching of high burnup $\mathrm{UO}_{2}$, then leach rates at $400^{\circ} \mathrm{F}$ could be about $10^{3}$ times faster than at room temperature. Since room temperature leach rátes for cesium ${ }^{10}$ (one of the most soluble fission products) would suggest a one-half hour leach fraction of about $2 \times 10^{-4}$; the potential. Teach fraction of $400^{\circ} \mathrm{F}$ might be about $2 \times 10^{-1}$. Such rapid leaching would require nearly ideal conditions and almost the whole fuel column in the broken rods would have to be leached before this source of volatile (and soluble except for $\mathrm{Kr}$ ) fission product activity would be equal to that produced by dissolution of the gap activity in the broken fuel rods. 
Neither complete leaching of the fuel columns nor complete dissolution of the gap activity would appear likely. However, since the actual amounts are unknown, it would seem conservative to assume that the equivalent of the total gap inventory could be taken into solution by the cask coolant before the end of blowdown. For $10 \%$ failed fuel rods this corresponds to cask inventory release fractions of $1.4 \times 10^{-2}$ for iodine, $1.0 \times 10^{-2}$ for cesium, and $1.0 \times 10^{-2}$ for tellurium. The gap inventory of insoluble krypton gas would be liberated at cladding failure giving a corresponding cask inventory release fraction of $4.0 \times 10^{-3}$. Al1 these species should escape the cask cavity during the coolant blowdown. They would then probably-form an airborne source outside the cask as the discharging hot water flashes to steam. Consequently, the total volatile fission product release fractions for the severe SFTA involving a water-cooled cask would be similar to the high-limit values given in Table 10.7 (helium-cooled cask) for the most volatile forms of these fission products. Therefore, the range of total release fractions for the helium-cooled cask case encompasses the potential releases for the water-cooled cask case.

\subsubsection{Synthesis of Releases for the Fuel Assembly Ejection Accident}

Another very severe SFTA was postulated in which an entire spent fuel assembly would be ejected from a shipping cask and impact a solid object. This accident was postulated to provide a mechanism for evaluating the significance of direct radiation doses arising from fuel debris outside the cask relative to radiation doses received from airborne sources. Such an event was assumed to result in impact failure of all fuel rods in the ejected assembly. An accident of this severity could also, as a worst case, result in failure of all fuel rods in the nine other assemblies remaining in the cask. Therefore airborne sources would be released from an accident of this type and nearby persons who might be in the path of the airborne source would be exposed to this hazard as well as the direct radiation field from the ejected assembly.

In attempting to estimate airborne sources for the accident, the release of volatile fission product gap inventories must be considered along with the potential for additional volatile fission product releases caused by oxidation of the $\mathrm{UO}_{2}$ fuel. The latter mechanism would be expected for the ejected fuel assembly since its temperature at the time of the accident could be as high as $1000^{\circ} \mathrm{F}$ and the accident would expose the hot $\mathrm{UO}_{2}$ directly to air. Under these conditions data are available ${ }^{11}$ which indicate that complete oxidation to $\mathrm{U}_{3} \mathrm{O}_{8}$ could occur in one to two hours. The fuel assemblies remaining in the damaged shipping cask would also probably undergo some $\mathrm{UO}_{2}$ oxidation and in the extreme all the fuel might be oxidized. The oxidation process would liberate volatile fission products. At temperatures of 400 to $600^{\circ} \mathrm{C}\left(750\right.$ to $1110^{\circ} \mathrm{F}$ ) experimental data indicate the following fission product release fractions ${ }^{12}$ :

$\begin{array}{ll}\text { Krypton } & 0.1 \\ \text { Iodine } & 0.2 \\ \text { Cesium } & 0.003 \\ \text { Tellurium } & 0.001 \\ \text { Ruthenium } & 0.001\end{array}$


Note that ruthenium has become another contributor to the release of volatiles because under these conditions it can form volatile oxides.

On the basis of the above observations a set of special volatile fission product release estimates was developed for the fuel assembly ejection accident scenario. The results for both a low and a high estimate case are given in Table 10.8. The general basis for the low and high estimates was the addition of fuel oxidation triggered releases to the fission product releases that would occur without oxidation. The latter releases thus depend on assumed chemical forms and these also affect the low and high estimate total values.

\subsection{ESTIMATION OF PARTICULATE RELEASES}

In addition to the release of volatile fission products, release of fuel dust is also possible in severe SFTA events. Since fuel material contains the whole collection of fission products, nonvolatile as well as volatile, the scope of the hazard represented by respirable fuel dust should be assessed. The available data on release of such particulates is quite limited, but the following subsections provide some rough estimates which are of use in evaluating the significance of fuel dust releases.

\subsubsection{Fuel Dust Releases from Fuel Rods}

Fuel dust or particulates which might be present within high burnup spent fuel rods could experience some release upon cladding failure. In the general accident scenarios described earlier (Section 10.2.2.1), cladding failures occur in the initial impact phase and in the extended cask heating phase only if temperatures become high enough to cause creep rupture. The mechanical forces associated with impact failure could create fuel particulates beyond what might be present in a fuel rod before the accident. Thermal creep rupture would probably not cause further particulate formation, however. In both failure modes the rapid depressurization that should follow cladding rupture would tend to sweep some part of the particulates from the rod into the cask cavity.

\subsubsection{Particulate Release Estimate for the Impact'Mode}

No direct data were located during the present study that could be used to define a particulate release fraction for this mode. Therefore it was decided to adopt the often-used non-mechanistic assumption of $1 \%$ release of non-voiatile materials in severe accident events. To obtain the fraction of fuel in the cask that would be released to the cavity, the above quantity was multiplied by the fraction of fuel rods assumed to fail during the impact event. This procedure was used for severe accidents involving either a helium-cooled or the water-cooled cask. The procedure was also used for the very severe accident in which a fuel assembly was postulated to experience ejection from the cask into a solid object. 
TABLE 10.8

ESTIMATED VOLATILE FISSION PRODUCT RELEASES FOR THE FUEL ASSEMBLY EJECTION ACCIDENT

\begin{tabular}{ccc}
\hline $\begin{array}{c}\text { Fission } \\
\text { Product }\end{array}$ & \multicolumn{2}{c}{ Fraction of Cask Inventory Released to Atmosphere } \\
\hline $\mathrm{Kr}^{(3)}$ & Low Limit(1) & High Limit(2) \\
$\mathrm{I}^{(4)}$ & $3 \times 10^{-2}$ & $1 \times 10^{-1}$ \\
$\mathrm{Cs}^{(5)}$ & $3 \times 10^{-2}$ & $3 \times 10^{-1}$ \\
$\mathrm{Te}^{(6)}$ & $3 \times 10^{-4}$ & $1 \times 10^{-1}$ \\
$\mathrm{Ru}^{(7)}$ & $1 \times 10^{-4}$ & $1 \times 10^{-1}$ \\
\hline
\end{tabular}

(1) Low limit based on impact failure of only the ejected fuel assembly. Fuel assemblies in cask intact. Gap inventories assumed to be reaction product forms.

(2) High limit based on impact failure of all fuel assemblies and the most volatile form of gap species.

(3) Release of gaseous gap inventory plus oxidation-liberated krypton from exposed fuel.

(4) Release of gaseous gap inventory (CsI assumed oxidized to $\mathrm{I}_{2}$ ) plus oxidation-liberated iodine from exposed fuel.

(5) Release of gaseous gap inventory plus oxidation-7iberated cesium from exposed fuel. The low limit values assume oxidation would not affect the low volatility of gap cesium.

(6) Release of gaseous gap inventory plus oxidation-liberated tellurium from exposed fuel. The low limit values assume oxidation would not affect the low volatility of gap tellurium.

(7) Release of oxidation-liberated ruthenium from exposed fuel. 
The particle size distribution of the released fuel dust is quite speculative and would be expected to depend on the exact conditions associated with the impact event. However, radiological hazard assessment requires some assumption regarding what fraction of the source lies in the human respirable size range, that is, the. weight fraction which includes particles having aerodynamic diameters of about 10 microns or less. For the purposes of the present work, two alternative assumptions were made. The first case conservatively assumed that all the released fuel dust would be in the respirable size range. The second case utilized the semi-quantitative experimental observation, made in an ORNL ${ }^{13}$ study of fuel particulate escape during simple fuel rod burst tests, that only about $2 \%$ by weight of the ejected particulates were fine enough to remain airborne in the flow apparatus so that they were collected on a downstream absolute filter.

On the basis of the above assumptions, the two alternative release estimates for respirable fuel particulates from the impact mode used in these gauging calculations were:

\section{1) $1 \times 10^{-2} \times$ fraction of rods broken \\ 2) $2 \times 10^{-4} \times$ fraction of rods broken}

\subsubsection{Particulate Release Estimate for Creep Rupture Mode}

The ORNL experiments mentioned above provide some basis for estimating fuel dust release fractions during thermally induced creep rupture of fuel rods since those tests specifically simulated this mode of fuel rod failure. The tests were done with one-foot lengths of high-burnup fuel rods which were sealed by end fixtures and pressurized with helium before undergoing a scheduled heating which produced cladding creep rupture. Measurements of fuel particulate escape from four rupture tests yielded an average release fraction of 250 parts per million $(\mathrm{ppm})$. As noted earlier, only about $2 \%$ of the released mass was in the form of particles that were small enough to escape the furnace tube and reach a downstream absolute filter. The one-foot section of fuel rod used in the tests is roughly one-tenth of the length of a commercial fuel rod: Due to flow restrictions, caused by a narrow gap or cracked and shifted fuel pellets, particulates very far removed from the location of the creep rupture would not be likely to escape from a failed rod. Therefore, it was decided that the $250 \mathrm{ppm}$ release fraction would pertain only to the fuel inventory in approximately $10 \%$ of a full length fuel rod. On this basis the release estimate for respirable fuel particulates from the creep rupture mode used in the gauging calculations would be:

$5 \times 10^{-7} \times$ fraction of rods which undergo creep rupture 


\subsubsection{Combined Fuel Rod Particulate Releases}

The total fuel dust releases from fuel rods for SFTA scenarios would be a combination of release due to initial impact failure and release due to thermal creep rupture. The combined releases for the three types of SFTA scenarios are summarized in Table 10.9. Inspection of values in the table rapidly indicates that estimated release fractions for the creep rupture mode are small compared to those for the impact mode.

\subsubsection{Fuel Dust Release From Casks}

\subsubsection{Release of the Impact Mode Particulates}

The driving force for release of fuel particulates from a helium-cooled cask cavity would be provided by leakage of the internal atmosphere. During the initial blowdown phase the discharge rate would be relatively high. Therefore, limited time would be available for aerosol settling so that particles in the respirable size range should experience the same release as the helium coolant, which would be about $60 \%$ (Section 10.2.2). Some simplified calculations for particles larger than the respirable size range indicated the degree of retention by settling in the cask cavity would depend on the location of the aerosol dispersal (the location of rod failure caused by the impact event) relative to the leakage opening through the cask wall. If the two locations were adjacent, then much of the larger particulate material might escape, but if the two locations were at opposite ends of the cask, then very little of the larger particulate material might escape. This uncertainty, however, was judged not to be particularly important in the present analyses because the larger particles that might escape would be expected to settle out near the cask and because these particles would not be respirable even if they might travel some distance from the cask. On the basis of the above observations, the respirable portion of the fuel particulates produced by the impact mode would likely experience a $60 \%$ release from the helium-cooled cask cavity during blowdown. A worst case assumption of $100 \%$ release was also considered credible if the location of rod damage were near the cask opening.

In the case of the water-cooled cask the initial release of fuel dust from broken fuel rods would be to a liquid water phase. Particle settling velocities would be much slower in water than in helium, but the time required for blowdown is much longer for a water-cooled cask. Boiling and turbulence in the coolant would tend to keep the particles suspended so that they would escape from the cask with the fluid. Therefore, the cask releases of respirable particulates were assumed to be $100 \%$ for the water cask case. Escaping large particles were also assumed to settle out near the cask and not constitute part of the atmospheric source term.

\subsubsection{Release of the Creep Rupture Mode Particulates}

Impact plus fire accident scenarios may lead to conditions in which fuel rod creep rupture would be predicted. At the time when creep ruptures 
TABLE 10.9

FUEL ROD PARTICULATE RELEASE ESTIMATES

\begin{tabular}{lcccccc}
\hline & \multicolumn{2}{c}{ Fraction of Fuel } & Inventory Released from Rods \\
\cline { 2 - 6 } $\begin{array}{l}\text { Cask and SFTA } \\
\text { Scenario }\end{array}$ & $\frac{\text { Impact Mode }}{\text { Low }}$ & High & $\begin{array}{c}\text { Creep Rupture } \\
\text { Mode }\end{array}$ & $\frac{\text { Total }}{\text { Low }}$ & High \\
\hline $\begin{array}{l}\text { He-cooled cask } \\
\text { Impact + fire(2) }\end{array}$ & $2 \times 10^{-5}$ & $1 \times 10^{-3}$ & $2 \times 10^{-7}$ & $2 \times 10^{-5}$ & $1 \times 10^{-3}$ \\
$\begin{array}{l}\text { Water-cooled cask } \\
\text { Impact + fire(3) }\end{array}$ & $2 \times 10^{-5}$ & $1 \times 10^{-3}$ & 0 & $2 \times 10^{-5}$ & $1 \times 10^{-3}$ \\
$\begin{array}{l}\text { He-cooled cask } \\
\text { Assembly ejection (4) }\end{array}$ & $2 \times 10^{-5}$ & $1 \times 10^{-2}$ & 0 & $2 \times 10^{-5}$ & $1 \times 10^{-2}$
\end{tabular}

(1) Particulates assumed to be in respirable size range

(2) $10 \%$ rod failure at impact; $40 \%$ rod failure by creep rupture

(3) $10 \%$ rod failure at impact; no rod failure by creep rupture

(4) Low value assumes only rods in the ejected assembly fail and lower impact mode fraction release applies. High value assumes all rods (both in the ejected assembly and those left in the open cask) fail and higher impact mode fraction release applies 
would occur, the leak rate from the cask cavity would be low. In fact, the estimated leak rate corresponds to a linear velocity in the cavity of only about $0.06 \mathrm{~cm} / \mathrm{sec}$. At this velocity, the time required for particulates, released near the mid-point of a fuel rod, to travel to one end of the cavity would be about one hour. Some simple settling rate calculations for various fuel particle sizes indicated that particles having diameters greater than about 0.4 microns (aerodynamic diameter of about 1.3 microns) would probably settle out before reaching the end of the cavity. Although the size distribution of the fine particles is unknown, the above result suggests that particles at the larger end of the respirable size range would not escape the cask. However, convective turbulence in the cavity space could interfere with particle settling and increase the escape fraction. Because of these uncertainties, the approach taken in the present work was to assume complete escape of the respirable particulates liberated during fuel rod creep rupture. Actually this parameter is not very important in the overall analyses because the estimated creep rupture fuel dust source is much smaller than that from the impact failure mode.

\subsubsection{Combined Cask Particulate Releases}

The total fuel dust cask releases for SFTA scenarios can now be summarized by combining the fuel rod particulates release fraction estimates from Section 10.3.1.3 with the pertinent cask escape fractions. The result of performing this exercise are given in Table 10.10. Releases from the impact mode dominate the total release fraction estimates. Even in the helium-cooled cask impact plus fire scenario, in which $40 \%$ of the rods were assumed to undergo creep rupture, the cask release from this mode was estimated to be a factor of 50 to 5000 less than that from the impact mode. This result is essentially due to the judgment that the impact mode probably involves stronger particulate dispersal forces, and the dispersal would be coincident with the process of coolant blowdown. In constrast the creep rupture mode involves less mechanical action, and it occurs at a time when cask leakage rates would be rather low.

\subsection{EXAMINATION OF PUBLIC HEALTH IMPACT OF RELEASE VARIATIONS}

\subsubsection{Dose Model for Airborne Sources}

The impact upon public health and safety due to airborne sources from an SFTA was assessed in terms of the radiation doses which could be received by persons present in the vicinity of the accidents. Airborne source terms were varied to reflect possible differences in accident scenarios and in source mitigation, and to assist in identifying what airborne source parameters may require better definition.

The consequences of an SFTA, i.e., the public health and safety impact, were evaluated by use of the computer code RSRCON. This model was developed during the Reactor Safety Study and is discussed in the Draft Report of the study ${ }^{\mathbf{1 4}}$. It computes dose consequences due to the release of a number of radionuclides to the environment, for combinations of weather 
TABLE 10.10

CASK PARTICULATE RELEASE ESTIMATES

\begin{tabular}{|c|c|c|c|c|c|}
\hline \multirow{3}{*}{$\begin{array}{l}\text { Cask and SFTA } \\
\text { Scenario }\end{array}$} & \multicolumn{5}{|c|}{ Fraction of fuel Inventory Released from Cask ${ }^{(1)}$} \\
\hline & \multicolumn{2}{|c|}{ Impact Mode } & \multirow{2}{*}{$\begin{array}{l}\text { Creep Rupture } \\
\text { Mode }\end{array}$} & \multicolumn{2}{|c|}{ Total } \\
\hline & Low & High & & Low & High \\
\hline $\begin{array}{l}\text { He- cooled cask } \\
\text { Impact }+ \text { fire( } 2)\end{array}$ & $1 \times 10^{-5}$ & $1 \times 10^{-3}$ & $2 \times 10^{-7}$ & $1 \times 10^{-5}$ & $1 \times 10^{-3}$ \\
\hline $\begin{array}{l}\text { Water-cooled cassk } \\
\text { Impact + fire }(3)\end{array}$ & $2 \times 10^{-5}$ & $1 \times 10^{-3}$ & 0 & $2 \times 10^{-5}$ & $1 \times 10^{-3}$ \\
\hline $\begin{array}{l}\text { He-cooled cask } \\
\text { Assembly ejection }\end{array}$ & $2 \times 10^{-5}$ & $1 \times 10^{-2}$ & 0 & $2 \times 10^{-5}$ & $1 \times 10^{-2}$ \\
\hline
\end{tabular}

(1) Particulates assumed to be in respirable size range

(2) Low value based on rod release from Table 10.3.1 and $60 \%$ escape from cask. High value based on rod release from Table 10.3.1 and $100 \%$ escape from cask.

(3) Values assume $100 \%$ escape of rod releases from cask or cask not effective in retaining any impact mode particulates 
conditions and population distributions. However, the interest in the present analysis was a comparison of doses due only to variations in source terms. Therefore, only one weather condition was considered: a wind speed of $2 \mathrm{~m} / \mathrm{sec}$ at Pasquill atmospheric stability Class D (neutral conditions), with a plume width of $15 \mathrm{deg}$ in the horizontal plane; all releases were considered to be puff releases at ground level. Likewise, only one population distribution was used: one person $/ \mathrm{km}^{2}$ out to 100 miles, with no evacuation. The calculated population dose commitment (in man-rem) will scale directly for any other population density.

Two radiation dose pathways were considered. The first is a direct external irradiation, or shine, both from the passing radioactive cloud and from radioactivity deposited on the ground by fallout from the cloud. Cloud shine persists throughout the time of its transit past a point in space. Ground shine was integrated over one day following deposition because evacuation of affected persons should be accomplished within a day if considered necessary. The second dose pathway is inhalation of radionuclides from the passing cloud into the lungs, from here they may translocate preferentially to critical body organs. All airborne radionuclides were assumed to be present as gases or as respirable-size particles. Each combination of radionuclide and body organ displays unique translocation and elimination rates which define dose conversion factors, which are discussed below. Radiation doses due to inhalation were integrated over a 50-year commitment time. Doses received from both external shine and from inhalation were determined for five body organs: the whole body, lungs, bone, thyroid, and gastro-intestinal tract.

The doses to the five body organs were calculated by the RSRCON code for each of 27 nuclides deemed to be of radiological significance after 180 days of fuel cooling. Eleven of these nuclides are fission products which are volatile or semi-volatile at normal fuel-operating temperatures and at the SFTA transient temperatures. They diffuse from the fuel pellets and are available for gaseous or vaporous release from damaged fuel rods, as discussed in Section 10.2.1. Nine non-volatile fission product nuclides are included also because they were known to be important dose contributors from the inhalation of particulate spent fuel aerosols. The remaining seven nuclides are radiologically important actinides which would be present in fuel particles.

The 27 nuclides are listed in Table 10.11, along with their half-lifes and cask inventories. Inventory data were taken from ORNL-4451 ${ }^{15}$, in which analyses are based on Diablo Canyon fuel with burnup of 33000 MWD/MTU as used in Section 10.2.1 above.

Dose conversion factors are listed in Table 10.12, based on data presented in ORNL-4992 ${ }^{16}$. Dose calculations with the RSRCON code were performed on a unit-release basis. This is, the dose conversion factors for a given nuclide were used with an assumed unit release (one percent) of that nuclide inventory outside the shipping cask. When considering postulated SFTA scenarios in which releases of individual nuclides differ from one percent, the consequences are directly proportioned to the actual percentages of releases. 
TABLE 10.11

NUCLIDES OF RADIOLOGICAL SIGNIFICANCE AND

THEIR CASK INVENTORIES

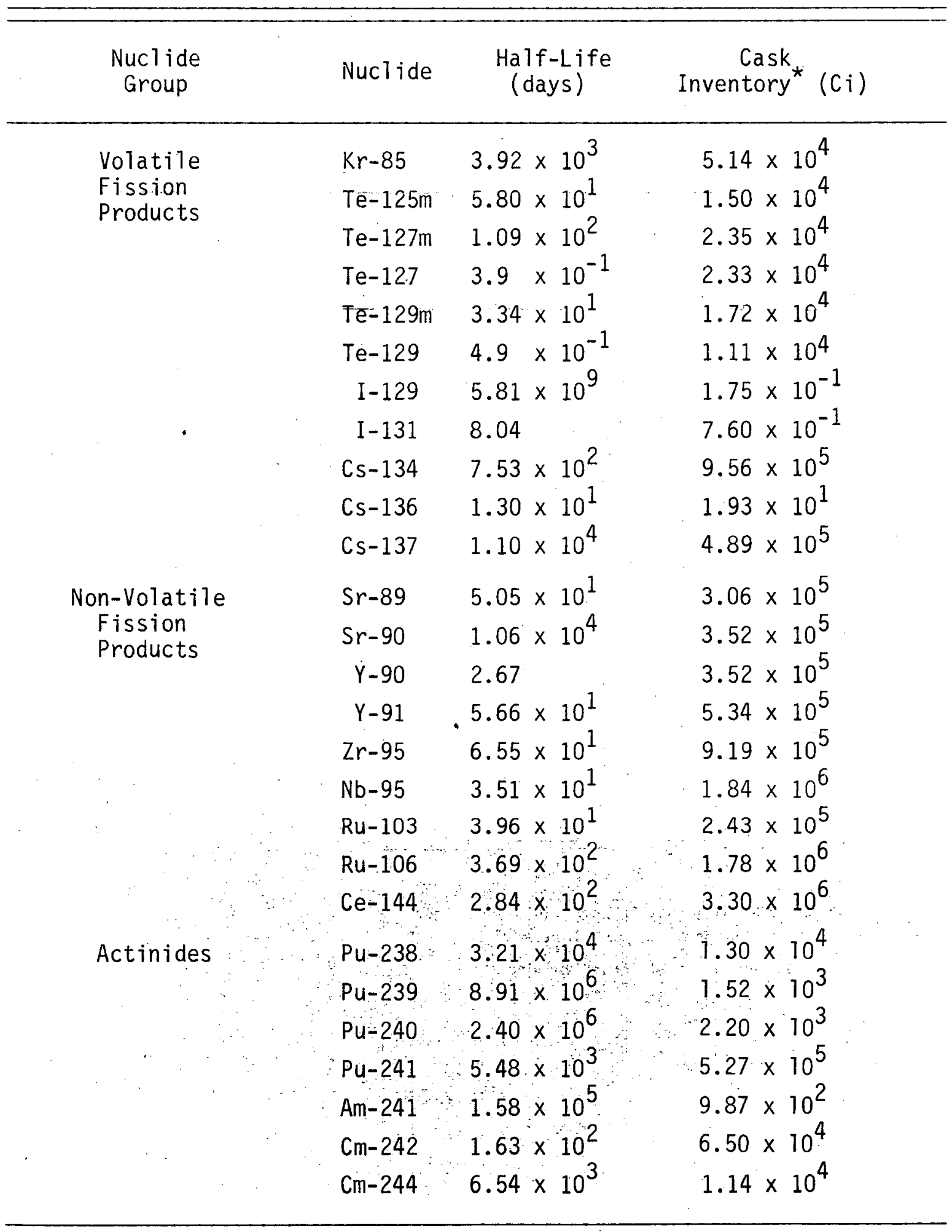

*Total inventory for 10 Diablo Canyon fuel assemblies irradiated to 33000 MWD/MTU; after 180 days cooling. 
TABLE 10.12

DOSE CONVERSION FACTORS USED WITH RSRCON

\begin{tabular}{|c|c|c|c|c|c|c|c|}
\hline \multirow[b]{2}{*}{ Nuclide } & \multicolumn{7}{|c|}{ Dose Conversion Factors for Shine and Inhalation" } \\
\hline & Ground Shine & Cloud Shine & Whole Body & Lungs & Bone & Thyroid & G.1. Tract \\
\hline $\mathrm{Kr}-85$ & 0.037 & $5.8 \times 10^{-4}$ & 0.0 & 0.0 & 0.0 & 0.0 & 0.0 \\
\hline Te-125m & 2.5 & 0.010 & 0.72 & 50. & 3.6 & 1.2 & 11. \\
\hline$T e-127 m$ & 0.77 & $2.6 \times 10^{-3}$ & 1.7 & 160. & 12. & 3.5 & 24. \\
\hline Te-127 & 0.074 & $1.1 \times 10^{-3}$ & 0.036 & 0.85 & 0.17 & 0.12 & 7.1 \\
\hline Te-129m & 2.1 & 0.011 & 4.4 & 200 & 18. & 6.7 & 53. \\
\hline Te-129 & 1.5 & 0.019 & 0.020 & 0.34 & 0.051 & 0.043 & 2.1 \\
\hline $1-129$ & 1.5 & $7.0 \times 10^{-3}$ & 7.0 & 90. & 0.0 & 5700 & 5.3 \\
\hline $1-131$ & 6.8 & 0.11 & 2.6 & 21. & 0.0 & 1400 & 21. \\
\hline$C s-134$ & 27. & 0.44 & 56. & 12. & 37. & 0.0 & 2.1 \\
\hline Cs-136 & 37. & 0.60 & 5.6 & 0.70 & 2.7 & 0.0 & 1.1 \\
\hline$C s-137$ & 9.5 & 0.0 & 32. & 9.5 & 61. & 0.0 & 1.1 \\
\hline $\mathrm{Sr}-89$ & 0.0 & 0.0 & 12. & 180. & 410. & 0.0 & 43. \\
\hline $5 r-90$ & 0.0 & 0.0 & 220. & 1200 & 1100 & 0.0 & 36. \\
\hline$Y-90$ & 0.0 & 0.0 & 0.62 & 21 & 23. & 0.0 & 71. \\
\hline$Y-91$ & 0.040 & $6.8 \times 10^{-4}$ & 9.0 & 210 & 330. & 0.0 & 43. \\
\hline $2 r-95$ & 13. & 0.20 & 16. & 200 & 62. & 0.0 & 21. \\
\hline $\mathrm{Nb}-95$ & 14. & 0.22 & 4.5 & 65. & 13. & 0.0 & 11. \\
\hline$R u-103$ & 9.2 & 0.14 & 0.77 & 76. & 1.6 & 0.0 & 21. \\
\hline$R u-106$ & 3.3 & 0.0 & 2.9 & 1200 & 20. & 0.0 & 110. \\
\hline Ce-144 & 0.89 & $5.5 \times 10^{-3}$ & 65. & 1000 & 1200 & 0.0 & 110. \\
\hline Pu-238 & 0.30 & $4.2 \times 10^{-4}$ & $1.4 \times 10^{5}$ & $1.9 \times 10^{5}$ & $5.7 \times 10^{6}$ & 0.0 & 43. \\
\hline Pu-239 & 0.11 & $1.7 \times 10^{-4}$ & $1.6 \times 10^{5}$ & $1.8 \times 10^{5}$ & $6.6 \times 10^{6}$ & 0.0 & 43. \\
\hline$P u-240$ & 0.26 & $3.6 \times 10^{-4}$ & $1.6 \times 10^{5}$ & $1.8 \times 10^{5}$ & $6.6 \times 10^{6}$ & 0.0 & 43. \\
\hline$P u-241$ & $2.0 \times 10^{-6}$ & 0.0 & $2.5 \times 10^{3}$ & $1.6 \times 10^{2}$ & $1.2 \times 10^{5}$ & 0.0 & 1.1 \\
\hline Am-241 & 1.4 & $7.3 \times 10^{-3}$ & $1.4 \times 10^{5}$ & $6.3 \times 10^{4}$ & $2.1 \times 10^{6}$ & 0.0 & 43: \\
\hline $\mathrm{Cm}-242$ & 0.27 & $4.1 \times 10^{-4}$ & $3.4 \times 10^{3}$ & $4.0 \times 10^{4}$ & $5.1 \times 10^{4}$ & 0.0 & 53. \\
\hline $\mathrm{Cm}-244$ & 0.29 & $2.0 \times 10^{-3}$ & $7.5 \times 10^{4}$ & $6.5 \times 10^{4}$ & $1.3 \times 10^{6}$ & 0.0 & 43. \\
\hline
\end{tabular}

* Units for Ground Shine DCF: $(\mathrm{rem} / \mathrm{h}) /\left(\mathrm{Ci} / \mathrm{m}^{2}\right)$

Units for Cloud Shine DCF: $\mathrm{rem} /\left(\mathrm{Ci}-\mathrm{sec} / \mathrm{m}^{3}\right)$

** Units for Inhalation DCF: rem/mCi inhaled 
Results of the analyses for unit-releases of the 27 nuclides may be summarized briefly as follows: whole body, lung, and bone doses are dominated by the actinides, $\mathrm{Sr}, \mathrm{Ru}$, and $\mathrm{Ce}$; thyroid and gastro-intestinal doses are due primarily to the non-volatile fission products and $\mathrm{Cs}$; in general, the volatile fission products are minor dose contributors.

\subsubsection{Direct Radiation Dose Model: Outline and Results}

The ejection of an intact fuel assembly from a shipping cask during an SFTA was selected as a low-credibility bounding event for this study. The assembly is assumed to come to rest and to remain in a fully unshielded location for 10 hours, within which time the assembly can be expected to have been shielded or repackaged by remote procedures. This is consistent with the scenario stated in WASH-123817. The unshielded fuel assembly presents a near point source of direct radiation at distances of interest. The source strength was estimated according to the equation

$$
D(R)=1600 \frac{C E \mu e^{-\mu R} t}{4 \pi R^{2}}
$$

where

$$
\begin{aligned}
D(R) & =\text { direct dose at distance } R \text {, rem } \\
C & =\text { number of Curies in fuel assembly } \\
& =1.8 \times 10^{6} \\
E \quad & =\text { average disintegration photon energy } \\
& =1.0 \mathrm{MeV} \\
\mu \quad & 1 \text { inear attenuation coefficient for air } \\
& =3.5 \times 10^{-3} / \mathrm{m}, \text { average from } 0.1 \text { to } 10 \mathrm{MeV} \\
\mathrm{R} & =\text { distance from fuel assembly, } \mathrm{m} \\
t & =\text { time fuel assembly is unshielded }
\end{aligned}
$$

The dose equation then becomes

$$
D(R)=8.2 \times 10^{6} \frac{\mathrm{e}^{-3.5 \times 10^{-3} \mathrm{R}}}{\mathrm{R}^{2}}
$$


from which the dose as a function of distance was calculated. Results are given in Section 10.4.3, Tables 10.16 and 10.17. A population dose estimate for this exposure pathway is given in Table 10.18.

\subsubsection{Results of Dose Calculations for Various Cask Release Cases}

Radiation doses resulting from the four spent fuel transportation accidents (defined in Table 10.13) were calculated at distances of 100, 1000, and 10,000 feet downwind from the accident site. Each of the 27 nuclides listed in Table 10.11, was analyzed separately using RSRCON. The dose which each nuclide delivers to each body organ was calculated, based on an assumed release fraction from the cask of 0.01 for each nuclide. These calculated doses were then weighted, according to the individual cask release fractions developed for each accident situation, and summed to arrive at collective doses for each accident. The individual cask release fractions are discussed in Section 10.2.2 and 10.3.2 and are summarized in Table 10.13. Dose results are given in Tables 10.14 through 10.18.

In the tables of dose results, nuclides are grouped into several physical categories, e.g., volatile fission products and particulate fission products, to facilitate a comparative ranking of the dose contributors. Only cesium and ruthenium were isolated as elements because their combinations of large inventories, potentially high volatiles, and significant dose conversion factors can lead to large doses, especially when particulate release fractions are not large.

Tables 10.14 through 10.17 give organ doses in rem which would be received by an individual residing under the radioactive plume, due to shine and to inhalation pathways. Tables 10.16 and 10.17 give results for the two accident scenarios in which a fuel assembly is ejected from the shipping cask, and therefore these tables also include rem doses due to the direct radiation from the unshielded assembly. These direct doses, integrated over 10 hours as described in Section 10.4.2, may be compared immediately with the doses from the airborne plume at 100,1000, and 10,000 feet from the assembly.

Table 10.18 gives organ doses in man-rem which would be received by a reference population of one person $/ \mathrm{km}^{2}$ residing under the plume, to 100 miles. Again the direct radiation dose from an unshielded fuel assembly is listed to allow an immediate comparison with doses from airborne pathways. While an unshielded assembly would irradiate persons located in all directions from the assembly, the direct radiation doses were calculated for only 0.042 fraction of a circle to coincide with the airborne plume width. More than 90 percent of the population dose from direct radiation occurs within the first 1000 feet.

\subsubsection{Inspection and Analysis of Dose Results}

A number of useful observations can be made from the dose results given in the previous section for the limiting release estimates connected with the 
TABLE 10.13

SUMMARY OF CASK RELEASE FRACTIONS DEVELOPED FOR FOUR TRANSPORTATION ACCIDENT SCENARIOS

\begin{tabular}{lllll}
\hline \multirow{2}{*}{ Nuclide Group } & \multicolumn{4}{c}{ Cask Release Fractions* } \\
\cline { 2 - 5 } & SFTA-1 & SFTA-2 & SFTA-3 & SFTA-4 \\
\hline & $1 \times 10^{-2}$ & $1 \times 10^{-2}$ & $1 \times 10^{-2}$ & $1 \times 10^{-1}$ \\
Noble Gas & $6 \times 10^{-7}$ & $4 \times 10^{-2}$ & $3 \times 10^{-2}$ & $3 \times 10^{-1}$ \\
Iodine & $3 \times 10^{-9}$ & $3 \times 10^{-2}$ & $3 \times 10^{-4}$ & $1 \times 10^{-1}$ \\
Cesium & $5 \times 10^{-10}$ & $9 \times 10^{-3}$ & $1 \times 10^{-4}$ & $1 \times 10^{-1}$ \\
Tellurium & - & - & $1 \times 10^{-4}$ & $1 \times 10^{-3}$ \\
Ruthenium & $1 \times 10^{-5}$ & $1 \times 10^{-3}$ & $2 \times 10^{-5}$ & $1 \times 10^{-2}$ \\
Particulates & & & & \\
\hline
\end{tabular}

* SFTA-1: He-cooled cask; impact damage with fire; lower-1jmit cask releases SFTA-2: He-cooled cask; impact damage with fire; upper-limit cask releases SFTA-3: He-cooled cask; ejection of one assembly; lower limit releases. SFTA-4: He-cooled cask; ejection of one assembly; upper limit releases. 
TABLE 10.14

INDIVIDUAL DOSES FROM HE-COOLED CASK INVOLVED IN IMPACT AND FIRE; LOWER-LIMIT AIRBORNE RELEASE ESTIMATES

\begin{tabular}{|c|c|c|c|c|c|}
\hline Nucl ide Group* & $\begin{array}{l}\text { Whole } \\
\text { Body }\end{array}$ & Lungs & Bone & Thyroid & $\begin{array}{l}\text { G.I. } \\
\text { Tract }\end{array}$ \\
\hline & \multicolumn{5}{|c|}{ Individual Doses at $10^{2}$ feet, rem } \\
\hline Cesium & $1.2 \times 10^{-5}$ & $2.9 \times 10^{-6}$ & $1.1 \times 10^{-5}$ & $3.7 \times 10^{-7}$ & $7.8 \times 10^{-7}$ \\
\hline Volatile F.P. & $2.5 \times 10^{-6}$ & $2.6 \times 10^{-6}$ & $2.5 \times 10^{-6}$ & $2.5 \times 10^{-6}$ & $2.5 \times 10^{-6}$ \\
\hline Particulate F.P. & $2.1 \times 10^{-1}$ & 3.7 & 2.6 & $3.1 \times 10^{-3}$ & $3.8 \times 10^{-1}$ \\
\hline \multirow{2}{*}{$\begin{array}{l}\text { Particulate Acti- } \\
\text { nides }\end{array}$} & 2.7 & 3.5 & $9.8 \times 10^{1}$ & $1.1 \times 10^{-6}$ & $2.8 \times 10^{-3}$ \\
\hline & \multicolumn{5}{|c|}{ Individual Doses at $10^{3}$ feet, rem } \\
\hline Cesium & $8.0 \times 10^{-6}$ & $2.0 \times 10^{-6}$ & $7.5 \times 10^{-6}$ & $2.6 \times 10^{-7}$ & $5.4 \times 10^{-7}$ \\
\hline Volatile F.P. & $1.9 \times 10^{-6}$ & $2.0 \times 10^{-6}$ & $1.9 \times 10^{-6}$ & $1.9 \times 10^{-6}$ & $1.9 \times 10^{-6}$ \\
\hline Particulate F.P. & $1.5 \times 10^{-1}$ & 2.6 & 1.8 & $2.2 \times 10^{-3}$ & $2.6 \times 10^{-1}$ \\
\hline \multirow{2}{*}{$\begin{array}{l}\text { Particulate Acti- } \\
\text { nides }\end{array}$} & 1.9 & 2.5 & $6.8 \times 10^{7}$ & $8.6 \times 10^{-7}$ & $2.3 \times 10^{-3}$ \\
\hline & \multicolumn{5}{|c|}{ Individual Doses at $10^{4}$ feet, rem } \\
\hline Cesium & $4.5 \times 10^{-7}$ & $1.1 \times 10^{-7}$ & $4.3 \times 10^{-7}$ & $1.6 \times 10^{-8}$ & $3.2 \times 10^{-8}$ \\
\hline Volatile F.P. & $4.8 \times 10^{-7}$ & $4.9 \times 10^{-7}$ & $4.9 \times 10^{-7}$ & $4.9 \times 10^{-7}$ & $4.9 \times 10^{-7}$ \\
\hline Particulate F.P. & $8.4 \times 10^{-3}$ & $1.5 \times 10^{-1}$ & $1.0 \times 10^{-1}$ & $1.4 \times 10^{-4}$ & $1.5 \times 10^{-2}$ \\
\hline $\begin{array}{l}\text { Particulate Acti- } \\
\text { nides }\end{array}$ & $1.0 \times 10^{-1}$ & $1.4 \times 10^{-1}$ & 3.8 & $4.2 \times 10^{-8}$ & $1.1 \times 10^{-4}$ \\
\hline
\end{tabular}

* Volatile Fission Products: $\mathrm{Kr}, \mathrm{Te}, \mathrm{I}_{2}$

* Particulate Fission Products: Cs, Kr, Te, I $2, \mathrm{Sr}, \mathrm{Y}, \mathrm{Zr}, \mathrm{Nb}, \mathrm{Ru}, \mathrm{Ce}$ * Particulate Actinides: $\quad \mathrm{Pu}, \mathrm{Am}, \mathrm{Cm}$ (Contained in the Fuel Particle Matrix) (Contained in the Fuel Particle Matrix) 
TABLE 10.15

INDIVIDUAL DOSES FROM HE-COOLED CASK INVOLVED IN IMPACT AND FIRE; UPPER-LIMIT AIRBORNE RELEASE ESTIMATES

\begin{tabular}{|c|c|c|c|c|c|}
\hline Nuclide Group* & $\begin{array}{l}\text { Whole } \\
\text { Body }\end{array}$ & Lungs & Bone & Thyroid & $\begin{array}{l}\text { G.I. } \\
\text { Tract }\end{array}$ \\
\hline & & Individual & Doses at $10^{2}$ & feet, rem & \\
\hline Cesium & $1.2 \times 10^{2}$ & $2.9 \times 10^{\hat{1}}$ & $1.1 \times 10^{2}$ & 3.7 & 7.8 \\
\hline Volatile F.P. & $6.4 \times 10^{-2}$ & 3.9 & $3.2 \times 10^{-1}$ & $1.1 \times 10^{-1}$ & $8.8 \times 10^{-1}$ \\
\hline Particulate F.P. & $2.1 \times 10^{1}$ & $3.7 \times 10^{2}$ & $2.6 \times 10^{2}$ & $3.1 \times 10^{-1}$ & $3.8 \times 10^{1}$ \\
\hline $\begin{array}{l}\text { Particulate Acti- } \\
\text { nides }\end{array}$ & $2.7 \times 10^{2}$ & $\begin{array}{l}3.5 \times 10^{2} \\
\text { Individual }\end{array}$ & $\begin{array}{c}9.8 \times 10^{3} \\
\text { Doses at } 10^{3}\end{array}$ & $\begin{array}{l}1.1 \times 10^{-4} \\
\text { feet, rem }\end{array}$ & $2.8 \times 10^{-1}$ \\
\hline Cesium & $8.0 \times 10^{1}$ & $2.0 \times 10^{1}$ & $7.5 \times 10^{1}$ & 2.6 & 5.4 \\
\hline Volatile F.P. & $4.4 \times 10^{-2}$ & 2.7 & $2.2 \times 10^{-1}$ & $7.8 \times 10^{-2}$ & $6.1 \times 10^{-1}$ \\
\hline Particulate F.P. & $1.5 \times 10^{1}$ & $2.6 \times 10^{2}$ & $1.8 \times 10^{2}$ & $2.2 \times 10^{-1}$ & $2.6 \times 10^{1}$ \\
\hline $\begin{array}{l}\text { Particulate Acti- } \\
\text { nides }\end{array}$ & $1.9 \times 10^{2}$ & $\begin{array}{l}2.5 \times 10^{2} \\
\text { Individual }\end{array}$ & $\begin{array}{l}6.8 \times 10^{3} \\
\text { Doses at } 10^{4}\end{array}$ & $\begin{array}{l}8.6 \times 10^{-5} \\
\text { feet, rem }\end{array}$ & $2.3 \times 10^{-1}$ \\
\hline Cesium & 4.5 & 1.1 & 4.3 & $1.6 \times 10^{-1}$ & $3.2 \times 10^{-1}$ \\
\hline Volatile F.P. & $2.5 \times 10^{-3}$ & $1.5 \times 10^{-1}$ & $1.3 \times 10^{-2}$ & $4.4 \times 10^{-3}$ & $3.4 \times 10^{-2}$ \\
\hline Particulate F.P. & $8.4 \times 10^{-1}$ & $1.5 \times 10^{1}$ & $i .0 \times 10^{1}$ & $1.4 \times 10^{-2}$ & 1.5 \\
\hline $\begin{array}{l}\text { Particulate Acti- } \\
\text { nides }\end{array}$ & $1.0 \times 10^{7}$ & $-1.4 \times 10^{7}$ & $3.8 \times 10^{2}$ & $4.2 \times 10^{-6}$ & $1.1 \times 10^{-2}$ \\
\hline
\end{tabular}

* Volatile Fission Products: $\mathrm{Kr}, \mathrm{Te}, \mathrm{I}_{2}$.

* Particulate Fission Products: Cs, Kr, Te, I, Sr, Y, Zr, Nb, Ru, Ce

*Particulate Actinides: $\quad \mathrm{Pu}, \mathrm{Am}, \mathrm{Cm}$ (Contained in the Fuel Particle Matrix) 
TABLE 10.16

INDIVIDUAL DOSES FROM HE-COOLED CASK INVOLVED IN IMPACT AND FIRE WITH

EJECTION OF ONE FUEL ASSEMBLY; LOWER-LIMIT AIRBORNE RELEASE ESTIMATES

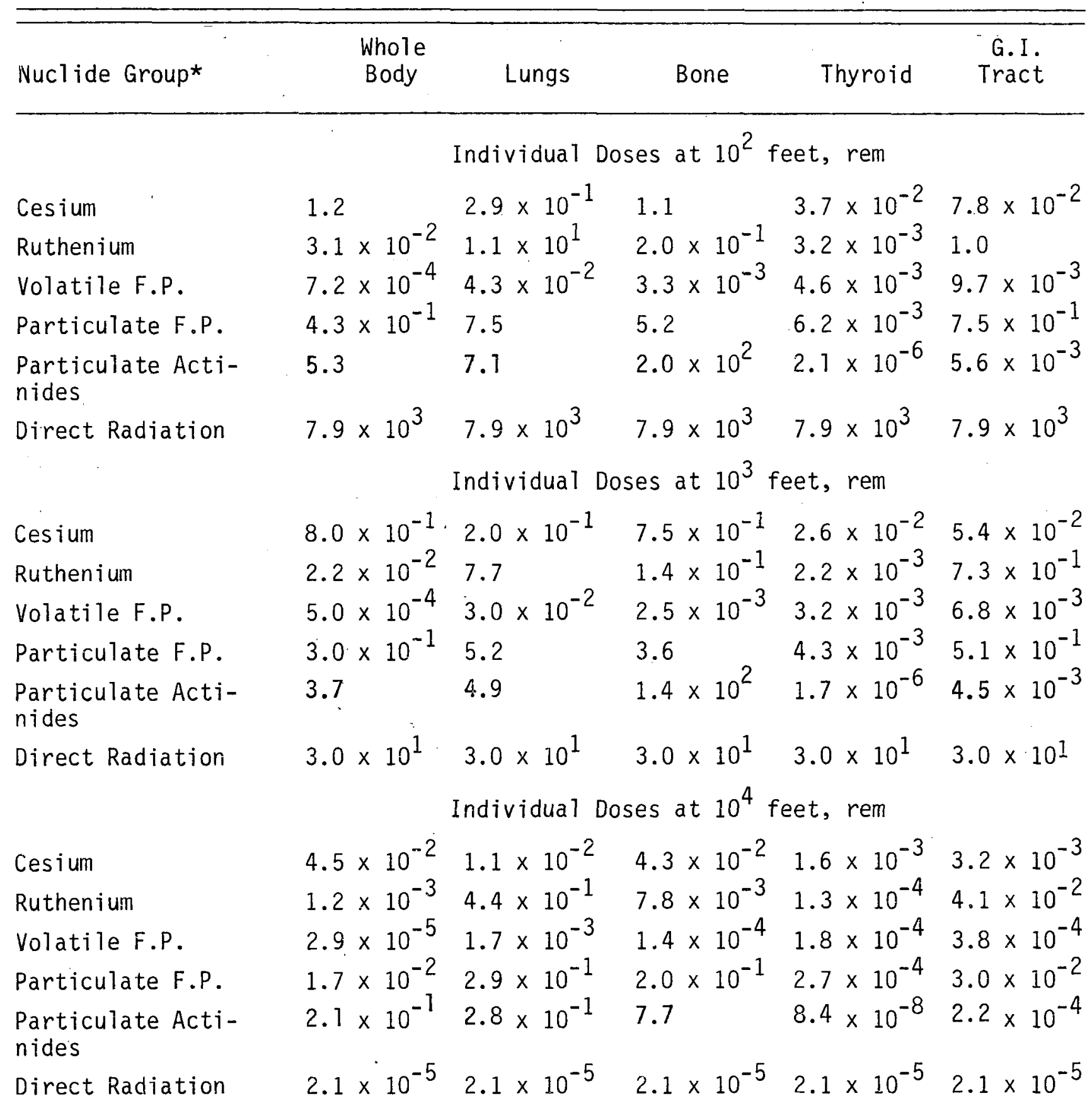

* Volatile Fission Products: $\mathrm{Kr}, \mathrm{Te}, \mathrm{I}_{2}$

* Particulate Fission Products: $\mathrm{Cs}, \mathrm{Kr}, \mathrm{Te}, \mathrm{I}_{2}, \mathrm{Sr}, \mathrm{Y}, \mathrm{Zr}, \mathrm{Nb}, \mathrm{Ru}, \mathrm{Ce}$

(Contained in the Fuel Particle Matrix)

* Particulate Actinides: . Pu, Am, Cm (Contained in the Fuel Particle Matrix)

* Direct Radiation Dose is Integrated over 10 hours. 
TABLE 10.17

INDIVIDUAL DOSES FROM HE-COOLED CASK INVOLVED IN IMPACT AND FIRE WITH EJECTION OF ONE FUEL ASSEMBLY; UPPER-LIMIT AIRBORNE RELEASE ESTIMATES

\begin{tabular}{|c|c|c|c|c|c|}
\hline Nucl ide Group* & $\begin{array}{l}\text { Whole } \\
\text { Body }\end{array}$ & Lungs & Bone & Thyroid & $\begin{array}{c}\text { G.I. } \\
\text { Tract }\end{array}$ \\
\hline & & Individual & Doses at $10^{2}$ & feet, rem & \\
\hline Cesium & $3.8 \times 10^{2}$ & $9.6 \times 10^{1}$ & $3.6 \times 10^{2}$ & $1.2 \times 10^{1}$ & $2.6 \times 10^{1}$ \\
\hline Ruthenium & $3.1 \times 10^{-1}$ & $1.1 \times 10^{2}$ & 2.0 & $3.2 \times 10^{-2}$ & $1.0 \times 10^{1}$ \\
\hline Volatile F.P. & $7.1 \times 10^{-1}$ & $4.3 \times 10^{1}$ & 3.6 & 1.2 & 9.8 \\
\hline Particulate F.P. & $2.1 \times 10^{2}$ & $3.7 \times 10^{3}$ & $2.6 \times 10^{3}$ & 3.1 & $3.8 \times 10^{2}$ \\
\hline $\begin{array}{l}\text { Particulate Acti- } \\
\text { nides }\end{array}$ & $2.7 \times 10^{3}$ & $3.5 \times 10^{3}$ & $9.8 \times 10^{4}$ & $1.1 \times 10^{-3}$ & 2.8 \\
\hline Direct Radiation & $7.9 \times 10^{3}$ & $7.9 \times 10^{3}$ & $7.9 \times 10^{3}$ & $7.9 \times 10^{3}$ & $7.9 \times 10^{3}$ \\
\hline & & Individual & Doses at $10^{3}$ & feet, rem & \\
\hline Cesium & $2.7 \times 10^{2}$ & $6.7 \times 10^{1}$ & $2.5 \times 10^{2}$ & 8.6 & $1.8 \times 10^{1}$ \\
\hline Ruthenium & $2.2 \times 10^{-1}$ & $7.7 \times 10^{1}$ & 1.4 & $2.2 \times 10^{-2}$ & 7.3 \\
\hline Volatile F.P. & $4.9 \times 10^{-1}$ & $3.0 \times 10^{1}$ & 2.5 & $8.6 \times 10^{-1}$ & 6.8 \\
\hline Particulate F.P. & $1.5 \times 10^{2}$ & $2.6 \times 10^{3}$ & $1.8 \times 10^{3}$ & 2.2 & $2.6 \times 10^{2}$ \\
\hline $\begin{array}{l}\text { Particulate Acti- } \\
\text { nides }\end{array}$ & $1.9 \times 10^{3}$ & $2.5 \times 10^{3}$ & $6.8 \times 10^{4}$ & $8.6 \times 10^{-4}$ & 2.3 \\
\hline Direct Radiation & $3.0 \times 10^{1}$ & $3.0 \times 10^{1}$ & $3.0 \times 10^{1}$ & $3.0 \times 10^{1}$ & $3.0 \times 10^{1}$ \\
\hline & & Individual & Doses at $10^{4}$ & feet, rem & \\
\hline Cesium & $1.5 \times 10^{1}$ & 3.8 & $1.4 \times 10^{1}$ & $5.3 \times 10^{-1}$ & 1.1 \\
\hline Ruthenium & $1.2 \times 10^{-2}$ & 4.4 & $7.8 \times 10^{-2}$ & $1: 3 \times 10^{-3}$ & $4.1 \times 10^{-1}$ \\
\hline $\begin{array}{l}\text { Volatile F.P. } \\
\text { Particulate F.P. } \\
\text { Particulate Acti- } \\
\text { nides }\end{array}$ & $\begin{array}{l}2.8 \times 10^{-2} \\
8.4 \\
1.0 \times 10^{2}\end{array}$ & $\begin{array}{l}1.7 \\
1.5 \times 10^{2} \\
1.4 \times 10^{2}\end{array}$ & $\begin{array}{l}1.4 \times 10^{-1} \\
1.0 \times 10^{2} \\
3.8 \times 10^{3}\end{array}$ & $\begin{array}{l}4.9 \times 10^{-2} \\
1.4 \times 10^{-1} \\
4.2 \times 10^{-5}\end{array}$ & $\begin{array}{l}3.8 \times 10^{-1} \\
1.5 \times 10^{1} \\
1.1 \times 10^{-1}\end{array}$ \\
\hline Direct Radiation & $2.1 \times 10^{-5}$ & $2.1 \times 10^{-5}$ & $2.1 \times 10^{-5}$ & $2.1 \times 10^{-5}$ & $2.1 \times 10^{-5}$ \\
\hline
\end{tabular}

* Volatile Fission Products:

$\mathrm{Kr}, \mathrm{Te}, \mathrm{I}_{2}$

* Particulate Fission Products:

Cs, Kr, Te, I $, \mathrm{Sr}, \mathrm{Y}, \mathrm{Zr}, \mathrm{Nb}, \mathrm{Ru}, \mathrm{Ce}$

(Contained in the Fuel Particle Matrix)

* Particulate Actinides:

$\mathrm{Pu}, \mathrm{Am}, \mathrm{Cm}$ (Contained in the Fuel Particle Matrix)

* Direct Radiation Dose is Integrated over 10 hours. 
TABLE 10.18

POPULATION*' DOSES FROM HE-COOLED CASK INVOLVED IN

IMPACT AND FIRE (FOUR SFTAS**)

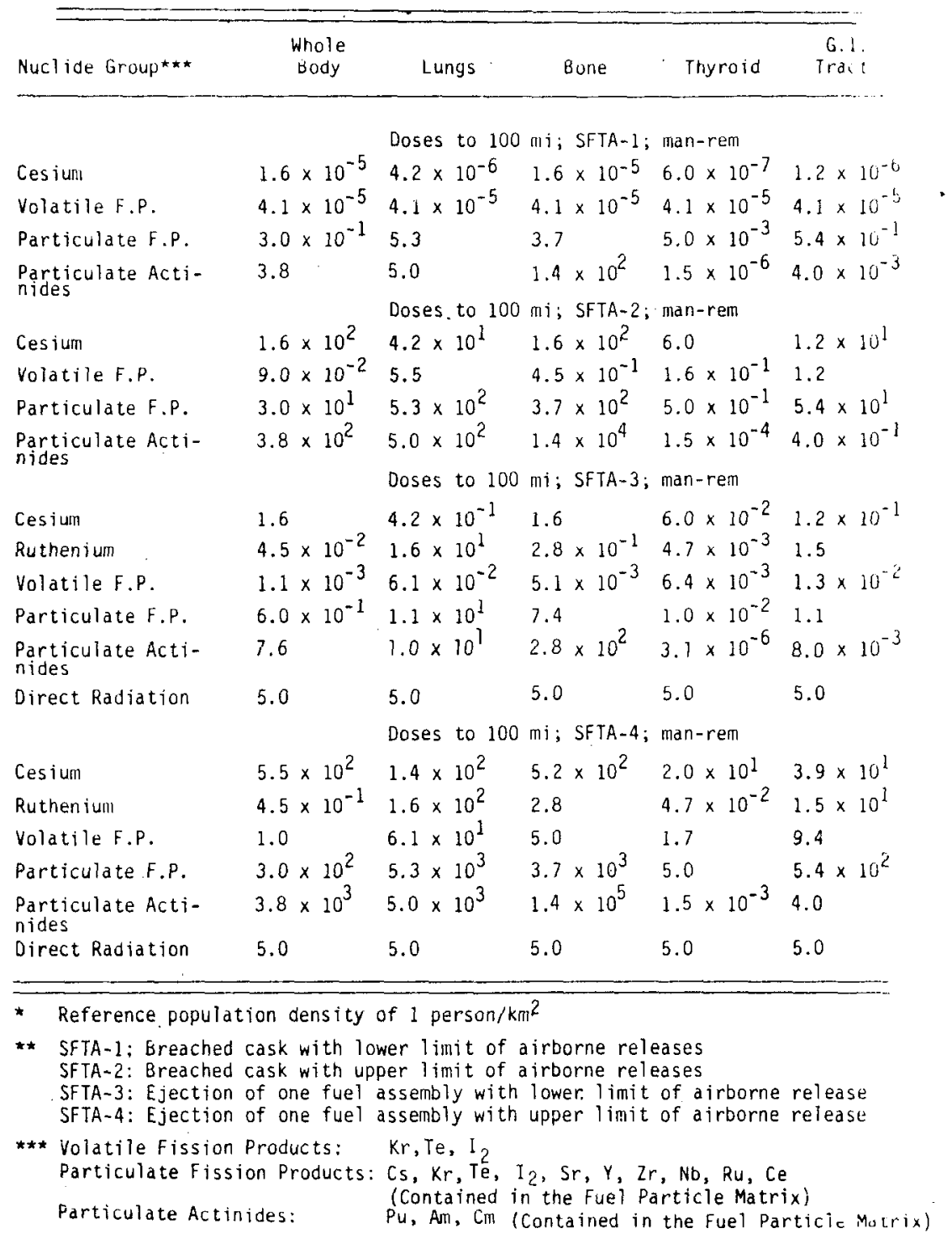


two principal types of severe SFTA events. These observations are discussed below in terms of (1) the important contributors to estimates of the public health impact of such accidents and (2) the release process or processes which are significant in determining the airborne source terms for these key contributors.

Inspection of the individual dose values given in Table 10.14 for the helium-cooled cask impact plus fire scenario show that, regardless of distance, the particulate fission product and actinide groups dominate all calculated organ doses. Actually the doses due to these species are dominant by factors ranging from about $10^{3}$ to $10^{7}$, depending on the body organ considered. The particles of course result from the estimated fuel dust releases for the SFTA scenario, and the principal source of the releases was estimated to come from the initial impact failure of $10 \%$ of the fue 1 rods. The releases of volatile fission products for this specific case were quite low (except for krypton), since they were assumed to exist as reaction products having low volatilities. Krypton would form no reaction products under these conditions. Hence its release is relatively large, but the radiological effects of krypton release are comparatively small. The above results indicate that if the volatile species (cesium, iodine, and tellurium) indeed exist as reaction products within spent fuel rods, then the quantity of respirable fuel dust that might escape a cask during a severe SFTA could well determine the magnitude of the public health impact. Unfortunately, very few data exist for determining this quantity, but within the context of the particular calculation being addressed here, the quantity could be orders of magnitude smaller than was assumed, and it would still be radiologically significant.

Inspection of the individual dose values given in Table 10.15 for the helium-cooled cask impact plus fire scenario show a somewhat different pattern than those in Table 10.14. The releases which produce these doses were based on high- or upper-limit assumptions for release of both volatile fission products and respirable fuel dust. In fact the volatiles were assumed to be in their most volatile forms. In Table 10.15, it can be observed that the particulate fission products and actinides still dominate the calculated doses, for the lungs, bone, and GI tract organs, but cesium contributes significantly to the doses for the whole body and thyroid. The other volatile fission products are smal. contributors to all organ doses but proportionally greater than in Table 10.14. The proportionally greater contribution from the volatiles is due to their greater release, relative to fuel dust release, in the high-limit release assumption than in the low-jevel release assumption. Nevertheless the results in Table 10.15 again indicate the potential significance of a respirable fuel dust release in determining the public health impact of a severe SFTA. The results also illustrate that the form of the volatile fission products is of some importance, and the data in both Tables 10.14 and 10.15 indicate that cesium is the most important of the volatile fission products with respect to public health impact.

The individual dose results in Tables 10.16 and 10.17 provide insight regarding two principal factors: (1) the significance of direct radiation dose from an ejected fuel assembly compared to doses from airborne releases 
and (2) the dose impact of releases caused by air oxidation of exposed spent fuel. The only difference between the two tables is in the total doses that result from different airborne release assumptions; the lowlimit case (only the ejected fuel assembly damaged and oxidized) or the high-limit case (all fuel assemblies damaged and oxidized). The respirable fuel dust releases were also quite different for the two cases (Table 10.10). The data in Table 10.16 show direct radiation doses which are higher than the airborne release doses at distances of $100 \mathrm{ft}$ and $1000 \mathrm{ft}$ from the cask but much lower at a distance of $10,000 \mathrm{ft}$. The data in Table 10.17 show direct radiation doses which are greater than the airborne release doses for al1 organs except bone at a distance of $100 \mathrm{ft}$. At $1000 \mathrm{ft}$ the direct radiation doses are less than the airborne release doses for all organs except the thyroid, and at $10,000 \mathrm{ft}$ the direct radiation doses are much lower than the airborne release doses. On the basis of these observations it appears that direct radiation from an ejected fuel assembly could be an important dose contributor out to distances of the order of $1000 \mathrm{ft}$.

The individual doses due to the low limit airborne releases (Table 10.16) show the particulate fission products and actinides are important but not controlling contributors to all organ doses except for bone dose. In addition cesium is an important contributor to whole body and thyroid doses, and ruthenium is an important contributor to lung and GI doses. The significance of cesium and ruthenium is due directly to their release during the assumed air oxidation of exposed fue 1 in the ejected assembly. The corresponding data in Table 10.17 for the high-limit airborne releases follow a similar pattern to that just outlined for the low-limit airborne releases, except that the particulates fission products and actinides are relatively more important dose contributors and ruthenium is a relatively less important dose contributor than in Table 10.16. Therefore, in general, this evaluation of a spent fuel assembly ejection accident indicates that fuel dust releases could have an important influence on public health impact assessments and the potential release of volatile fission products during postulated fuel oxidation could also be a significant factor.

The population dose results given in Table 10.18 for the four combinations of SFTA scenarios and radionuclide release limits show the same general trends as discussed above the for individual dose results. Interestingly, in the case of the spent fuel assembly ejection accident, the population doses due to direct radiation are roughly comparable to the population doses from the low-limit airborne releases. However, the high-limit airborne releases for this accident tend to dominate the estimated population doses. Worth noting also is that the population doses listed in the table are based on a reference population density of 1 person $/ \mathrm{km}^{2}$. Hence the doses would not reflect the magnitude of population doses in a heavily populated region. However, the reference approach used here is sufficient for the comparative objectives of this study. 


\section{REFERENCES}

1. Pacific Gas and Electric Co., "Final Safety Analysis Report," Vol. VI, Diablo Canyon Site, Units 1 and 2, Docket Nos. 50-275 and 50-323.

2. R. L. Ritzman and D. L. Morrison, "FRCRL2 - A Computer Code for Calculating Fission-Product Release in Reactor Accident Analyses," BMI1913 (August 1971).

3. L. D. Noble, R. A. Lorenz, and R. L. Ritzman, "ANS-5.4 Fission Gas Release Mode1," A Series of Three Papers in ANS Topical Meeting on LWR Fuel Performance, Program and Paper Summaries, Portland, April 29-May 3, 1979.

4. U. S. Nuclear Regulatory Commission, "Reactor Safety Study, An Assessment of Accident Risks in the U.S. Commercial Nuclear Power Plants," WASH-1400 (USNRC Report NUREG 75/014), Appendix C of Appendix VII (October 1975).

5. R. C. Weast, Ed., Handbook of Chemistry and Physics, 51st Edition, The Chemical Rubber Co., Cleveland, Ohio, 1970-1971.

6. C. J. Smithells, Metals Reference Book, Buttersworth, New York, 1962.

7. M. W. Chase, et al., "JANAF Thermochemical Tables, 1974 Supplement," Journal of Physical and Chemical Reference Data, American Chemical Society and American Institute of Physics (1974).

8. U. S. Nuclear Regulatory Commission, "Potential Releases of Cesium from Irradiated Fuel in a Transportation Accident," NUREG-0069.

9. J. E. Mende1, "A Review of Leaching Test Methods and the Leachability of Various Solid Media Containing Radioactive Wastes," BNWL-1765 (July 1973).

10. Y. B. Katayama and J. E. Mende1, "Leaching of Irradiated LWR Fuel Pellets in Deionized Water, Sea Brine, and Typical Ground Water," PNL-SA-6416 (December 1977).

11. G. W. Parker, et al., "Out-of-Pile Studies of Fission-Product Release from Overheated Reactor. Fuels at ORNL, 1955 - 1965," Figure 6.6, ORNL-3981 (July 1967).

12. G. W. Parker, et al., "Out-of-Pile Studies of Fission-Product Release from Overheated Reactor Fuels at ORNL, 1955 - 1965," Figure 6.9, ORNL-3981 (July 1967).

13. A. P. Malinauskas, et al., "Quarterly Progress Report on Fission Product Behavior in LWRs for the Period July-September 1977, " ORNL/ NUREG/TM-170 (January 1978). 
14. U. S. Atomic Energy Commission, "Reactor Safety Study, An Assessment of Accident Risks in U.S. Commercial Nuclear Power Plants, "Appendix VI, WASH-1400 (Draft) (August 1974).

15. Oak Ridge National Laboratory, "Siting of Fuel Reprocessing Plants and Waste Management Facilities," ORNL-4451 (July 1970).

16. G. G. Killough, et al., Oak Ridge National Laborator, "A Methodology for Calculating Radiation Doses from Radioactivity Released to the Environment," ORNL-4992 (March 1976).

17. U. S. Atomic Energy Commission, "Environmental Survey of Transportation of Radioactive Materials to and from Nuclear Power Plants," WASH-1238 (December 1972). 


\section{0 RECOMMENDATION FOR INFORMATION DEVELOPMENT}

This section presents an evaluation of the information needed to specify increasingly realistic source terms for a severe SFTA, as well as a set of research recommendations based on that evaluation. Information needs are ranked using the procedure discussed in Section 11.1. The results of the ranking are presented in tabular form, together with the recommendations, in Section 11.2.

\section{1 METHOD OF ESTABLISHING PRIORITIES}

A simple form of multi-attribute decision analysis was used to establish priorities in the areas in which information was needed. The alternatives evaluated were those of Table 7.1. The attributes which were evaluated were:

1. Extent of the probable risk reduction (probability times consequence) to the public of a severe SFTA, should research be performed. The needed research could be concerned either with obtaining experimental data, with developing analytical or phenomenological models, or both.

2. Cost of producing the information.

3. Likelihood of successful research despite experimental difficulties, complexity of the various interacting phenomena under investigation, and so forth.

4. Extent of technical disagreement on the importance of the research area in relation to the magnitude of the source term.

A Delphi technique is frequently used to evaluate the alteratives against the attributes. In that technique, a panel of experts anonymously ranks the alternatives and gives the rationale for their judgment. Results and explanations are presented objectively: to the panel. The process is repeated until consensus is obtained, or until no further reconsideration seems fruitful. Use of the Delphi technique would have been difficult in this project because the alternatives encompass subjects not usually found in a single expert's specialty area', e.g., stress analysis, nuclear analysis, and chemical forms of radionuclides. Therefore, the increased cost and the effect on scheduling made use of the Delphi technique impractical.

The first three authors used the Delbecq technique to evaluate the attributes and weighting factors. In this technique, the cognizant panel member presents his assessment for group discussion and consensus. The first three criteria above were ranked on an ordinal scale from 1 to 5 , in which 1 reflected low risk reduction, low success probability, and low cost. The fourth criterion was judged as yes or no. An estimate of the reliability of the evaluations was made, but the results did not appear to contri- 
bute to this project. The scale of 1 to 5 was selected arbitrarily, but upon review, the results seemed to provide adequate discrimination. Generally it was found that a high cost was associated with high risk reduction and that moderate cost was associated with low risk reduction. The probability of success was not generally a factor, except that a low probability of success was associated with low cost, low risk alternatives.

When practical, it is desirable to condense the evaluation of several attributes into one using weighting factors. Several methods were investigated, but simple addition and subtraction illustrated the relative merits as well as the more complicated ones. Accordingly, the value of cost was subtracted from the sum of the risk reduction and probability of success values to obtain the priority ranking.

\section{2 RECOMMENDATIONS}

The alternatives for developing information to permit a more realistic evaluation of SFTA's are shown in Table 11.1, along with their recommended priority. For convenience, the adequacy rankings of Section 7 are repeated. As has been explained previously in Section 7.5, each of the items in Table 11.1 was evaluated for adequacy against four criteria defined as follows:

A - The level of understanding regarding basic phenomena and processes associated with the item

B - The availability of analytical models, correlations, or codes for the item

C - The availability of key input conditions, property data, and rate parameters for the item

D - The completeness of the output resulting from application of available analytical methods

Three rankings were used to indicate the relative adequacy of the information base for each item-criterion combination, which is reflected in the following point system:

$\begin{array}{cl}\begin{array}{c}\text { Point } \\ \text { Value }\end{array} & \begin{array}{l}\text { Degree of Adequacy of } \\ \text { the Information Base }\end{array} \\ 1 & \begin{array}{l}\text { Generally inadequate } \\ 2\end{array} \\ 3 & \text { Mixed adequate/inadequate } \\ & \text { Generally adequate }\end{array}$

The fifth column contains the recommended priority for informative development: a high number indicates a high priority. An asterisk indicates an area of technical disagreement. 


\section{TABLE 11.1}

EVALUATION OF THE ADEQUACY OF EXISTING DATA AND PRIORITY RECOMMENDATIONS FOR INFORMATION DEVELOPMENT

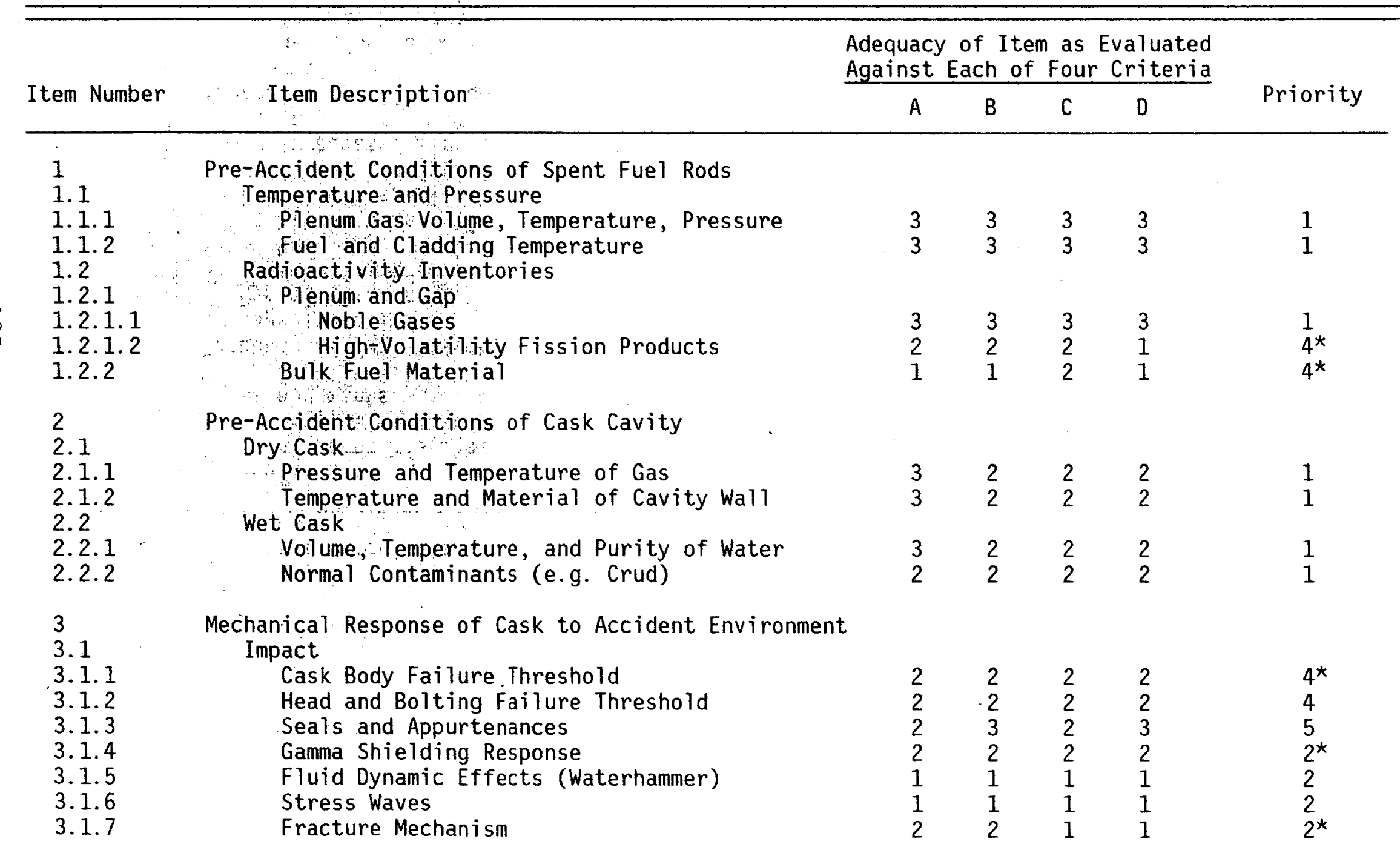


TABLE 11.1 (Continued)

EVALUATION OF THE ADEQUACY OF EXISTING DATA AND PRIORITY RECOMMENDATIONS FOR INFORMATION DEVELOPMENT

\begin{tabular}{|c|c|c|c|c|c|c|}
\hline \multirow[b]{2}{*}{ Item Number } & \multirow[b]{2}{*}{ Item Description } & \multicolumn{4}{|c|}{$\begin{array}{l}\text { Adequacy of Item as Evaluated } \\
\text { Against Each of Four Criteria }\end{array}$} & \multirow[b]{2}{*}{ Priority } \\
\hline & & $A$ & $B$ & $C$ & $\bar{D}$ & \\
\hline $\begin{array}{l}3.2 \\
3.2 .1 \\
3.2 .2 \\
3.2 .3\end{array}$ & $\begin{array}{l}\text { Puncture } \\
\text { Airborne Missiles } \\
\text { Projections/Stubs } \\
\text { Abutments }\end{array}$ & $\begin{array}{l}1 \\
1 \\
1\end{array}$ & $\begin{array}{l}2 \\
2 \\
2\end{array}$ & $\begin{array}{l}2 \\
2 \\
2\end{array}$ & $\begin{array}{l}2 \\
2 \\
2\end{array}$ & $\begin{array}{l}1 \\
3^{*} \\
2\end{array}$ \\
\hline $\begin{array}{l}4 \\
4.1 \\
4.2 \\
4.2 .1 \\
4.2 .2 \\
4.2 .3 \\
4.3 \\
4.3 .1 \\
4.3 .2\end{array}$ & $\begin{array}{l}\text { Response of Fuel Assemblies to Impact } \\
\text { Load Transmission } \\
\text { Dynamic Response } \\
\text { Inertial Loads } \\
\text { Buckling } \\
\text { Stress Waves } \\
\text { Failure Thresholds } \\
\text { Irradiated Zirc Static Properties } \\
\text { Irradiated Zirc Dynamic Properties }\end{array}$ & $\begin{array}{l}3 \\
3 \\
3 \\
3\end{array}$ & $\begin{array}{l}2 \\
1 \\
1\end{array}$ & $\begin{array}{l}2 \\
1 \\
1\end{array}$ & $\begin{array}{l}2 \\
2 \\
1 \\
1 \\
2 \\
1\end{array}$ & $\begin{array}{l}2^{\star} \\
2 \\
4 \\
4^{\star} \\
5 \\
3\end{array}$ \\
\hline $\begin{array}{l}5 \\
5.1 \\
5.1 .1 \\
5.1 .2 \\
5.1 .3 \\
5.1 .4 \\
5.1 .5 \\
5.1 .6 \\
5.2 \\
5.2 .1 \\
5.2 .2 \\
5.2 .3\end{array}$ & $\begin{array}{l}\text { Thermal-Hydraulic Response of Cask and Fuel } \\
\text { Thermal } \\
\text { Heat Source Magnitude } \\
\text { Thermal Properties of Fuel, Cladding, Gap } \\
\text { Thermal Properties of Cask Materials } \\
\text { Convective and Radiative Properties } \\
\text { Gap Fission Gas Pressure } \\
\text { Cladding Perforation } \\
\text { Hydraulic } \\
\text { Geometric Factors } \\
\text { Transient Convection } \\
\text { Energy Distribution Effects }\end{array}$ & $\begin{array}{l}3 \\
3 \\
3 \\
2 \\
2 \\
2 \\
2 \\
3 \\
3\end{array}$ & $\begin{array}{l}3 \\
2 \\
2 \\
2 \\
2 \\
2\end{array}$ & $\begin{array}{l}3 \\
3 \\
3 \\
2 \\
2 \\
2\end{array}$ & $\begin{array}{l}3 \\
2 \\
2 \\
2 \\
2 \\
2 \\
1 \\
2 \\
1\end{array}$ & $\begin{array}{l}2 \\
2 \\
1 \\
3 \\
3 \\
2 \\
\\
0 \\
3 \\
1\end{array}$ \\
\hline
\end{tabular}




\section{TABLE 11.1 (Continued)}

EVALUATION OF THE ADEQUACY OF EXISTING DATA AND PRIORITY RECOMMENDATIONS FOR INFORMATION DEVELOPMENT

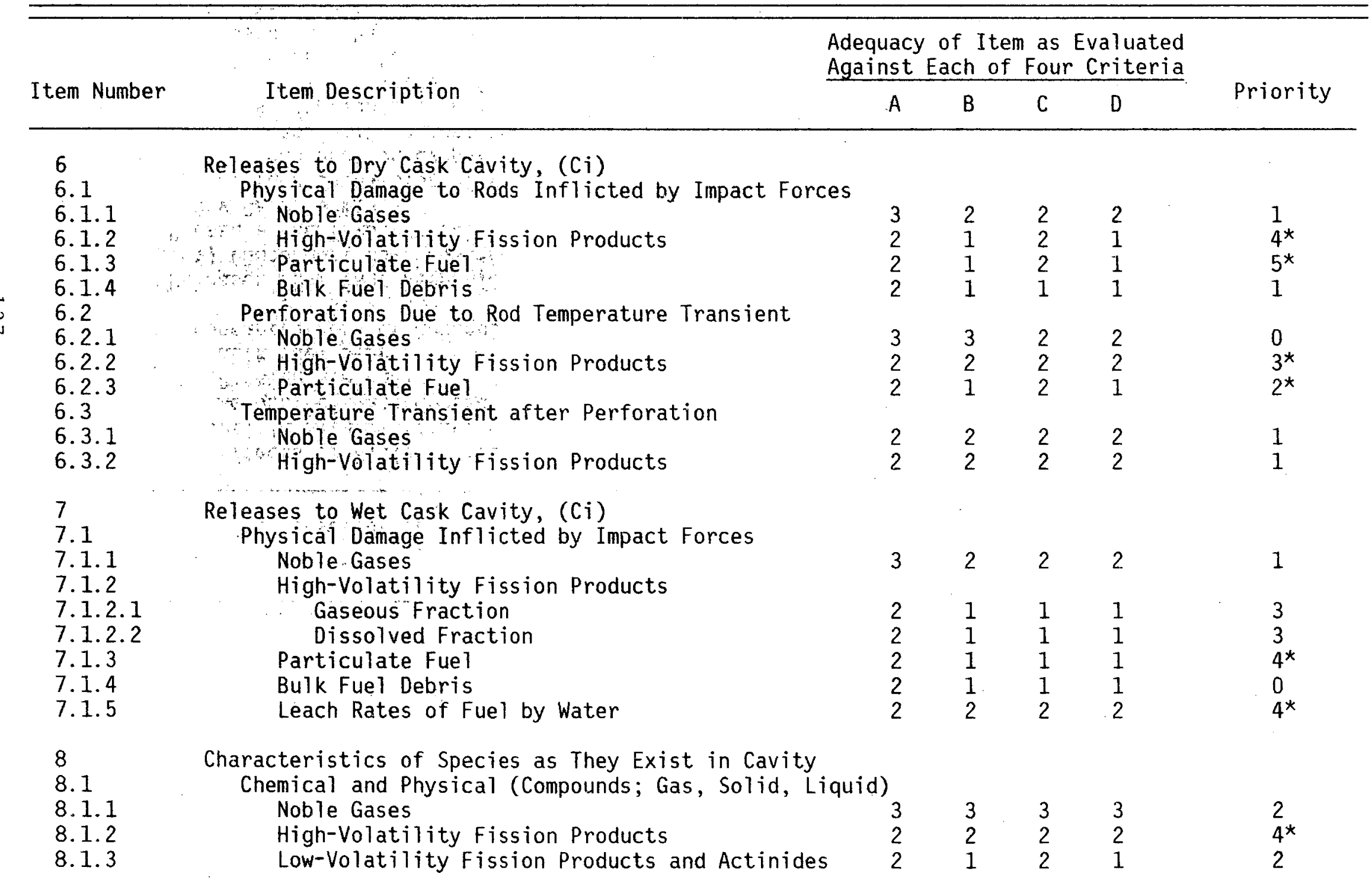


TABLE 11.1 (Continued)

EVALUATION OF ADEQUACY OF EXISTING DATA AND PRIORITY RECOMMENDATIONS FOR INFORMATION DEVELOPMENT

\begin{tabular}{|c|c|c|c|c|c|c|}
\hline \multirow[b]{2}{*}{ Item Number } & \multirow[b]{2}{*}{ Item Description } & \multicolumn{4}{|c|}{$\begin{array}{l}\text { Adequacy of Item as Evaluated } \\
\text { Against Each of Four Criteria }\end{array}$} & \multirow[b]{2}{*}{ Priority } \\
\hline & & A & $\mathrm{B}$ & $\mathrm{C}$ & D & \\
\hline $\begin{array}{l}8.1 .4 \\
8.2\end{array}$ & $\begin{array}{l}\text { Effects of Fluid Environment } \\
\text { Particle Size Distributions }\end{array}$ & 2 & 1 & 2 & 1 & 4 \\
\hline 8.2 .1 & Aerosol of Recondensed Vapors from Fuel Melt & 1 & 1 & 2 & 1 & 0 \\
\hline 8.2 .2 & Particulate Fuel & 1 & 1 & 2 & 1 & $5^{*}$ \\
\hline 8.2 .3 & Bulk Fuel Debris & 1 & 1 & 2 & 1 & 3 \\
\hline 8.3 & Concentrations of Aqueous-Leached Species & 2 & 1 & 2 & 1 & $5^{\star}$ \\
\hline 9 & $\begin{array}{l}\text { Releases from (and Retention in) Cask Cavity, } \\
\text { (Ci) (Dependent upon Post-Accident Histories of } \\
\text { Pressure and Temperature) }\end{array}$ & & & & & \\
\hline $\begin{array}{l}9.1 \\
9.1 .1\end{array}$ & $\begin{array}{l}\text { Dry Cask Cavity } \\
\text { Surface Deposition of Vapors }\end{array}$ & & & & & \\
\hline 9.1 .1 .1 & Condensation/Evaporation Effects & 3 & 2 & 2 & 2 & $3^{*}$ \\
\hline 9.1 .1 .2 & Reaction/Decomposition Effects & 2 & 2 & 1 & $\overline{1}$ & 4 \\
\hline 9.1 .1 .3 & Adsorption/Desorption Effects & 2 & 2 & 1 & $\overline{1}$ & 2 \\
\hline 9.1 .2 & Surface Deposition of Particulates & $\overline{2}$ & 2 & 1 & $\overline{1}$ & $6^{*}$ \\
\hline 9.1 .3 & Cask Leak Rate & 3 & 3 & 2 & $\overline{2}$ & 4 \\
\hline 9.1 .4 & $\begin{array}{l}\text { Cask Leak Path Geometry } \\
\text { Wet Cask Cavity }\end{array}$ & 3 & 1 & 1 & 1 & 2 \\
\hline $\begin{array}{l}9.2 .1 \\
9.2 .1 .1\end{array}$ & $\begin{array}{l}\text { Water-Filled Region } \\
\text { Solubility Limits of Dissolved and Leached Species }\end{array}$ & 2 & 1 & 2 & 1 & 4 \\
\hline 9.2 .1 .2 & Deposition Rates from Solution & 2 & 1 & $\frac{1}{2}$ & $\frac{1}{2}$ & 2 \\
\hline $\begin{array}{l}9.2 .1 .4 \\
9.2 .2\end{array}$ & $\begin{array}{l}\text { Water Leak Rate } \\
\text { Gas-Filled Region }\end{array}$ & 3 & 3 & 2 & 2 & 4 \\
\hline 9.2 .2 .1 & $\begin{array}{l}\text { Deposition of Exposed (Wet) Surfaces } \\
\text { (Comparable to Items } 9.1 .1 \text { and } 9.1 .2 \text { ) }\end{array}$ & 2 & 2 & 1 & 1 & 2 \\
\hline 9.2 .2 .2 & Gas Leak Rate & 3 & 2 & 2 & 2 & 4 \\
\hline
\end{tabular}


TABLE 11.1 (Continued)

EVALUATION OF THE ADEQUACY OF EXISTING DATA AND PRIORITY RECOMMENDATIONS FOR INFORMATION DEVELOPMENT

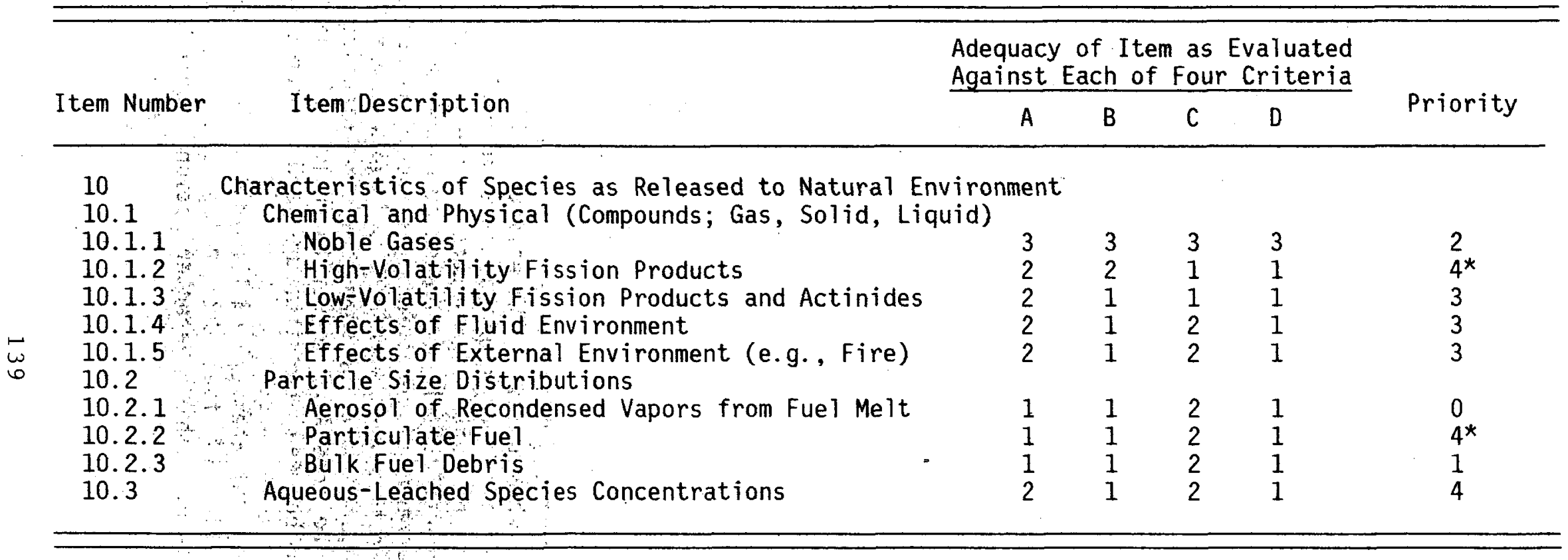

*Indicates area of technical disagreement 
The entries of Table 11.1 overlap; for example, particulate characterization appears in several places. Therefore, the recommendations are stated in areas of research that are recommended along with a summary of the rationale.

It should be emphasized that the priority rankings reflect the best judgment of the authors, based on the gauging calculations and evaluations described in this report. Subsequent efforts will be to plan specific research programs, identify techniques to be used, select facilities, and evaluate costs. Even with the choice of alternatives narrowed by scoping studies, however, the process remains a formidible effort. Such a process, perhaps combined with additional risk calculations, would improve considerably the establishment of priorities.

\subsubsection{Area 1 - Fuel Dust Particulate Sources}

All of the accident radiation dose estimates were either controlled or influenced by the respirable particulate fission products and actinides. These of course would be contained in any respirable fuel dust that might escape in a severe SFTA. Body organs most heavily affected by the particulate radionuclides were the lungs and bone. Actually the significance of the fuel dust source would depend somewhat on the volatility; hence the release magnitude of the volatile fission products. If the volatiles (except for krypton, which is of minor radiological importance) indeed exist as low volatility reaction products in spent fuel rods (a condition which has some experimental support), the potential release of respirable fuel dust becomes very important. Unfortunately, almost no direct measurements or characterization of fuel dust release under severe SFTA or other accident conditions are available.

Additional experimental and/or analytical work of various types is required to permit adequate definition of this source term in terms of the amount of respirable fuel dust that would escape to the atmosphere under a range of SFTA conditions. This would require development of data not only for the mass fraction of fuel release, but also for particle size distributions so that the respirable fractions could be specified. An important factor to evaluate in such studies is the effect of initial impact conditions on fuel rod integrity and on particulate formation. Release via this mode was judged to be quite significant in the present work. This judgment needs to be quantitatively evaluated by either analytical or experimental means over a range of conditions. It would be necessary to use actual spent fuel rods rather than simulations in experiments. Analytical work should utilize property data for spent fuel and cladding. Full-scale tests might eventually be necessary to verify analytical models and/or to investigate interactions between cask structures and the spent fuel load.

Depending on the findings of the work on the initial impact mode effects, additional characterization of fuel dust releases during thermal creep rupture might be necessary. This characterization requires either good information on thermal conditions in the cask, or thermal response tests of the system for different accident conditions. The investigation would 
also have to analyze or measure fluid flow conditions to obtain information on cavity transport and release. Agairi it is important to develop data on the particle size distribution of the released fuel particulates.

\subsubsection{Area 2 - Volatile Fission Product Sources}

The most critical uncertainty regarding the radiological significance of the volatile fission products involves their volatilities and release behavior under various SFTA conditions. The results of the present work indicate that information. for cesium is most needed. Thermodynamic property data would be of some help, but the transient nature of transportation accidents indicates the possible need for kinetic data as well. The complex chemical system within spent fuel rods and shipping casks almost demands that the problem be addressed experimentally rather than theoretically.

Cesium (and the other reactive volatiles) could be proportioned among several chemical species with the proportions changing as a function of thermal and fluid flow conditions. Some redistribution of species may occur under normal shipping conditions (i.e., prior to an accident), since some rods may experience temperatures as high as $1000^{\circ} \mathrm{F}$. An experimental program is needed which attempts to identify and quantify forms before an accident and then investigates changes and measures releases resulting from impact failure as well as during delayed thermal creep rupture of fuel rods. Cask retention due to internal plate-out competing with leakage might be examined using an experimental mockup of a shipping cask cavity. In addition the releases assumed in this study for the case of postulated air oxidation of exposed fuel within or outside a cask need to be either verified or modified through experimental investigation. This would include measurement of ruthenium volatility (release) also since the dose results indicated ruthenium releases could be radiologically significant.

\subsubsection{Area 3 - Other Radionuclide Release Uncertainties}

Depending on the outcome of the fuel dust and cesium release characterization studies outi ined above, it might be necessary to obtain better clarification of potential tellurium releases. Tellurium was observed to make some contribution to thyroid doses in the radiological impact calculations. The study of tellurifum release should be done along the same lines as the recommended study of cesium release characteristics.

Another release process which was judged to be not particularly significant in developing SFTA release ranges was the aqueous leaching of soluble fission products by hot water in the case of the water-cooled cask accident. Although not a priority item, it would be useful to obtain some very shortterm and some extended time leach rate data for high burnup fuel using elevated temperature, and perhaps pressurized, water. The data and extrapolations used to evaluate this process in the present study can be questioned and should be subjected to some further verification. The leaching mecha- 
nism at higher temperatures might be quite different from that which occurs at room temperature.

\subsubsection{Area 4 - Response of Cask Body to Impact}

The results of the Sandia and ORNL full-scale cask tests, the PNL scoping calculations which used very conservative failure criteria, and the investigations performed for this study suggest the preliminary conclusion that accidents leading to gross failure of a cask body are very unlikely. While none of the programs referenced was intended to establish this conclusion definitively, the results strongly suggest that such an investigation can be completed with a reasonable expenditure of effort.

It is recommended that a program be instituted using scale models of representative casks subjected to a consistent set of severe impact environments. The model tests should be pre-predicted with available analytical tools so that the test results would provide information as to actual cask response for benchmarking the tools. It should be possible to accomplish the task without extensive use of sophisticated finite element computer analysis. Rather, cask areas shown to be critical by scale model tests and/or more straightforward tools can be subjected to detailed analysis as appropriate.

It is recommended that this task be given a high priority in the short term. If it can be established beyond a reasonable doubt that gross structural failure should not be a consideration in evaluating transportation accidents, research and development resources can be directed to other more productive areas. Additionally, establishment of the failure thresholds necessary to accomplish this task will provide a set of baseline loadings for use in evaluating fuel response.

\subsubsection{Area 5 - Appurtenances, Seals, and other Key Design Features}

This is an area in which not much generic development work has been done and where added margins of safety could pay off in terms of reducing the probability of exposure to the public. This position implies the qualitative judgment that low and intermediate severity accidents such as lowspeed impacts, low-height drops, assembly errors, etc., are considerably more likely than design basis accidents. Such accidents pose hazards such as small amounts of failed fuel or loss of neutron shield water combined with a seal leak or valve failure that could result in small, but undesirable, leaks of radioactive material from the cask.

The following areas warrant further investigation:

- Redundant seals, such as welded bellows or omega seals as backup to the normal flange seal. Such seals should be flexible so as to maintain integrity after distortion of the cask. 
o Shock absorption capability for the fuel assembly supports. This item is addressed in more depth in the discussion on fuel assembly response.

It is recommended that generic development programs be instituted to identify designs as candidates for inclusion in this category. Methods for implementing improved key design features into present and future casks need to be investigated.

\subsubsection{Area 6 - Fuel Assembly. Response to Impact}

As noted previously, little work has been done in the area of fuel assembly response to impact environment. The assemblies contained in the fullscale cask tests were unirradiated and therefore yielded little information as to the response of irradiated ones.

Analytic prediction of fuel assembly response to impact environments is complex because of its geometry and the large number of close clearance fits. It is doubtful therefore that the problem can be handled satisfactorily by analysis alone. It is possible to show with gauging calculations, however, that the failure threshold for individual rods under impact conditions is probably much lower than for the cask itself. This fact, combined with the possibility of a small leak due to loss of integrity of seals and appurtenances raises the possibility of providing shock absorption mechanisms within the cask to limit fuel damage on impact. A significant improvement in the probability of radioactive materials release can be obtained by increasing the assurance of maintenance of fuel integrity in conjunction with improved seal, appurtenance, and weld design. These measures would strengthen both barriers to release.

It is recommended that a two-step program be undertaken. First, obtain more accurate information on the failure thresholds of irradiated fuel, either with basic materials tests on irradiated Zircaloy, or with impact tests on irradiated dummy assemblies, or both. Second, use the failure threshold information to generate requirements for fuel assembly shock absorption mechanisms that would raise the failure threshold above any credible impact environment.

\subsubsection{Area 7 - Cask Puncture}

Cask puncture is an area believed to constitute the most credible failure mode that falls in the "gross failure" category. The scoping calculations indicated that it is highly unlikely that airborne missiles other than armor-piercing ordnance would pose a threat to cask integrity, but that a drop from relatively low heights on a high-sectional density projection at a near-normal angle of incidence could result in a puncture into the cask inner cavity. A medium-to-high speed fall from a moving vehicle could result in the same type of failure. It is emphasized that this event is 
considered very unlikely, as the gauging calculations show that for more than a degree or two off normal incidence, the cask will. destroy the projection.

Little or no work has been done previously on the various potential categories of puncture accidents, probably because they are very unlikely. However, if these types of accidents are to be considered for further evaluation, then much work needs to be done in the penetration mechanics area. No analytical methods of general applicability were found in the penetration mechanics literature, and only a small amount of empirical information was obtained as a result of the literature survey conducted.

It is recommended that, if a decision is made to consider the low likelihood puncture events mentioned above, a program to ascertain the state-ofthe-art in penetration mechanics as it applies to cask puncture be conducted. It is believed that expertise exists at defense-related laboratories. It will probably be necessary at that point to plan and execute a series of scale-model tests to determine puncture-resistant cask design features for severe environments.

\subsubsection{Area 8 - Other Cask Structural Response-Related Recommendations}

As continued analytical work will be needed both for design purposes and to design and analyze experimental work, programs should be conducted to obtain high strain-rate materials data for cask structural materials; stee 1, lead, uranium, aluminum, and copper. 


\section{NRC FORM 335 $(7.77)$ \\ U.S. NUCLEAR REGULATORY COMMISSION \\ BIBLIOGRAPHIC DATA SHEET}

TITLF AND SUBTITLE (Add Volume No, if appropriate)

A Scoping Study of Spent Fuel Cask Transportation Accidents

7. AUTHOR!S

W. R. Rhyne and others

9. PERFORMING ORGANIZATION NAME AND MAILING ADDRESS (lnc/ude Zip Code)

Science Applications, Inc.

Oak Ridge, Tennessee 37830

12. SPONSORING ÓRGANIZATION.NAME AND MAILING ADDRESS (Include Zip Code)

Office of Nuclear Regulatory Research

U.S. Nuclear Regulatory Commission

Washington, D.C. 20555
1. REPORT NUMBER (Assigned by $D D C$ )

NUREG/CR-0811

2. (Leave blank)

3. RECIPIENT'S ACCESSION NO.

5. DATE REPORT COMPLETED \begin{tabular}{l|l}
\hline MONTH & YEAR
\end{tabular} June

DATE REPORT ISSUED

\begin{tabular}{l|l}
\hline MONTH & YEAR \\
\hline JUTE
\end{tabular} June 1979

6. (Leave blank)

8. (Leave blank)

10. PROJECT/TASK/WORK UNIT NO 11. CONTRACT NO.

13. TYPE OF REPORT

PERIOD COVERED (Inc/usive dates/

15. SUPPLEMENTARY NOTES

14. (Leave blank)

16. ABSTRACT (200 words or (ess)

A scoping study of spent fuel cask transportation accidents was performed to provide an assessment of existing information and to recommend, on a priority basis, the additional information that should be obtained to allow specification of increasingly realistic source terms. The scope was 1 imited to the escape of radionuclides from the cask to the environment resulting from severe accidents. The evaluation of the accident scenarios is as realistic as possible. Information was found to be inadequate to make correlations between accident severity and radionuclide release. Generally, cask and fuel rod thermal-hydraulic data and analytical capability were found to be reasonably adequate; however, data and analytical capability for evaluating structural response to impact are not. Radionuclide behavior information is adequate for noble gases but generally inadequate for most volatile radionuclides and for fuel particulates. 